NBER WORKING PAPER SERIES

\title{
ESTIMATING THE DIRECT AND INDIRECT EFFECTS OF MAJOR EDUCATION REFORMS
}

\author{
Michael Gilraine \\ Hugh Macartney \\ Robert McMillan
}

Working Paper 24191

http://www.nber.org/papers/w24191

\author{
NATIONAL BUREAU OF ECONOMIC RESEARCH \\ 1050 Massachusetts Avenue \\ Cambridge, MA 02138 \\ January 2018, Revised August 2020
}

\begin{abstract}
Previously circulated as "Education Reform in General Equilibrium: Evidence from California's Class Size Reduction." We would like to thank Pat Bayer and Gregorio Caetano for helpful discussions, and Marc-Antoine Chatelain, Damon Clark, Elaine Guo, Steve Lehrer, Ted Rosenbaum, Eduardo Souza-Rodrigues, Wilbert van der Klaauw, workshop participants at the University of Bristol (CPMO), Federal Trade Commission, New York Federal Reserve and University of Toronto, and participants at the CIREQ Applied Economics Conference and 2018 SOLE Meetings for additional comments. Financial support is gratefully acknowledged from the IES, SSHRC, Duke University, and the University of Toronto Mississauga. All remaining errors are our own. The views expressed herein are those of the authors and do not necessarily reflect the views of the National Bureau of Economic Research.
\end{abstract}

NBER working papers are circulated for discussion and comment purposes. They have not been peer-reviewed or been subject to the review by the NBER Board of Directors that accompanies official NBER publications.

(C) 2018 by Michael Gilraine, Hugh Macartney, and Robert McMillan. All rights reserved. Short sections of text, not to exceed two paragraphs, may be quoted without explicit permission provided that full credit, including $(\odot$ notice, is given to the source. 
Estimating the Direct and Indirect Effects of Major Education Reforms

Michael Gilraine, Hugh Macartney, and Robert McMillan

NBER Working Paper No. 24191

January 2018, Revised August 2020

JEL No. H40,I21,I22

\section{ABSTRACT}

We propose an approach for credibly estimating indirect sorting effects of major education reforms and placing them alongside the reforms' direct and persistent effects for the first time. Applying our approach to California's state-wide class size reduction program, we estimate a large positive direct effect of smaller classes on test scores and an even larger indirect effect due to demographic changes as private school students switch into public schools; both effects also persist. Accounting for sorting using these estimates raises the program's benefit-cost ratio significantly. Further, our analysis indicates that indirect sorting is likely relevant in policy evaluations more generally.

Michael Gilraine

New York University

Department of Economics

19 West 4th Street

New York, NY 10012

mike.gilraine@nyu.edu

Hugh Macartney

Duke University

Department of Economics

239 Social Sciences Building

Box 90097

Durham, NC 27708

and NBER

hugh.macartney@duke.edu
Robert McMillan

University of Toronto

Department of Economics

150 St. George Street

Toronto, ON M5S 3G7

CANADA

and NBER

mcmillan@chass.utoronto.ca 


\section{Introduction}

Empirical policy analysis often focuses on the direct, intended effects of policies "holding all else equal." Measuring such direct effects accurately is an important ingredient in policy making, although it is well appreciated that large-scale reforms may have substantial indirect effects that work in offseting or reinforcing ways. Because of their potential to alter the policy-making calculus significantly, estimating the size of these indirect effects is of considerable practical interest. Yet doing so presents challenges for empirical research, not least because additional sources of independent variation are required to identify indirect effects separately from the direct impact of policies. As a consequence, the literature seeking to gauge their extent is relatively undeveloped. ${ }^{1}$

This paper sets out an estimation approach that allows us to measure indirect effects of largescale reforms in a credible way and place them on a common footing with the direct policy effects for the first time. We focus on an education context and a type of indirect response likely to matter whenever (i) a reform improves public school quality significantly - the basic goal of most education reforms, ${ }^{2}$ and (ii) private school options are popular pre-reform. In this common configuration of circumstances, some households will have an incentive to re-sort by switching out of private schools, potentially changing the student composition of public schools. In turn, to the extent that resulting compositional changes influence education production, either because the new public school students are more advantaged or via peer spillovers, so they should affect measured outcomes such as test scores - the indirect effects we seek to identify. ${ }^{3}$

We develop our approach in the context of California's class size reduction (CSR) program of the late-1990s - up to that point, the largest state-led education reform ever implemented in the United States. Inspired by Project STAR in Tennessee, a well-known experimental evaluation in education and the subject of a number of influential studies, ${ }^{4}$ the California legislature sought to replicate Project STAR's publicized experimental benefits at an altogether larger scale. To that end, the CSR program targeted kindergarten through third grade (as did Project STAR), and cut class sizes in these early grades by around 20 percent throughout the state. The reform involved a grade-specific roll-out, starting with first grade in 1996-97, and schools had to hire enough teachers to lower class sizes below 20 in the relevant grades in order to be eligible for CSR funding, amounting

\footnotetext{
${ }^{1}$ Exceptions are Jepsen and Rivkin (2009) and Dinerstein and Smith (2016), which we discuss further below. Another careful analysis, by Bianchi (2020), considers the indirect effects of a policy to expand Italian university enrollment: as will be made clear, our focus is on policies that change school quality directly, with enrollment changes being an indirect response.

${ }^{2}$ School finance reforms provide one example - see Jackson, Johnson and Persico (2015) and Lafortune, Rothstein and Schanzenbach (2018).

${ }^{3}$ Other indirect effects may include changes to teacher labor markets - see Jepsen and Rivkin (2009) and Jackson (2012) - and household residential sorting.

${ }^{4}$ Prominent among these are Krueger (1999), Krueger and Whitmore (2001), and Chetty et al. (2011).
} 
to 10 percent of per-pupil expenditure.

The combination of strong financial incentives to implement the reform according to its specific timetable, the substantial reductions in class size it produced, and the sheer scale of California's public education system would lead one to expect CSR to have broader effects. Convincing research by Jepsen and Rivkin (2009) has already highlighted impacts on the teacher labor market, showing that there was a sudden, significant increased need for new teacher hires, which dampened CSR's benefits in the short term. Further, the effects of the policy were non-uniform, with some schools experiencing reductions in class size without any appreciable decline in teacher quality, thus becoming potentially more attractive to parents as a result. Such public school quality changes might in turn be expected to lead to sociodemographic sorting from some private to public schools in response to $\mathrm{CSR} .{ }^{5}$

We first document that significant re-sorting did occur. A difference-in-differences research design comparing treated versus untreated grades before and after the reform reveals that CSR caused a reduction in local private school shares of 1.4 percentage points for relevant elementary grades, or 12 percent of the pre-CSR K-3 average private school share. Further, we see pronounced changes in school sociodemographics in public schools with nearby private alternatives (relative to those without), the proportion white increasing while the proportion Hispanic declined - evidence consistent with recent research by Dinerstein and Smith (2016). ${ }^{6}$ We also show that a significant fraction of the extra 37,500 students found in public elementary schools in a given year as a result of CSR remained there beyond third grade for the duration of elementary school; the evidence points to around two-thirds of these students then returning back to the private sector for middle school.

To explore the effects of this substantial re-sorting on student performance, we use a framework that parameterizes the public school education production function. This captures the reform's direct and indirect effects in terms of test scores, contemporaneously and also persisting into the future, as in well-known recent research (see Chetty et al. 2011 and Chetty, Friedman and Rockoff 2014). Specifically, we assume the production technology is linear and additive in its inputs, as is standard in much of the education literature, and express each cohort's grade-year average test score in terms of parameters governing the current and persisting effects of school resources and sociodemographics, respectively.

Central to our analysis, we show the policy's direct and indirect effects can be estimated on a

\footnotetext{
${ }^{5}$ These indirect sorting effects will be our primary focus, rather than indirect effects of CSR on the teaching force studied by Jepsen and Rivkin (2009). The approach to estimating direct and indirect effects we propose will account for changes in teacher quality using a control strategy (described below) that draws on Jepsen and Rivkin (2009).

${ }^{6}$ Those authors provide persuasive evidence that increased funding for public schools in New York City drew private school students into the public system, both by choice and through the forced closure of (typically small) private schools. They quantify the impact of public school policy on private school students, while we study the direct and indirect effects on existing public school students.
} 
comparable footing using this framework. The direct effect of the reform can be recovered given the additive linear structure by taking differences in average test scores across adjacent cohorts in the same academic year, leveraging their differential exposure to the reform over time; any non-CSR effects are then controlled for by deducting off corresponding differences for older adjacent cohorts never subjected to the reform. For the indirect effect, we draw on variation in elementary school grade spans, using the fact that students in areas served by K-5 schools can move back to the private sector for middle school earlier than students attending K-6 public schools, in turn generating exogenous differences in public school compositions (K-5 and K-6 being easily the predominant elementary grade configurations in the state). The indirect sorting effect is then isolated using three layers of differencing in which we contrast the performance of sixth grade public school students under the two types of grade configuration, relative to fifth grade, before versus after CSR students entered sixth grade. ${ }^{7}$

Our estimates indicate that both direct and indirect effects are significant and positive. ${ }^{8}$ Of note, the precisely estimated indirect sorting effect is even greater in magnitude $(0.16 \sigma$ in terms of mathematics scores) than the direct effect $(0.11 \sigma) .{ }^{9}$ Further, we find that both the direct and indirect effects persist into subsequent years, at approximately the same rate in each case. These findings are important from a measurement point of view, as estimates of the direct effect would be biased (as we demonstrate in Section 5) when applying difference-in-differences in the presence of indirect sorting or persistence. ${ }^{10}$ Together, the parameter estimates and our framework indicate that the overall benefits of CSR in the longer term are substantial when accounting for these two relevant factors. Although the indirect effect inflates recurrent costs by 20 percent, we compute a suggestive net benefit-cost ratio of the reform considerably above one and more than double the ratio obtained when ignoring the indirect effect.

The magnitudes of our direct and indirect estimates support the view that household sorting

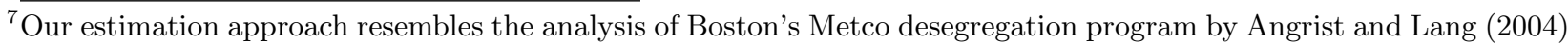
in that it uses distinct sources of variation to identify the separate effects of interest (differences in types of policy and study goals to one side).

${ }^{8}$ Across a variety of settings, studies in the class size literature have found positive effects on achievement (for instance, Krueger 1999, Angrist and Lavy 1999, Krueger and Whitmore 2001, and Gilraine 2020) as well as no effects (including Hoxby 2000 and Angrist, Battistin and Vuri 2017). Research studying the Californian context has delivered mixed results similar to the broader literature (see Unlu 2005 and Jepsen and Rivkin 2009 for positive test score effects and Bohrnstedt and Stecher 2002 for non-effects).

${ }^{9} \mathrm{~A}$ bounding exercise in Section 7.1 indicates that peer spillovers are likely to account for a significant portion - well over half - of the indirect sorting effect, with an implied social multiplier in line with the estimates in the compelling analysis by Graham (2008).

${ }^{10}$ Intuitively, the relevant difference-in-differences would compare treated versus untreated grades after the reform's implementation versus before - for example, comparing third versus fourth grade in this way. Given the roll-out of the reform, all third grade students are already treated by the reform in at least the two years prior, so if the effects of CSR persist, then no pure pre-treatment year for third graders can be found. At the same time, the differencein-differences estimate would also include the indirect effect. By the same reasoning, difference-in-differences cannot recover the total (direct plus indirect) effect of the reform. 
should be treated as a primary factor when assessing the impact of large-scale reforms that alter public school quality, rather than a phenomenon that can reasonably be abstracted from. This is especially likely in other contexts when private school enrollment is high pre-reform and a large number of households are on the margin of switching - conditions that hold in many US states, for example. Our analysis thus indicates that studies ignoring sorting effects are likely to mis-measure the overall impact of major education reforms to a high degree in often-encountered circumstances. In terms of class size, our analysis reinforces recent research highlighting that the impacts of class size reforms are often quite context-specific (see Ding and Lehrer 2010 and Gilraine 2020).

From a methodological perspective, our estimation approach is applicable more generally when two sources of variation are available: (i) a major reform applies to some groups (in our case, school grades) and not others - given constrained public funds, this is a common occurrence; (ii) there is variation in school grade spans (used to identify indirect sorting effects), a widespread feature of many public education systems in practice. ${ }^{11}$ The data requirements of the approach are quite minimal: all the data in this study are observational, involve school-grade-year averages and are available publicly. As such, they are likely to be satisfied in various other settings. Taking these elements together, our paper provides researchers with a transparent means of gauging the indirect sorting effects alongside the direct effects of policy in a range of alternative applications.

The rest of the paper is organized as follows: Section 2 presents a conceptual framework that shapes our approach. Section 3 describes the institutional background to CSR in California and the data set we have assembled. In Section 4, we provide evidence that the reform caused significant re-sorting, and explore implications of that. Section 5 is the heart of the paper, where we set out the approach for estimating the parameters governing the direct and indirect effects in a formal way, drawing on the conceptual framework. Section 6 presents the resulting estimates, Section 7 examines policy implications, and Section 8 concludes.

\section{Conceptual Framework}

In this section, we present a formal framework, using this to define the empirical quantities of interest and to state the measurement goals of the paper.

The framework is built around an education production technology, used to describe a standard policy setting in which indirect sorting effects may arise following a major reform. For concreteness, we focus on a state's education system (such as California's), where the students are served by a

\footnotetext{
${ }^{11}$ Alternatively, one could consider a partial treatment of the public system in which some public schools are treated while others do not, the untreated schools being the analog to private schools in our analysis. School assignment is often residence-based, so households would have to move to re-sort (unlike with private schools).
} 
mixture of public and private schools, and where the two student populations may differ markedly.

Education Production Technology: Consider an environment in which an outcome $y$ depends on inputs consisting of a policy variable and a set of other relevant factors. A reform is implemented through a change in this policy variable, which may give rise to direct and indirect effects. We will think of outcomes primarily as test scores, given the education data available to us. In response to a major policy change, the policy's effects can then be understood in terms of an education production technology in which education inputs together affect measured test score performance - in our application, it is the public school's technology. ${ }^{12}$

We are interested in uncovering the parameters of this technology. We focus on a specification in which education output is affected by three main inputs, denoted $\{R, X, Q\}$, where $R$ measures school resources (under the direct control of the policy maker), $X$ represents productive student characteristics (their ability and possible peer interactions) in the school, and $Q$ is teacher quality. There is also a further noise component, $\epsilon$, reflecting unobservable random influences on contemporaneous test scores.

We make the following explicit assumptions about the technology.

\section{Assumption 1: The production technology is linear and additive.}

We will approximate the true education production function, following the bulk of education literature, with a technology that is linear and additive in its observed and unobserved inputs - needed in order to apply the differencing approach we develop in Section 5.2.

\section{Assumption 2: The production technology is cumulative.}

Under this assumption, we allow current inputs in one period to have persistent impacts in subsequent periods as students acquire (and retain) knowledge and skills; this accords with convincing prior evidence that education inputs have cumulative effects (see Rivkin, Hanushek and Kain 2005, and Chetty, Friedman and Rockoff 2014, for example).

In line with these two assumptions, the following technology accounts for the current and persistent effects of resources, student sociodemographics and teachers on scores in period $t$ :

$$
y_{t}=\gamma_{R} \sum_{\tau=0}^{L}\left(\delta_{R}\right)^{\tau} R_{t-\tau}+\gamma_{X} \sum_{\tau=0}^{L}\left(\delta_{X}\right)^{\tau} X_{t-\tau}+h\left(Q_{t}\right)+\epsilon_{t} .
$$

This specification will provide the basis for our estimation approach. It is chosen in light of what we will be able to reasonably identify using the available data, aggregated to the school-cohort

\footnotetext{
${ }^{12}$ In the background, there is a local education market with public and private schooling options. Public schools are free and have to admit all students who wish to enroll, typically within a given attendance zone around the school. Private schools, in contrast, charge tuition and can be selective.
} 
level, and the sources of exogenous variation we have access to.

The large-scale reform can be represented by the change in school resources $(\Delta R)$ associated with the policy intervention, relative to a suitable baseline - for example, a counterfactual setting in which the reform was never introduced (as in our empirical implementation in Section 5). We will think of the extra resources appearing exogenously, as corresponds reasonably well to the case of the California CSR reform.

The introduction of the reform has two contemporaneous effects on learning: (i) the direct effect, given by the product of the $\gamma_{R}$ parameter and the change in resources $\Delta R$; and (ii) the indirect effect arising from student sorting between private and public school systems, given by the product of the $\gamma_{X}$ parameter and the induced change in student composition $\Delta X$ (associated with $\Delta R)$ due to a demand increase. ${ }^{13}$

In terms of the latter, a demographic change in the composition of students in the public system may affect test score outcomes through two channels. First, if the incoming students are of higher ability than students already enrolled in public school and score more highly themselves, then outcomes will improve through what we term the 'own' effect. Second, the change in the demographic composition of public schools may result in spillover benefits to incumbent public school students, perhaps via positive peer influences in the classroom. The aggregate nature of our data - described in Section 3.2 - limits our capacity to separate these two channels so we will combine them for the most part; in Section 7.1, we will conduct an informative bounding exercise.

In terms of persistence in our specification, the effect of past resources (smaller classes) on current test scores is given by $\delta_{R}$ - a parameter of interest in prior research (see, for example, Krueger and Whitmore 2001). Specifically, $\delta_{R}$ measures the persistent effect on test scores of a one-unit increase in resources one period ago into the present. Further, resources from at most $L$ periods in the past are allowed to influence current test scores, following a geometric decay. Similarly, the parameter $\delta_{X}$ captures the persistent effects of induced prior school demographic compositions on current test scores. Adding persistence allows direct and indirect effects from earlier periods to accumulate over time. ${ }^{14}$

An additional effect may arise through induced changes in teacher quality $Q_{t}$, influencing test

\footnotetext{
${ }^{13}$ As public school quality rises, so more households will prefer the public school option, leading to an increase in enrollment and the change in school demographics, $X$, the change depending on the magnitude of the inflow and the extent to which public and private school student populations differ initially.

${ }^{14}$ The structure implies expressions for each effect. For example, a shock to class sizes $l$ periods ago will give rise to an indirect sorting effect in the current period of $\gamma_{X} \Delta X\left(\delta_{X}\right)^{l}$, where $\Delta X$ measures the induced within-period sorting response $l$ periods ago. In turn, taking a forward-looking perspective, a class size shock at $t$ will have a total indirect sorting effect on scores that propagates into the future in an amount equal to $\gamma_{X} \Delta X_{t} \sum_{\tau=0}^{L}\left(\delta_{X}\right)^{\tau}$. We can use the estimates and this structure to compute the overall test score benefits of CSR, as we will in Section 7.
} 
scores in equation (2.1) through $h\left(Q_{t}\right)$. In Section 5.2, we will account for the impact of teacher quality non-parametrically using a control function technique.

\subsection{Empirical Goals}

Looking ahead, the main empirical goals of the paper are to estimate, on a common scale, the key parameters of interest $\left\{\gamma_{R}, \gamma_{X}, \delta_{R}, \delta_{X}\right\}$. Doing so will shed light on the respective sizes of the direct and indirect effects of major education reforms along with their persistent impacts. ${ }^{15}$ To estimate these parameters, we will take the framework to the data in the context of California's CSR reform, described in the next section, measuring output in terms of test scores.

From a policy perspective, we also wish to learn how accounting for the indirect sorting effect influences the overall policy calculus. We will do so in Section 7 by combining the framework in this section with the estimated effects in a cost-benefit calculation that allows indirect sorting to influence both costs and benefits.

\section{Institutional Background and Data}

We now describe the relevant institutional background to CSR. Doing so serves to emphasize that the reform was very large in scope and so likely to have broader effects, and that it was rolled out in a particular way, useful for applied research. We also discuss our data - the sources and descriptive evidence.

By way of context, California's CSR program was introduced in the spring of 1996, and was the largest state-led education reform implemented in the United States up to that time. Impetus for the reform arose in the wake of disappointing national test score rankings when National Assessment of Educational Progress (NAEP) scores first became available on a state-by-state basis four years earlier. Those rankings revealed California to be among the worst-performing states in both mathematics and reading. Further, as subsequent years made clear, the low performance issue was persistent. ${ }^{16}$

California lawmakers enacted the class size reduction reform in a bid to address these problems in July 1996, motivated in part by Project STAR. ${ }^{17}$ While the policy was widely supported by

${ }^{15}$ Related to the variation in school demographics that underlies the indirect effect, we will also be interested in estimating an auxiliary parameter that measures the proportion of switching students who return to private school after the reform's treatment ends, given that costs of switching are not zero. We will discuss this parameter (denoted $\psi$ ) and our approach to estimating it in Section 4.

${ }^{16}$ For instance, the 1994 NAEP results showed California to be the very bottom state (along with Louisiana) in fourth grade reading, and in 1996, it tied with Tennessee at the bottom of the eighth grade mathematics rankings.

${ }^{17}$ See a report from the associated legislative discussions, available at http://files .eric.ed.gov/fulltext/ED407699. pdf. 
both parents and teachers, its implementation did not arise in a consensual way, the Republican Governor adamant that extra funding available from the state's budget surplus in the mid-1990s (which by a 1988 constitutional initiative had to be spent on education) would not be used as discretionary funding that could flow into higher teacher salaries. To ensure this, the Governor avoided funding the union-dominated education boards by arranging to give the money directly to schools that had class sizes below a certain threshold.

\subsection{The Reform}

The reform provided targeted incentives to reduce class sizes in early grades from a statewide average of 28.5 down to 20 , according to a specific timetable. ${ }^{18}$ For the first year of operation, 1996-97, the program applied only to first graders. Second grade classes then became subject to the program incentives in the following year (1997-98), and schools were able to choose to implement CSR in either kindergarten or third grade beginning in 1998-99. We exploit this differential timing of implementation by grade when examining changes in private school share, sociodemographic compositions, and test scores.

Even though participation was voluntary, substantial financial payments of $\$ 650$ per pupil enrolled in a class of 20 or fewer students (relative to average 1995-96 per-pupil expenditures of $\$ 6,068)$ led to nearly universal adoption by districts and schools such that 88 percent of first graders were in a CSR-compliant class in the first year of the reform. For districts to participate in CSR, they only needed to opt into the program, and the vast majority did. ${ }^{19}$ In contrast, schools had to reduce class sizes in the relevant grade to receive CSR funding. Around 10 percent of schools delayed their implementation of CSR, primarily because of a lack of space. ${ }^{20}$ Given potential concerns about selection, school adoption decisions will only be used to show robustness of our findings (see the triple-differences designs in Appendix B and Appendix C). In our main analysis, we assume all schools and districts that were eligible did adopt, the full-adoption assumption leading us to understate the true effects of CSR - the implementation rates suggest by around a tenth.

The coverage of the policy is shown in Figure 1, making clear the way it was rolled out. In line with that roll-out, Figure 2 highlights the broad impact of CSR that we exploit, plotting student-

\footnotetext{
${ }^{18}$ This subsection draws on the lively account of the background to CSR in Schrag (2006). As described there, an unidentified staffer for the Governor stated that the class size goal of 20 was set based primarily on what was deemed affordable.

${ }^{19}$ Forty-two (out of 895 ) districts did not implement CSR in the first year, either because (i) they had class sizes just above twenty and did not think it was worth seeking the extra funding to hire a new teacher, or (ii) they already had many class sizes below twenty and did not realize they were eligible. See http://www.1ao.ca.gov/1997/021297_ class_size/class_size_297.html.

${ }^{20}$ In a survey by the CSR Research Consortium, eighty percent of principals who had not implemented CSR stated that space issues were the main impediment. See http://www.classize.org/summary/97-98/summaryrpt.pdf.
} 
to-teacher ratios in elementary and middle schools for school years 1990-91 through 2006-07. It shows a clear drop in student-to-teacher ratios for elementary schools when CSR was implemented in 1996-97, with no comparable change in middle schools.

Our empirical approach is shaped by several institutional factors that make studying CSR challenging. First, despite the scale of the reform, no systematic program evaluation method was put in place. ${ }^{21}$ This was a consequence of the initial announcement and roll-out of the actual policy being sudden and unanticipated, generating headlines such as "Sacramento Surprise - Extra Funds / Governor wants to use money to cut class size" in the San Francisco Chronicle (Lucas 1996); as an aside, this suddenness also meant that no districts, schools or parents could anticipate the reform's introduction. Second, in terms of measuring student performance, student testing did not begin until the 1997-98 school year, when the Standardized Testing and Reporting Program - another initiative of the Republican Governor - began. Thus, researchers do not have access to a comparable pre-reform test. ${ }^{22}$ We address this issue by using various exogenous differences in treatment, described below. Third, further limitations include a lack of individual student or classroom-level data and an inability to track teachers or students over time. ${ }^{23}$ Our measurement approach makes use of data aggregated to the school-grade-year level: in Section 5, we will show how such aggregated data can still be used to identify the effects of interest based on the differencing strategy we propose.

\subsection{Data}

The main data set we have assembled draws on several useful public data sources provided by the California Department of Education (CDE) - see Appendix Table A.1 for more detail. The first provides student enrollments for all public schools and districts at the grade level from the 1990-91 through the 2008-09 school years. ${ }^{24}$ We augment the enrollment data with additional demographic information from CDE, including race, 'English as a Second Language' (ESL) status, and Free or Reduced-Price Meal status. ${ }^{25}$ Second, the CDE also provides grade-level enrollment data (but no demographic information beyond these totals) for private schools from 1990-91 to 2008-09 inclusive.

${ }^{21}$ The legislature did create the CSR Research Consortium to conduct a four-year comprehensive study to evaluate the implementation and impact of CSR, though it had to confront the same data limitations that we highlight.

${ }^{22}$ Earlier tests in the state - the CLAS test, for instance - were discontinued in the face of budget cuts and union resistance. Appendix A offers a quick primer on California statewide testing.

${ }^{23}$ California's teacher identifiers were scrambled each year to prevent following the same teacher over time. They continue to be scrambled in the statewide files to the present.

${ }^{24}$ We stop in 2008-09 due to a CSR funding formula change in the following academic year so that schools would not lose all their CSR funding if class sizes exceeded twenty students. This change caused a substantial rise in K-3 class sizes.

${ }^{25}$ This serves as a measure of the poverty rate of the entire student body. It is not available at the grade level, unlike our other public school demographic variables. 
Together, these two CDE data sets allow us to study the effects of CSR on local private school shares, starting well before CSR's introduction - an advantage relative to the available test score information.

The third data source provides test score data from California's Standardized Testing and Reporting Program for second grade and higher. All students in second through eleventh grade took the Stanford Achievement Test in both mathematics and English near the end of the academic year (with some minor exceptions ${ }^{26}$ ). The Stanford Achievement Test was a national norm-referenced multiple-choice test introduced in the 1997-98 school year. Because the policy was in place for first grade since the 1996-97 school year and included second grade beginning in 1997-98, we do not observe a purely pre-reform period in terms of test scores. Thus, identifying the effect of CSR on test scores necessarily involves exploiting differences in treatment over time once the reform came into effect; our estimation strategy is designed to use that variation. ${ }^{27}$

For comparability of test scores over time, we use the percentile ranking as our test score measure. This captures the percentage of students in a nationally-representative sample of students, in the same grade, tested at a similar time of the school year, who fall below the test score for the mean student in a given school-grade-year. The shading in Figure 1 indicates the availability of these data by year and grade alongside the CSR policy rollout.

Table 1 provides summary statistics for the enrollment and demographic variables used in our analysis (summary statistics for the test score data by year and grade are shown in Table A.2). We present overall means and also break these down in the next three columns - into the period preceding the introduction of the CSR reform in California (1990-91 through 1995-96), the period during its phase-in across grades (1996-97 through 1999-00), and the period following its full implementation (2000-01 through 2008-09).

The evolution of the student-teacher ratio in elementary schools over time (shown in the first row) indicates that the CSR reform had a dramatic effect: the ratio fell from 25 to 21.6, reflecting a 15 percent decline in class size, although the actual class size decline in K-3 was likely around double that. ${ }^{28}$ (In the notation of the conceptual framework, $\Delta R$ changed substantially.) The

\footnotetext{
${ }^{26}$ Students were exempted if they were special education students or if a parent or guardian submitted a written request for an exemption. Test taking rates were high nonetheless: in 1998-99, over ninety-three percent of students in grades 2-11 took the relevant test, for example.

${ }^{27}$ We restrict some of our analyses to the academic years 1997-98 through 2001-02, even though test scores are reported through 2008-09. This is because the monotonicity of scores by grade is no longer preserved for the 2002-03 academic year and onward due to a change in testing regimes (see Appendix A).

${ }^{28}$ The student-teacher ratio of the school is used as a proxy for class size given we do not observe teacher assignment data prior to the introduction of CSR. As elementary schools often include grades 4-6, we underestimate the decline in CSR grades (K-3) since non-CSR grades (4-6) are included in the calculation. Schrag (2006) indicates that the pre-CSR K-3 average class size was about 28.5. The actual class size decline caused by CSR in grades K-3 is likely closer to 30 percent, given that post-CSR average K-3 class sizes are around 19.5.
} 
private school share of enrollment at the state level also declined during the period of interest, falling from 9.9 percent prior to CSR implementation to 8.8 percent afterwards. Because there was a similar trend of declining private school shares nationally during the time period (Buddin, 2012), we will adopt a grade-by-grade research design in the next section to assess whether CSR had a causal impact on these shares over and above the national trend. In addition, the table shows a marked change in the composition of students in public schools, with a reduction of about 10 percentage points in the share of white students and a corresponding increase in the fraction of Hispanic students.

\section{Sorting Responses and Effects}

In this section, we present causal evidence of sorting responses to the reform (captured by $\Delta X$ in the conceptual framework), in turn likely to engender the direct and indirect effects of interest. We first investigate the impact of the reform on private school shares, drawing out the scale of the sorting response; second, we provide complementary evidence relating to changes in public school demographics; third, we examine whether the sorting due to CSR was transitory or not - relevant when identifying the reform's indirect effects; and fourth, we present initial reduced-form evidence of the impact of sorting on test scores.

\subsection{Private Schools}

We examine the effect of CSR on private school shares by taking advantage of the reform's gradeby-grade roll-out in grades K-3. For each period $t$, we define the treatment group as any grade that implements CSR and the control group as any grade that does not. Thus we assume that all eligible grades adopted CSR according to the state's roll-out, abstracting from the voluntary participation decision by districts and schools; doing so is likely to understate the true effects of CSR (as noted above). We then apply a difference-in-differences approach, which compares treatment and control grades before and after the reform came into effect. The analysis uses the following regression:

$$
\text { share }_{d g t}=\beta_{0}+\beta_{1} \text { post }_{g t}+\beta_{2} \text { treat }_{g}+\beta_{3}\left(\text { post }_{g t} * \text { treat }_{g}\right)+\eta_{d}+\theta_{t}+\phi X_{d g t}+\epsilon_{d g t},
$$

where share $_{d g t}$ is the private school share for district $d$ in grade $g$ at time $t,{ }^{29}$ post $_{g t}$ indicates

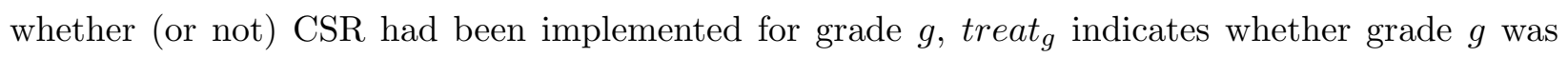
ever subject to the CSR reform, $X_{d g t}$ is a set of district-grade-year covariates (percent ESL, race and enrollment), and $\eta_{d}$ and $\theta_{t}$ are district and time fixed effects, respectively. Observations are

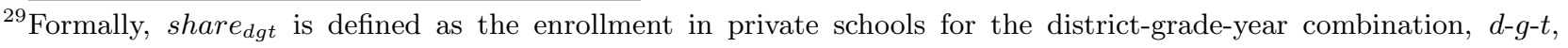
divided by the total $d-g$ - $t$ enrollment. 
weighted by district-grade-year enrollment. ${ }^{30}$

The difference-in-differences coefficient of interest is $\beta_{3}$. It is identified under the assumption that CSR and non-CSR grades would have experienced the same change in private school share in the absence of the reform. Evidence of any differential pre-trends (below) will shed light on the validity of this 'parallel trends' assumption.

Results: Our difference-in-differences approach exploits variation in the time when different grades became subject to CSR. The relevant variation can be visualized in Figure 3, which plots the change in private school enrollment share overall (the dashed line) and in CSR grades (the lines in different shades) over time. The visual evidence is clear: when CSR is first implemented in the public system for a particular grade, the corresponding private share for that grade declines relative to other grades, suggesting that the reform attracted private school students into the public system. ${ }^{31}$

Given the patterns in Figure 3, we estimate the difference-in-differences estimator in equation (4.1) including various controls, and report the results in Table 2. According to our preferred specification with all controls included, treated grades experience a 1.4 percentage point decline in private school share relative to untreated grades as a result of CSR. This decline is equivalent to 12 percent of the pre-CSR K-3 average private school share of 11.7 percent - a significant amount - and 17 percent of its standard deviation. In terms of student numbers, these estimates imply an extra 37,500 students were found in public elementary schools in a given year as a result of CSR. ${ }^{32}$ Regarding the 'parallel trends' assumption that underpins our interpretation of these estimates, we plot coefficient estimates by year, and find no evidence of differential pre-trends prior to the reform (see Figure A.2). Our results are also robust to leveraging school-adoption decisions in a triple-differences framework (see Appendix B).

The steep decline in private school share caused by CSR makes it likely that the extensive margin - the number of schools - would also be affected, as in Dinerstein and Smith (2016). Figure 4 plots the number of private schools per 1000 school-aged children in California and the rest of the country. ${ }^{33}$ As expected, there is a noticeable reduction in private schools per head following the

\footnotetext{
${ }^{30}$ Weighting is used to account for smaller districts that do not contain any private schools. Alternatively, the regression can be restricted to only those school districts with a private school option. We present results for the 'weighting' method, as the sample restriction produces similar estimates.

${ }^{31}$ For example, the share of students in private schools in the entire state in first grade is flat in the two academic years preceding 1995-96. Then by the start of 1996-97 (the first year that CSR affects public school class sizes in first grade), there is a pronounced dip down in first grade while the shares for other grades remain steady, consistent with there being a switch into public schools for that grade.

${ }^{32}$ The 37,500 estimate is calculated as follows: the pre-CSR K-3 private school share is 12 percent, and there are 1.827 million K-3 public school students. Multiplying the total number of K-3 students - $(1.827 / 0.88)$ million - by the 0.12 private school share and by our effect size of 0.014 gives the estimate.

${ }^{33}$ To make this comparison, we use data from the Private School Universe Survey, conducted by the National Center for Education Statistics. It is available at https://nces.ed.gov/surveys/pss/pssdata. asp.
} 
1996-97 reform in California relative to the rest of the country. ${ }^{34}$ Specifically, we estimate a 0.06 decline in the number of private schools per 1000 school aged children, which amounts to closing 360 private schools in California - itself a ten percent decline from the 3,467 private schools in the state prior to CSR's implementation.

\subsection{Public Student Composition}

Building on the evidence that CSR caused students in relevant grades to switch from private schools into the public system, our public school data allow us to explore the impact of this influx of new students in terms of public school sociodemographic compositions at the school-grade-year level. To do so, our econometric approach involves a triple-differences design, using the same grade and time differencing in equation (4.1) as well as a third dimension of differencing related to whether a private school is nearby: our preferred specification defines 'nearby' as being within $3 \mathrm{~km}$. (A more detailed description of our approach is given in Appendix C.)

Given that the proportion of white students in private school is initially about fifteen percent higher and the proportion of Hispanic students about twenty three percent lower compared to their public counterparts (see Table A.5), enrollment changes to the public system are likely to involve these two groups primarily. ${ }^{35}$ This is indeed what we find: the evidence in that table shows that CSR led to a 2.9 percentage point increase in the fraction of white students and a decline of 1.5 percentage points in the fraction of Hispanic students in public schools with nearby private alternatives (relative to public schools without nearby private competitors), indicating pronounced sociodemographic sorting.

\subsection{Sorting: Transitory or Permanent?}

The causal evidence relating to the initial impact of the reform prompts the question whether the sorting we have documented is transitory or not; this will be relevant when pinning down the reform's indirect effects. There are three possibilities: (i) students previously in the private school system might return to private schools directly upon completion of third grade when the CSR treatment ends; (ii) they might return after completing all grades offered by the public school they switched into (say, after fifth grade in a K-5 school); or (iii) they might remain in the public system

\footnotetext{
${ }^{34}$ See Table A.4 for estimates of the extensive margin effects of CSR in difference-in-differences and triple-differences frameworks (Appendix B provides a fuller description). These effects can be further broken into private school entry and exit responses - see Figures A.4(a) and A.4(b). There we show a sharp increase in private school exit rates and a decline in entry rates in California relative to the rest of the country after the 1996-97 CSR reform.

${ }^{35}$ While we do not have detailed private school demographic data, the NCES provides school-level demographics for the 1997-98 school year and every two years thereafter. Based on this data source, the public-private demographic disparities we report are thus one year after CSR began in 1996-97.
} 
for the duration of their primary and secondary education. Which possibility obtains is likely to depend on the (unobserved) switching costs involved.

While our data do not provide measures of individual switching behaviour directly, we are able to shed light on this issue using private school share data aggregated to the district level. Specifically, we exploit the differential exposure of cohorts to the reform, drawing on the idea that pronounced changes in private school share should line up with elementary school grade spans if the second possibility above holds. To that end, we implement the following regression discontinuity design:

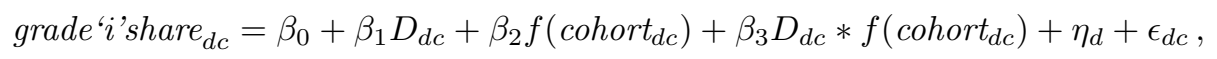

for $-b \leq$ cohort $_{d c} \leq b$, where grade $^{6}{ }^{\prime}$ share $_{d c}$ is the private school share in grade $i$ belonging to cohort $c$ in district $d$, indicator $D_{d c}$ denotes whether cohort $c$ was exposed to CSR, $f(\cdot)$ is a flexible polynomial function, cohort $t_{c}$ is the cohort number (defined by the year that the student enters kindergarten and normalized by that year's relation to the year the reform was introduced), ${ }^{36} \eta_{d}$ is a district fixed effect, and $b$ is some bandwidth.

Intuitively, this regression discontinuity design compares the private school share in each grade for the first cohort (the 1996-97 first-grade cohort) to be affected by CSR relative to the last cohort (namely the 1995-96 first-grade cohort) unaffected by CSR, although subsequent and antecedent cohorts are also used to improve statistical precision. The coefficient of interest, $\beta_{1}$, from this design thus identifies CSR's impact on the private school share of cohorts in a given grade $i$. As the most common grade configurations in California by far are K-5 and K-6, accounting for 47 and 42 percent respectively of schools serving elementary grades in the state, ${ }^{37}$ the second possibility rehearsed above would imply an increase in $\beta_{1}$ from elementary school non-CSR grades (4-6) to the middle school grades (7-8), while the first possibility would imply no such increase.

The RD results in Table 3 show the estimated average effects of CSR on private school shares by grade span (grouped by grades to increase power). The coefficient is negative and significant for CSR grades (first through third), and we find the same negative and significant point estimate for non-CSR elementary grades (fourth through sixth), while the absolute magnitude of the point estimate drops by two-thirds for middle school grades (seventh and eighth) - specifically, the effect size falling from -0.30 in elementary non-CSR grades to -0.10 in middle school grades. ${ }^{38}$ (The effect for kindergarten should be considered a placebo, as the first CSR cohort was exposed in first grade

\footnotetext{
${ }^{36}$ The cohort entering kindergarten in 1995-96 is designated 'cohort zero' as it is the first cohort to be exposed to CSR in first grade. Since the cohort variable is discrete, we add 0.5 to each value so that zero is the midpoint between the first treated and untreated cohorts.

${ }^{37}$ See Table A.10, which reports the numbers and percentages of elementary schools by grade configuration in California.

${ }^{38}$ Figure A.5 plots the estimated effect of CSR on private school share for each grade.
} 
only; this is borne out in the table by an estimate statistically indistinguishable from zero.)

The finding that approximately two-thirds of the CSR 'treatment effect' on private school share disappears when making the transition to middle school is consistent with the following interpretation: nearly all private school students drawn into the public system by CSR remain there until they transition to middle school, at which point approximately two-thirds return to the private system. Further, the relevant grade span at the school in question will influence the timing of this return. In particular, a sizeable fraction - around two thirds - of the sixth-grade students who had been attending K-5 public schools then switched back to the private system for middle school one year earlier than those attending K-6 public schools. We will use this estimate below when gauging the likely extent of the indirect effect.

\subsection{Indirect Effects: Reduced-Form Evidence}

The evidence of sorting in response to the reform prompts the question whether these compositional changes affect measured output. We now explore the indirect effects of the reform in terms of test scores, showing how they can be identified using three sources of variation in a triple-differences regression. This compares students (i) attending K-6 versus K-5 schools, (ii) enrolled in sixth versus fifth grade, and (iii) from a cohort affected by CSR directly versus one unaffected by it. (Similar sources of variation will be used to isolate the indirect effect using our differencing approach based on the conceptual framework in the next section.)

The rationale for this grade configuration comparison stems from two facts. First, as just discussed, nearly all private school students drawn into the public system by CSR remain there until they transition to middle school, at which point approximately two-thirds return to the private system. The import of this fact ('Fact 1' for convenience) is that the indirect effects of the reform should influence elementary school grades whether or not they are subject to CSR until these students transition into middle school. In other words, because students do not return to the private system en masse immediately after third grade, fourth grade classrooms (for example) will also be affected indirectly through induced changes in student compositions, even though fourth grade students were never subject to CSR directly.

As the second fact ('Fact 2'), we have also noted that schools with K-5 and K-6 grade spans account for the substantial majority of schools serving elementary grades in California. Alongside Fact 1, this fact gives rise to exogenous grade span variation that generates differential spillovers from CSR. Sixth-grade public school students formerly in K-5 schools lose a large proportion of the indirect effect, since around two-thirds of students who move into their school following the reform already returned to the private sector; in contrast, sixth-grade students in K-6 schools continue to 
receive the entire indirect effect, as the transition to middle school has yet to occur.

Formally, we conduct our reduced-form estimation by considering grades $g$ and $g-1$ and schools with K-5 or K-6 configurations, and running the following regression:

$$
\begin{aligned}
y_{s g t} & =\alpha+\phi_{g} G_{g}+\phi_{k} K 6_{s}+\phi_{t} \text { post }_{t}+\zeta_{g k} G_{g} * K 6_{s}+\zeta_{g t} G_{g} * \text { post }_{t}+\zeta_{k t} K 6_{s} * \text { post }_{t} \\
& +\Phi_{K 6-K 5, g-(g-1), p o s t-p r e} G_{g} * K 6_{s} * \text { post }_{t}+\phi X_{s g t}+\epsilon_{s g t}
\end{aligned}
$$

where $y_{s g t}$ is the test score in school $s$ in grade $g$ at time $t, G_{g}$ is an indicator for grade $g, K 6_{s}$ is an indicator for the K-6 grade span configuration (equalling one for that configuration), post $t_{t}$ refers to the 2001-02 school year and later, and $X_{s g t}$ is a vector of school-grade-year characteristics. The coefficient of interest is $\Phi_{K 6-K 5,6-5, p o s t-p r e}$, which compares sixth and fifth grade scores between K5 and K-6 schools before and after the 2001-02 school year (when the first CSR cohort entered sixth grade). It represents the indirect spillover effect of the reform, which we expect to be positive. All other triple-differences between adjacent grades $\left(\Phi_{K 6-K 5, g-(g-1), p o s t-p r e} \forall g \neq 6\right)$ serve as placebo tests.

Results: Figure 5 plots the triple-differences point estimates (K-5 versus K-6, and the treated versus untreated cohort) for each difference between consecutive grades (e.g., sixth versus fifth grade). We only find a significant triple-differences estimate, as expected, when comparing sixth and fifth grades, with all other grade comparisons yielding an estimate that is statistically indistinguishable from zero. (These point estimates are also reported in Table A.6 with varying levels of controls.) Our triple-differences estimate for the sixth versus fifth grade comparison is $0.11 \sigma$, indicating a large indirect effect of the reform on test scores.

The triple-differences comparison recovers an intent-to-treat of the indirect effect of CSR. The treatment-on-the-treated effect is then obtained by scaling up the intent-to-treat effect by a factor of 1.5 (dividing by 0.67 ), in order to account for the two-thirds of students estimated to return to the private system. This suggests that the total indirect effect of CSR was $0.17 \sigma(=0.11 / 0.67)$. Our treatment-on-the-treated estimate almost exactly matches the model-based estimate we will present in the next section. ${ }^{39}$

\section{Main Estimation Approach}

The evidence of significant sorting in response to CSR raises the main empirical issues addressed in this paper: how do the indirect sorting effects of this large-scale policy compare with the policy's

${ }^{39}$ Our actual estimate there is $0.16 \sigma$, the slight difference attributable to the fact that it only uses one pre-reform year and one post-reform year of data, while the triple-differences regression exploits multiple pre- and post-reform years. 
direct effects, and to what extent does each effect persist? To address these issues, we turn to the differencing approach at the heart of our analysis, showing how independent variation across cohorts and school configurations can be used to determine the direct and indirect effects of the reform along with their persistent impacts.

The approach is based on an estimation framework that links directly to the conceptual model in Section 2. We describe this framework next, then present our approach for identifying the key parameters of interest, before showing formally why a difference-in-differences analysis will yield biased estimates. We also discuss the generality of the estimation approach.

\section{$5.1 \quad$ Estimation Framework}

We start by adapting the linear cumulative production technology with geometric decay in equation (2.1) to reflect the available data, aggregated to the school-grade-year level. (For expositional clarity, we suppress teacher quality $(Q)$ for now, incorporating it later in the section.) Thus we write the school-grade-year $(s-g-t)$ test score $y_{s g t}$ as a function of current and past inputs:

$$
y_{s g t}=\gamma_{R} \sum_{\tau=0}^{L}\left(\delta_{R}\right)^{\tau} R_{s, g-\tau, t-\tau}+\gamma_{X} \sum_{\tau=0}^{L}\left(\delta_{X}\right)^{\tau} X_{s, g-\tau, t-\tau}+\epsilon_{s g t} .
$$

To keep track of grades and time, we use the $\tau$ index to increment both successive grades $(g \in$ $\{0,1, \ldots, 6\})$ and academic years $(t \in\{1996-97,1997-98, \ldots\})$. All unobserved determinants of the test score are represented by $\epsilon_{s g t}$.

Given our interest in modeling the response of test scores to the introduction of a major education reform like CSR, we draw notional contrasts between observed scores at the school-grade-year level and 'counterfactual' scores that would have prevailed had the reform not been enacted. Differencing in this way means the resulting estimates are relative to a baseline in which the reform never came into effect.

The comparisons we make involve school averages. Specifically, averaging over all schools serving grade $g$ in year $t$ and denoting the total number of relevant schools simply by $N_{s}$ in each case, define $\Delta y_{g t} \equiv y_{g t}-y_{g t}^{u} \equiv \frac{1}{N_{s}} \sum_{s}\left(y_{s g t}-y_{s g t}^{u}\right)$ as the difference between the actual average test score for that grade-year combination and the unobserved (superscripted by ' $u$ ') average score that would arise in a counterfactual setting in which the reform had never been implemented. Analogously, define $\Delta R_{g t}$ and $\Delta X_{g t}$ based on average differences between actual and counterfactual school resources and sociodemographics, respectively.

In practice, we cannot construct $\Delta y_{g t}$ directly, given that $y_{s g t}^{u}$ is unobserved. Instead, we obtain a prediction of the counterfactual score (denoted by $\hat{y}_{g t}^{u}$ ) based on data for untreated cohorts under 
assumptions stated below. Forming the predicted difference $\widehat{\Delta y}_{g t} \equiv y_{g t}-\hat{y}_{g t}^{u}$, the estimating equation is given by:

$$
\widehat{\Delta y}_{g t}=\gamma_{R} \sum_{\tau=0}^{L}\left(\delta_{R}\right)^{\tau} \Delta R_{g-\tau, t-\tau}+\gamma_{X} \sum_{\tau=0}^{L}\left(\delta_{X}\right)^{\tau} \Delta X_{g-\tau, t-\tau}+\Delta \epsilon_{g t} .
$$

On the RHS, $\Delta \epsilon_{g t} \equiv y_{g t}^{u}-\hat{y}_{g t}^{u},{ }^{40}$ and $\Delta R_{g-\tau, t-\tau}$ and $\Delta X_{g-\tau, t-\tau}$ represent the change in school resources and the mix of students arising from CSR (relative to the counterfactual baseline) for students in grade $g-\tau$ and academic year $t-\tau$.

For treated grade-years, represented in Figure 1 with a ' $\times$ ' symbol, resources increase $\left(\Delta R_{g t} \neq 0\right)$ and sociodemographics adjust $\left(\Delta X_{g t} \neq 0\right)$, as the descriptive evidence above shows. Thus we would expect to see non-zero test score effects relative to the 'no-CSR' counterfactual baseline (yielding $\Delta y_{g t} \neq 0$ ) for treated cohorts, according to the sequence of relevant educational inputs ( the "input trajectory") received by students as they progress through the education system. For all control combinations (such as third grade and above in 1997-98), represented in Figure 1 with a '.' symbol, we have $\Delta R_{g t}=\Delta X_{g t}=0$, which implies that $\Delta y_{g t}=0$ from equation (5.2).

\subsection{Identification Using Differencing}

Applying our differencing approach, we show how the direct effect, the indirect effect and the persistence parameters are identified, before extending the identification strategy to account for teacher quality.

Identifying the Direct Effect: To estimate the direct effect, we carry out a within-year comparison of two adjacent cohorts that received differential exposure to the CSR reform. Specifically, we focus on the input trajectories of students in third and fourth grades in 2001-02 for our estimation of the direct effect, although in principle other pairings could be used. These trajectories are illustrated in Figure 6, highlighted by two upward diagonal outlines that each enclose four points. It is clear that third graders in that school year had received four successive years of direct exposure to smaller classes, while the fourth graders received only three. We will argue that differencing the two trajectories will isolate the direct effect of interest. The differencing argument draws on two further assumptions, over and above the structure from Section 2 (expressed there as Assumptions 1 and 2).

We make the identification argument formally using the estimation framework. The structure of the argument can be summarized at the outset as follows: First, we use estimating equation (5.2)

${ }^{40} \overline{\text { To see this, note that } \widehat{\Delta y} y_{g t}=\Delta y_{g t}+\Delta \epsilon_{g t}}$. Thus, $\Delta \epsilon_{g t}=\widehat{\Delta y} y_{g t}-\Delta y_{g t}=\left(y_{g t}-\hat{y}_{g t}^{u}\right)-\left(y_{g t}-y_{g t}^{u}\right)=y_{g t}^{u}-\hat{y}_{g t}^{u}$. Intuitively, $\Delta \epsilon_{g t}$ shrinks as the prediction improves. 
to obtain an expression for the average predicted test score difference for the third grade cohort in 2001-02, $\widehat{\Delta y}_{3,01-02}$, and similarly $\widehat{\Delta y}_{4,01-02}$ for the fourth grade cohort in the same year. Second, we form the difference $\widehat{\Delta y}_{3,01-02}-\widehat{\Delta y}_{4,01-02}$, deducting the latter from the former. (The relevant expressions are set out in full in Appendix D.) Third, under a plausible assumption regarding input trajectories - Assumption 3 below - this difference simplifies to the following expression:

$$
\widehat{\Delta y}_{3,01-02}-\widehat{\Delta y}_{4,01-02}=\gamma_{R} \Delta R_{3,01-02}+\left(\Delta \epsilon_{3,01-02}-\Delta \epsilon_{4,01-02}\right) \text {. }
$$

Fourth, under a parallel trends assumption (Assumption 4 below), the differenced error term in equation (5.3) equals zero. This implies that the RHS of the expression consists solely of the direct effect of interest, $\gamma_{R} \Delta R_{3,01-02}$. Further, the same parallel trends assumption allows us to express the LHS in terms of known quantities - differences in grade-year average test scores - thus completing the identification argument for the direct effect.

We now state the two required assumptions and justify each one. First is an assumption (in two parts) about input levels experienced by cohorts that were treated (at least in some years) under CSR:

Assumption 3: (a) $\Delta R_{g t}=\Delta R_{g^{\prime} t}$, and (b) $\Delta X_{g t}=\Delta X_{g^{\prime} t} \quad \forall g, g^{\prime}$. According to part (a), all grades treated by CSR in a given year $t$ experience the same class size 'treatment.' Supporting evidence in Table A.7 shows that CSR grades had similar class sizes once the reform was implemented. In addition, Bohrnstedt and Stecher (2002) report that following CSR's full implementation in 2000-01, 95 to 98 percent of students in each CSR grade were in CSR-compliant classrooms, indicating little heterogeneity in grade-level implementation rates.

Part (b) says the indirect effects of CSR in a given year $t$ are the same across grades. This is plausible given part (a): if resource changes $(\Delta R)$ are identical across grades, then the sortinginduced transformations to school demographics caused by these resource changes should also be similar across grades. We confirm this empirically in Table A.8, which analyzes public school compositional changes induced by CSR separately for each K-3 grade via triple differences, indicating that the grade-specific estimates are statistically indistinguishable from each other. Subsequently, given that a large fraction of students who switch into the public system remain there until they transition to middle school (Fact 1 from the previous section), Assumption 3(b) should hold across all elementary school grades, which in practice means at least until the end of fifth grade, given the wide prevalence of K-5 schools in the state.

Assumption 3 implies - and the evidence above also indicates - that differences in class size inputs across treated grades in the same year are all zero and differences in sociodemographic inputs across grades in the same year (comparing the relevant cohorts) are also zero, so both can 
be ignored. Thus, sociodemographic differences between the third and fourth grade cohort in 200102 drop out as both cohorts have been affected by three years of altered sociodemographics. The change in class size in third grade in 2001-02 is then left as the only remaining school input affecting score differences between these two cohorts - in short, $\gamma_{R} \Delta R \cdot{ }^{41}$

The expression in equation (5.3) makes clear that we still have to attend to the error difference term $\left(\Delta \epsilon_{3,01-02}-\Delta \epsilon_{4,01-02}\right)$ on the RHS. This captures any error introduced by the prediction of the counterfactual: identification of the direct effect thus hinges on the quality of that prediction. We state the following parallel trends assumption.

\section{Assumption 4: In the absence of the reform, test score differences between grades $g$} and $g^{\prime}$ are time-invariant: $y_{g t}^{u}-y_{g^{\prime} t}^{u}=y_{g t^{\prime}}^{u}-y_{g^{\prime} t^{\prime}}^{u}$

The assumption implies that no other contemporaneous reforms affect grades differentially. Support for this assumption in our setting comes from the fact that grade differences for untreated cohorts are statistically indistinguishable from each other over time (see Table A.9). ${ }^{42}$

Assumption 4 allows observations for untreated cohorts to serve as controls for their nevertreated counterparts. A natural candidate is the within-year difference between third and fourth grades in 1997-98 (represented in Figure 6 by the two encircled points), as neither of these cohorts was ever affected by the reform.

Two relevant consequences follow from Assumption 4. First, the difference $\widehat{\Delta y}_{3,01-02}-\widehat{\Delta y}_{4,01-02}$ can be expressed in terms of known quantities only - specifically, $\left(y_{3,01-02}-y_{4,01-02}\right)-\left(y_{3,97-98}-\right.$ $\left.y_{4,97-98}\right)$. Definitionally, $\widehat{\Delta y}_{3,01-02}-\widehat{\Delta y_{4,01-02}}=\left(y_{3,01-02}-y_{4,01-02}\right)-\left(\hat{y}_{3,01-02}^{u}-\hat{y}_{4,01-02}^{u}\right)$, so Assumption 4 allows us to replace the unobserved counterfactual scores $\left(\hat{y}_{3,01-02}^{u}-\hat{y}_{4,01-02}^{u}\right)$ with observed values from untreated cohorts $\left(y_{3,97-98}-y_{4,97-98}\right)$. The second consequence is that the test score difference on the RHS of (5.3) is itself equal to the direct effect of the reform, which is the quantity of interest. This will be the case if the error term difference $\left(\Delta \epsilon_{3,01-02}-\Delta \epsilon_{4,01-02}\right)$ in (5.3) is equal to zero, as it is under Assumption $4 .^{43}$

To summarize, identification of the direct effect $\left(\gamma_{R} \Delta R\right)$ requires average test scores of two different cohorts to be compared within the same treated year, controlling for any non-CSR differences by deducting off corresponding average scores for older cohorts not subject to the reform. Based on the timing of CSR's implementation, this sequence of treatments occurs in our context

\footnotetext{
${ }^{41}$ See equation (D.1) in Appendix D for a formal derivation.

${ }^{42}$ Table A.9 shows the difference in test scores in fourth through sixth grades for the final two cohorts who were never treated by the reform. Differences between fifth and fourth grade test scores in Panel A (and sixth and fifth grade in Panel B) for these cohorts are nearly identical, bolstering the argument that differences between treated and untreated cohorts would have been the same in the absence of CSR.

${ }^{43}$ To see why, use actual scores in 1997-98 to predict counterfactual scores in 2001-02 and apply the assumption. Then we have: $\Delta \epsilon_{3,01-02}-\Delta \epsilon_{4,01-02}=\left(y_{3,01-02}^{u}-\hat{y}_{3,01-02}^{u}\right)-\left(y_{4,01-02}^{u}-\hat{y}_{4,01-02}^{u}\right)=\left(y_{3,01-02}^{u}-y_{4,01-02}^{u}\right)-\left(y_{3,97-98}^{u}-y_{4,97-98}^{u}\right)=0$.
} 
for third and fourth grade in the 2001-02 school year, with the same grades in 1997-98 accounting for the non-CSR counterfactual.

Identifying the Indirect Effect: We now present a differencing strategy based on school grade span configurations to recover the indirect effect $\left(\gamma_{X} \Delta X\right)$. In particular, we compare sixth and fifth grade test scores in areas with K-6 versus K-5 configurations, and do so for a school year in which CSR affects sixth grade cohorts (2001-02, for instance) relative to a school year where sixth grade is unaffected by the reform. (This identification approach effectively mirrors our triple-differences reduced-form strategy from Section 4.4 in the context of the conceptual framework.) Formally, we have:

$$
\begin{aligned}
\widehat{\Delta y}_{6,01-02, K 6}= & \left(\delta_{R}\right)^{5} \gamma_{R} \Delta R_{1,96-97}+\left(\delta_{R}\right)^{4} \gamma_{R} \Delta R_{2,97-98}+\left(\delta_{R}\right)^{3} \gamma_{R} \Delta R_{3,98-99} \\
& +\left(\delta_{X}\right)^{5} \gamma_{X} \Delta X_{1,96-97}+\left(\delta_{X}\right)^{4} \gamma_{X} \Delta X_{2,97-98}+\left(\delta_{X}\right)^{3} \gamma_{X} \Delta X_{3,98-99} \\
& +\left(\delta_{X}\right)^{2} \gamma_{X} \Delta X_{4,99-00}+\delta_{X} \gamma_{X} \Delta X_{5,00-01}+\gamma_{X} \Delta X_{6,01-02, K 6}+\Delta \epsilon_{6,01-02, K 6}
\end{aligned}
$$

where the extra subscript 'K6' represents students in schools with a K-6 configuration (and similarly for the 'K5' subscript). The RHS of equation (5.4) reflects the input trajectory involving both resources and sociodemographics that sixth graders in 2001-02 have been exposed to while in their K-6 schools. $^{44}$

This trajectory is illustrated in the schematic Figure 7(a), which makes clear the CSR 'resource shock' only applied for three of those six years, while sociodemographic spillovers from CSR applied in each of the six years. The average predicted achievement difference for sixth grade K-5 configuration students in 2001-02 can be written analogously, with Figure 7(b) representing the associated trajectory.

We make the following assumption about inputs for K-6 and K-5 schools:

Assumption 5: (a) $\Delta R_{g, t, K 6}=\Delta R_{g, t, K 5} \quad \forall g \leq 5$, and (b) $\Delta X_{g, t, K 6}=\Delta X_{g, t, K 5} \quad \forall g \leq 5$.

This is a refinement to Assumption 3 above, given grade span differences: the increased resources and student composition changes due to CSR are assumed to be identical across grade configurations for all common grades up to and including fifth grade. Assumption 5(a) holds since the reform was applied uniformly across configurations (see Table A.10). Assumption 5(b) is supported by Fact 1 as well as the lack of significant differences in demographic sorting across K-5 and K-6 schools in a triple-differences design, as described in Appendix C.

Taking the difference between sixth grade students in K-6 versus K-5 configurations yields:

\footnotetext{
${ }^{44}$ Here, given our focus on variation in grade configurations, averages are taken over all schools with a particular grade configuration.
} 


$$
\begin{aligned}
\widehat{\Delta y}_{6,01-02, K 6}-\widehat{\Delta y}_{6,01-02, K 5} & =\gamma_{X} \Delta X_{6,01-02, K 6}-\gamma_{X} \Delta X_{6,01-02, K 5}+\left(\Delta \epsilon_{6,01-02, K 6}-\Delta \epsilon_{6,01-02, K 5}\right) \\
& =\psi \gamma_{X} \Delta X_{6,01-02, K 6}+\left(\Delta \epsilon_{6,01-02, K 6}-\Delta \epsilon_{6,01-02, K 5}\right),
\end{aligned}
$$

where the parameter $\psi \leq 1$ gives the proportion of the students initially switching into the public system as a result of CSR who then exit the public system during the transition to middle school. Specifically, we let $\Delta X_{6, t, K 5}=(1-\psi) \Delta X_{6, t, K 6}$, estimating $\psi$ to be equal to two-thirds (Fact 1 above).

Under the parallel trends assumption (Assumption 4), 1997-98 scores can serve as valid counterfactuals for the scores of K-5 and K-6 schools in 2001-02 in the absence of CSR (implying $\left.\Delta \epsilon_{6,01-02, K 6}-\Delta \epsilon_{6,01-02, K 5}=0\right)$. The indirect effect of interest $\left(\gamma_{X} \Delta X_{6,01-02, K 6}\right)$ can in turn be recovered from the known left-hand side of equation (5.5), given by

$$
\widehat{\Delta y}_{6,01-02, K 6}-\widehat{\Delta y}_{6,01-02, K 5}=\left(y_{6,01-02, K 6}-y_{6,01-02, K 5}\right)-\left(y_{6,97-98, K 6}-y_{6,97-98, K 5}\right)
$$

Here we are using two layers of differencing (rather than one) to provide the counterfactual, so identification relies on parallel trends holding in difference-in-differences rather than first differences, which is weaker than Assumption 4. As the first layer, we account for systematic differences between K-5 and K-6 schools by differencing out fifth grade test scores in K-5 ( $y_{5,01-02, K 5)}$ and K-6 schools $\left(y_{5,01-02, K 6}\right)$. As the second layer, we use the pre-reform test scores for both fifth and sixth grades in K-5 and K-6 schools as counterfactuals for the observed test scores in fifth and sixth grades in the 2001-02 school year. ${ }^{45}$ On that basis, we have:

$$
\begin{aligned}
\psi \gamma_{X} \Delta X_{6,01-02}= & {\left[y_{6,01-02, K 6}-y_{5,01-02, K 6}-\left(y_{6,97-98, K 6}-y_{5,97-98, K 6}\right)\right] } \\
& -\left[y_{6,01-02, K 5}-y_{5,01-02, K 5}-\left(y_{6,97-98, K 5}-y_{5,97-98, K 5}\right)\right]
\end{aligned}
$$

which allows us to identify the indirect effect $\left(\gamma_{X} \Delta X\right)$ using observed scores on the RHS and our estimate of $\psi{ }^{46}$

Identifying the Persistence Parameters: Next, we isolate the parameters governing the persistence of the reform $\left(\delta_{R}\right)$ and the persistence of changes in student demographics $\left(\delta_{X}\right)$ using a similar approach. To do so, we take the estimated contemporaneous effects $\gamma_{R} \Delta R$ and $\gamma_{X} \Delta X$ as given and construct the following two differences: (i) between fourth- and third-grade test scores in the 2000-01 school year, and (ii) between fourth- and fifth-grade test scores in the 2000-01 school

\footnotetext{
${ }^{45}$ Here, we are over-identified. We could use 1997-98, 1998-99 and 1999-00 as counterfactuals, since cohorts in fifth and sixth grades were not subject to CSR in those years. In practice, we use all three and take an average of the estimates, although estimates are quantitatively similar regardless of which counterfactual year we use.

${ }^{46}$ While the identification of the indirect effect $\left(\gamma_{X} \Delta X\right)$ requires comparing cohorts in K-6 and K-5 schools for 2001-02 or later, a change to test scores for the 2002-03 school year prevents us from using subsequent cohorts in practice.
} 
year. This forms a system of two non-linear equations - equations (D.6) and (D.7) in Appendix D.1 - with two unknowns $\left(\delta_{R}\right.$ and $\left.\delta_{X}\right)$, which we then solve for, computing bootstrapped standard errors for each.

Intuitively, we identify the persistence parameters by exploiting variation across third, fourth, and fifth grade cohorts in 2000-01. All three cohorts were affected through the direct class size reduction channel for three years, but were affected by the indirect channel for different lengths of time (three, four and five years for third, fourth and fifth grades, respectively). This allows us to separate the persistence of the indirect effect $\left(\delta_{X}\right)$, which affected some grades more than others, from the persistence of the direct effect $\left(\delta_{R}\right)$, which influenced all grades equally, although it was applied at different points in time.

Accounting for Teacher Quality: Our identification strategy can be extended to include the indirect teacher quality effects in the equations used to identify the direct effect, the indirect sorting effect, and persistence parameters. We allow teacher quality to differ according to year, whether the grade was subject to CSR or not, and how removed the treatment is from the grade-year combination of interest (i.e., the lag).

In essence, we follow Jepsen and Rivkin (2009) by appealing to variation in observable teacher experience as a proxy for teacher quality. ${ }^{47}$ Those authors document a pronounced increase in the overall proportion of inexperienced teachers following the introduction of CSR, and a subsequent decline to pre-CSR levels after a few years. Given that our framework relies on variation across CSR and non-CSR grades over time, we draw on evidence relating to the way in which teacher inexperience evolved by grade, presented in Appendix Table A.11. ${ }^{48}$ Such changes are observable each year, allowing our treatment of these indirect teacher quality effects to be non-parametric, rather than following the 'geometric decay' formulation used for class size (resources) and student demographics. (We set out the full reasoning in Appendix D.3.)

\subsection{Comparison with Difference-in-Differences}

Following on from the discussion of identification, it is instructive to see why estimating the impact of a large-scale reform using a difference-in-differences ('D-in-D') specification will not, in general, be appropriate for estimating the direct effect. Doing so would entail comparing the pre-/postreform difference in average scores of students in a grade who became subject to the policy with the corresponding scores of students in a control grade (as discussed). We show that even if the

${ }^{47}$ This is necessary given that the number of parameters exceeds what can be identified through variation in test scores alone: there is a parameter for every ' $x$ ' or '.' contained within a cohort's trajectory, across all cohorts analyzed.

${ }^{48}$ Jepsen and Rivkin (2009) control implicitly for teacher observables that evolve by grade, using school-grade-year controls and grade-year fixed effects, and so do not document patterns at the grade-year level. 
linear technology and parallel trends assumptions (Assumptions 1 and 4 above) hold, such a strategy will produce biased estimates as long as at least one of two statements is true: (i) the effect of past resources persists $\left(\delta_{R} \neq 0\right)$, or (ii) there are indirect effects $\left(\gamma_{X} \Delta X \neq 0\right)$.

To see why, consider students in third and fourth grade in the 1998-99 school year. As already rehearsed, the third grade cohort in 1998-99 is affected by the CSR reform in first, second and third grade, both directly and indirectly (due to the spillover), while the fourth grade cohort in 199899 is never affected. Based on the definition of $\Delta y_{g t}$ and Assumption 4, the D-in-D specification comparing third (CSR) and fourth (non-CSR) grades from 1997-98 to 1998-99 is:

$$
\begin{aligned}
\Delta y_{3,98-99}-\Delta y_{4,98-99} & =y_{3,98-99}-y_{4,98-99}-\left(y_{3,98-99}^{u}-y_{4,98-99}^{u}\right) \\
& =y_{3,98-99}-y_{4,98-99}-\left(y_{3,97-98}-y_{4,97-98}\right) .
\end{aligned}
$$

Taking the terms on the LHS and appealing to the technology, $\Delta y_{3,98-99}$ is given by:

$$
\begin{aligned}
\Delta y_{3,98-99} & =\left(\delta_{R}\right)^{2} \gamma_{R} \Delta R_{1,96-97}+\delta_{R} \gamma_{R} \Delta R_{2,97-98}+\gamma_{R} \Delta R_{3,98-99} \\
& +\left(\delta_{X}\right)^{2} \gamma_{X} \Delta X_{1,96-97}+\delta_{X} \gamma_{X} \Delta X_{2,97-98}+\gamma_{X} \Delta X_{3,98-99},
\end{aligned}
$$

and from equation (5.2), we have $\Delta y_{4,98-99}=0$. The direct effect of the reform in this instance is $\gamma_{R} \Delta R_{3,98-99}$. Yet it is clear that the RHS of (5.7), $y_{3,98-99}-y_{4,98-99}-\left(y_{3,97-98}-y_{4,97-98}\right) \neq$ $\gamma_{R} \Delta R_{3,98-99}$, the RHS of (5.8), unless $\delta_{R}=0$ and there are no indirect effects $\left(\gamma_{X} \Delta X_{g t}=0\right)$ in any of the three years. That is, the direct effect is not identified if there is persistence in the student learning technology or there are indirect effects. ${ }^{49}$

This issue applies more broadly, to other data structures. For example, if the reform applied to all eligible grades directly upon its introduction, researchers would still need an approach for estimating the indirect effect and controlling for that when estimating the direct effect. Otherwise, the latter would continue to be biased using D-in-D.

\subsection{Generality of the Approach}

We have proposed the differencing approach in this section to identify the direct and indirect effects of a large-scale reform in the presence of data limitations (not least, a lack of pre-reform data) that make the empirical analysis of California's CSR program challenging. Our approach is applicable more widely - to settings in which a policy reform treats a subset of grades shared by two or more grade configurations. Combined variation of these two forms is widespread: schools are often subject to a major reform that extends across co-existing grade configurations; and our approach

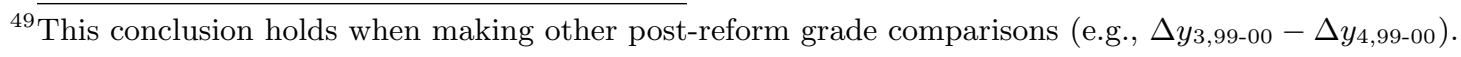


applies as long as only a subset of grades is treated by the reform. ${ }^{50}$

To see why these are the relevant requirements, recall that our approach for uncovering indirect effects exploits the differential sorting behavior of students attending schools with different grade spans. This provides variation in student exposure to indirect inputs (school demographics) while leaving their exposure to direct inputs (school resources) unchanged; the latter can then be differenced away. As a consequence, the indirect sorting effect can be identified when such grade-span variation is available, allowing the appropriate triple difference to be constructed.

In terms of estimating the direct effect, if the implementation of the reform is staggered by grade (as in the case of CSR), then our differencing approach for identifying the direct effect is required. If, instead, the rollout of the reform is not staggered but rather affects treated grades simultaneously, an alternative would be to use a combination of a standard difference-in-differences approach with the methodology we propose for estimating (and so controlling for) the indirect effect, as regular D-in-D estimators will incorporate the impacts of both resources and sociodemographics. The fact that the D-in-D research design alone is unable to identify the direct effect, irrespective of whether the introduction of the reform is staggered or not, underscores the need for the proposed estimation approach.

From an implementation standpoint, our estimation approach is appealing in that it can be used in observational settings without the use of individual data, making it viable when researchers face common data limitations. Of note, all the data used in our analysis are available publicly, and are averaged to the school-grade-year level. In other settings where researchers do not face such data restrictions, applying our approach will generate over-identified estimating equations, in turn allowing researchers to conduct diagnostics assessing the assumptions we have made.

\section{Estimates}

This section presents results from implementing the differencing approach set out in Section 5.2. Table 4 provides the main estimates for the parameters governing the contemporaneous direct effect of CSR $\left(\gamma_{R}\right)$, the indirect effect of CSR on school composition $\left(\gamma_{X}\right)$, as well as the persistence of resources associated with CSR $\left(\delta_{R}\right)$ and school sociodemographics $\left(\delta_{X}\right)$, respectively.

The table's layout, organized in four columns in pairs of two, reflects a bounding exercise that relates to the sorting parameter, $\gamma_{X}$. The first and second pairs of columns are calculated using two different assumptions about the proportion of students, $\psi$, who return to private school after completing all grades offered by the public school they switched to initially. In columns (1) and

\footnotetext{
${ }^{50}$ For example, kindergarten through fifth grades are shared by K-5 and K-6 configurations, and our approach only requires that at least one of those grades is untreated in the K-5 configuration.
} 
(2), we follow the regression discontinuity evidence in Table 3 and take $\psi=\frac{2}{3}$, using the fact that two-thirds of the students are estimated to return to the private system when the middle school transition occurs; these are our preferred estimates. A lower bound estimate for $\gamma_{X}$ is then provided in columns (3) and (4) by assuming that all students who were drawn into the public system by CSR return to the private system during the middle school transition $(\psi=1)$; if fewer students return when the transition occurs, then our estimate gets scaled up. ${ }^{51}$

Relative to columns (1) and (3), columns (2) and (4) add county fixed effects. In keeping with the evidence in Jepsen and Rivkin (2009), we find that controlling for teacher quality is important, and so only report estimates that include teacher quality controls. (The teacher quality estimates themselves are given in Table A.12.) All the estimates in columns (2) and (4) are significant, and somewhat more precise than those without county fixed effects in columns (1) and (3) - the standard errors for the $\gamma$ ('input') parameters are recovered using the delta method, while we bootstrap the standard errors for the $\delta$ (persistence) parameters.

Focusing on the estimates in column (2) - our preferred ones - based on the estimated share $\psi=\frac{2}{3}$ and including county fixed effects, the direct impact of CSR accounts for a 2.2 unit increase in the mean percentile rank of students, which corresponds to a $0.11 \sigma$ increase in the school-grade test score distribution. The magnitude of this estimate is in line with experimental estimates: for instance, Krueger and Whitmore (2001) find that Project STAR raised test scores by around 0.1 standard deviations.

Alongside the direct effect, the sorting effect accounts for a 3.3 unit increase in the mean percentile rank of students, which is equivalent to a $0.16 \sigma$ increase in the school-grade test score distribution. It is precisely estimated, and is larger in magnitude than the direct effect. ${ }^{52}$ This is the first estimate in the empirical education literature of sorting effects placed on the same footing (in terms of test scores) as the direct effects of major reforms; as noted previously, it almost exactly matches our reduced-form triple-differences estimate in Section 4.4.

Turning to the persistence parameters, $\delta_{R}$ and $\delta_{X}$, we find that in our preferred specification, both the direct and indirect effects fade out in the range of 45-57 percent each year. These estimates accord with much of the literature on fade-out, which finds that the class size test score gain is "reduced approximately to half to one quarter of its previous magnitude" (Krueger and Whitmore 2001, page 11), although such test score gains then reappear later in the labor market (Chetty et al. 2011). These estimates are also consistent with fade-out estimates in the teacher effects literature

\footnotetext{
${ }^{51}$ This is apparent from the LHS of equation (5.6) above, given by $\psi \gamma_{X} \Delta X_{6,01-02}$, where a lower value of $\psi$ implies a higher value of $\gamma_{X}$ for a given change in sociodemographics.

${ }^{52}$ We discuss the interpretation of this effect below - specifically, whether it is plausible to think that spillovers from incoming to existing public school students might be important.
} 
(see Jacob, Lefgren and Sims 2010, and Kinsler 2012).

To summarize, our preferred estimates indicate that the reform has a significant direct effect of $0.11 \sigma$ (in terms of mathematics scores) and an indirect effect due to student sorting measured on the same basis that is even larger. Thus, the effects of sorting in response to a major qualityimproving education reform are first order. Further, we find that both direct and indirect effects persist strongly, and at similar rates.

\section{Magnitudes for Policy}

We now turn to the implications of these estimates for the policy calculus. The scale of the indirect sorting effect suggests that focusing only on the direct channel may substantially underestimate the overall impact of CSR from the perspective of students already enrolled in the public system. We assess the extent to which this is likely by first decomposing the indirect effect of the reform into two components, capturing compositional and spillover effects. Using those estimates, we can then compare the test score benefits of CSR alongside its fiscal consequences. We also discuss the pre-conditions for uncovering sorting effects of the magnitude we find - conditions determining their likely importance in other contexts.

\subsection{Decomposing the Indirect Effect}

Given the size of the indirect effect we have estimated, one might wonder about the likely extent of spillovers experienced by existing public school students that arise as a result of sorting, an issue clearly relevant when computing the benefits of CSR for students already enrolled in public school.

Conceptually, as already noted in Section 2, the indirect effect can be divided into two components - the compositional ('own') effect and the spillover effect. The compositional effect occurs mechanically because students who would have enrolled in private schools in the absence of the reform would typically be expected to score higher on standardized tests (on average) than their public school counterparts: the spillover effect occurs when public school students receive benefits from their new (also probably higher-scoring) classmates, most likely through positive peer influences.

In order to decompose the $0.16 \sigma$ indirect effect estimated in Section 6 into these two components, which is our goal here, one needs to know the test score of the marginal private school student who switches into the public school system due to CSR - the 'private-public switcher.' While the average test score of the private-public switchers is unobserved in our data, we carry out the decomposition under different scenarios relating to the percentile rank that the average switcher is drawn from, 
thereby constructing informative bounds.

Table 5 sets out the results. Each column reports a different percentile of the private school test score distribution that the private-public switcher could be drawn from. We take public and private school test score distributions from the 1996 California NAEP fourth grade results. ${ }^{53}$ The first row reports the average test score of the private-public switchers in terms of the public school test score distribution. Since class-level standard deviations are much smaller than individual-level standard deviations, we multiply increases in individual-level standard deviations by three to place them in the distribution of school-grade test scores. ${ }^{54}$

It is reasonable to expect that private-public switchers are relatively high up the private school test score distribution, with high-ability, low-income students likely to be the most responsive to an increase in public school quality (see Epple and Romano 1998, for example). Under the scenario in which the private-public switcher is at the $75^{\text {th }}$ percentile of the private school test score distribution (column (2) in the table), around sixty percent (or 0.10/0.16) of the indirect effect comes from positive spillovers onto public school students because of peer effects. In this case, the implied social multiplier is 1.73 , which is very similar to that in the convincing study by Graham (2008), who uses a linear-in-means peer effects model and Project STAR data to estimate a social multiplier of 1.86 .

Overall, for plausible scenarios in which the private-public switcher is drawn from the mean or higher in the private school score distribution, the spillover effect accounts for between 50 and 80 percent of the estimated indirect effect (given by the entries in the third row of the table, divided by 0.16 - see columns (1)-(3)). While this evidence is only suggestive, it does point to additional benefits from the reform that many pre-existing public students are likely to enjoy.

\subsection{Cost-Benefit Analysis}

Next we are interested drawing out the implications of our estimates in terms of likely benefits and costs, and the predicted benefit-cost ratio - that is, once indirect sorting and persistence are allowed for.

Benefits: We can use our framework and estimates to construct measures of the overall benefits of CSR, both in the short and longer term.

After one year of exposure, students in the public school system are predicted to score $0.15 \sigma$

\footnotetext{
${ }^{53}$ See Table 2.7A in https://files.eric.ed.gov/fulltext/ED425943.pdf. All effects sizes are normalized at the school-grade level to be mean zero and standard deviation one in the public school system.

${ }^{54}$ See Finn and Achilles (1990), where the estimated impact of small class sizes on the distribution of classroom means is three times larger than on the distribution of individual scores, for instance.
} 
higher - in other words, almost one-and-a-half times the direct effect. The one-year impact of CSR is the sum of three components, as implied by the linear technology from equation (5.1) and incorporating teacher effects. Specifically, the predicted score after one year (setting $\tau=0$ in the formula) is equal to $\hat{\gamma}_{R}+\hat{\gamma}_{X}+\hat{\gamma}_{Q}$ : the sum of (i) the direct effect, (ii) the indirect effect excluding its compositional ('own') component, ${ }^{55}$ and (iii) changes to teacher quality. The respective components contribute the following to the $0.15 \sigma$ total test score gain: $0.11 \sigma$ due to the direct effect, $0.10 \sigma$ from the indirect spillover effect (having netted out the 'own' effect), and a $0.06 \sigma$ decline due to the reduction in teacher quality. ${ }^{56}$

For a longer term view, we estimate the benefits of CSR cohorts experiencing the full four years of the program, again based on the linear technology from equation (5.1) combined with our estimated persistence parameters. Specifically, the test score effect for (end-of-grade) third grade students is calculated by including an additional input for teacher quality and assuming that teacher quality effects persist at the same rate as the direct effect (similar to the persistence estimates in Chetty, Friedman and Rockoff 2014); we then substitute the parameter estimates from Tables 4 and A.12 (in standard deviation units) into that equation, ${ }^{57}$ giving:

$$
\hat{y}_{3}=\sum_{\tau=0}^{3} \hat{\delta}_{R}^{\tau} \hat{\gamma}_{R}+\sum_{\tau=0}^{3} \hat{\delta}_{X}^{\tau} \hat{\gamma}_{X}+\sum_{\tau=0}^{3} \delta_{Q}^{\tau} \hat{\gamma}_{Q}
$$

At the end of third grade, students who experienced CSR in grades K-3 are estimated to score $0.29 \sigma$ higher than they would have in the absence of CSR. For reference, our estimate is in the range reported by Unlu (2005), who compared California NAEP scores to other states before and after CSR and found that four years of exposure to CSR raised fourth grade mathematics test scores by $0.2-0.3 \sigma$.

We monetize the longer term benefit of CSR using estimates in Chetty et al. (2011), who find that a one standard deviation improvement in kindergarten class quality raises student test scores by $0.32 \sigma$, in turn raising lifetime earnings by approximately $\$ 39,100$ for the average individual in 2009 dollars. Given that CSR increases student test scores by $0.15 \sigma$ after one year, we assume that CSR increased class quality by about half a standard deviation in the units of Chetty et al. (2011) (since a one- $\sigma$ improvement raises scores by $0.32 \sigma$ in that setting), suggesting that CSR raised the present value of individual earnings by $\$ 18,300$ (in 2009 dollars).

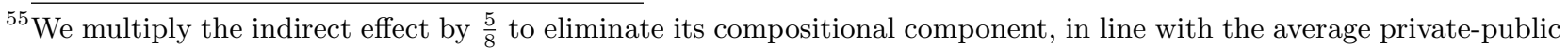
switcher scoring at the seventy fifth percentile of the private school test score distribution - see Table 5 .

${ }^{56}$ This latter estimate comes from subtracting CSR teacher quality from non-CSR teacher quality in the final year we have data (2001-02) for in Table A.12.

${ }^{57}$ The parameters are: $\hat{\gamma}_{R}=0.11, \hat{\gamma}_{X}=0.16, \hat{\gamma}_{Q}=-0.06, \hat{\delta}_{R}=0.45, \hat{\delta}_{X}=0.57, \delta_{Q}=\hat{\delta}_{R}$ (by assumption), and multiplying $\hat{\gamma}_{X}$ by $\frac{5}{8}$ to eliminate the compositional component of the indirect effect. 
These estimates shed new light on what are the substantial benefits of class size reduction, given the size of the indirect sorting effect and the evidence of positive persistence above. In this respect, our results accord with the convincing studies that document longer-term benefits of class size reduction, focusing on Project STAR - see Krueger and Whitmore (2001) and Chetty et al. (2011). To the extent that CSR is representative of other major reforms intended to improve school quality, a fuller consideration of the test score benefits indicates that abstracting from indirect sorting is likely to result in considerable omitted variables bias. This view is only reinforced when assessing the fiscal costs, which we do next.

Costs: $\quad$ Once fully implemented, the State of California expected CSR to cost approximately $\$ 1.2$ billion per year (in 1996 dollars), multiplying the 1.827 million eligible K-3 public school students by the $\$ 650$ per student CSR funding. ${ }^{58}$ In this calculation, the state neglected the fact that each year, more students would be educated in the public system in response to CSR. The state average per student expenditure (including CSR funding) was $\$ 5,800$, implying that the sorting effect raised the per-year cost of the program by about $\$ 220$ million dollars $(=37,500 \times 5,800)$, or by 20 percent. By not taking account of the indirect costs of the reform, the state thus under-estimated the reform's total cost by one-fifth, highlighting the magnitude of the indirect sorting response to CSR in terms of costs. ${ }^{59}$ We add that these are the recurrent costs predicted to be incurred each year.

Based on these considerations, we estimate the cost of CSR to be around $\$ 2$ billion a year in 2009 dollars, or $\$ 1,100$ per student.

Benefit-Cost Ratio: It is instructive to combine these estimates into a simple number. In light of the $\$ 18,300$ increase in the individual present value earnings created by CSR, our net benefit calculation implies a substantially positive benefit-to-cost ratio, on the order of fifteen. In contrast, the benefit-to-cost ratio would be around five if the indirect effect was neglected, highlighting the potential for indirect effects to alter the policy calculus in an entirely first-order way.

Two further points are worth noting. First, it is straightforward to assess the sensitivity of these numbers, given they are computed on the basis of estimates taken from our study and other papers in the literature. Second, we note that in the broader scheme of things, policy makers should (of course) place CSR alongside other feasible alternative policies, many of which are significantly less costly.

\footnotetext{
${ }^{58}$ The state's cost expectations are available for the first few years only, and those values are on the low side since only a few grades were affected; for instance, the budgeted cost in the first year was $\$ 971$ million. According to Brewer et al. (1999), actual costs in 1997-98 were $\$ 1.5$ billion, but those include one-time funding of $\$ 300$ million for facilities.

${ }^{59}$ Here we only focus on the permanent costs of the reform to the government, and not the temporary costs of helping schools make the transition to smaller classes.
} 


\subsection{Indirect Sorting Effects: General Relevance}

The estimated size of the indirect sorting effect we obtained from California's CSR reform is likely to carry over to other settings when certain pre-conditions hold: (i) the reform-related shock to public school quality is large; (ii) pre-reform, the private school share is high; and (iii) the characteristics of students in private versus public schools differ so that changes in peer quality occur post-reform.

These same pre-conditions hold in other US states, for example. Taking them in turn, first, various statewide education reforms have been enacted at considerable expense, designed to raise quality significantly. Second, at the time of CSR, California ranked 20th (out of 50 states) in its private school enrollment rate (Yun and Reardon 2005). Third, California's large private-public test score gap is typical of most other states - Altonji, Elder and Taber (2005) report a national eighth grade private-public test score gap of $0.4 \sigma$, for instance. Thus it is reasonable to expect similar sorting responses following large reform-related shocks to public school quality elsewhere in the United States.

We note further that the size of the sorting effect will be larger to the extent that private schools are relatively passive to the reform, and students in private schools are more responsive to relative changes in quality between public and private schools, placing a larger share on the margin of switching. In terms of passivity (or otherwise), we find some suggestive evidence of adjustments on the part of private schools, serving to mitigate the size of the sorting effect we have estimated. ${ }^{60}$ To keep track of the proportion of marginal students likely to be responsive to quality changes, a model of public and private school behavior and individual 'consumer' choice comes naturally to mind, although estimating that would require more disaggregated information about the decisions of the relevant economic agents than our school-grade-year-averaged California data provide. ${ }^{61}$

\section{Conclusion}

In this paper, we have presented a transparent approach for estimating indirect sorting effects of major reforms alongside their often-analyzed direct effects, and also the persistent impacts of each. While these indirect effects may be sizeable, they are typically difficult to identify, and so have not been a prime focus of policy-oriented empirical research.

\footnotetext{
${ }^{60}$ Specifically, following CSR, fewer private schools entered in the state (relative to trend), and more private schools exited, consistent with evidence from New York City presented in Dinerstein and Smith (2016). On the quality margin, we also see suggestive evidence that private schools responded to the boost in public school quality associated with CSR by lowering their own class sizes. (These latter results are available on request.)

${ }^{61}$ For example, Bayer, Ferreira and McMillan (2004) use an equilibrium sorting model estimated using census microdata to gauge the reinforcing effect of improvements to public school quality that work through household location choices.
} 
Central to our approach is a framework that relates education inputs to measurable outcomes, allowing those inputs to have persistent effects. We have shown how the framework's key parameters can be identified by applying a differencing procedure that leverages two sources of exogenous variation: in the way local public goods are provided (differences in school grade span, for instance), and in the reform's coverage, where some groups are affected while others are not (as may occur due to budgetary considerations). Both sources of variation arise in many settings. Further, the data requirements for the approach we propose are minimal.

We developed the empirical analysis in the context of a major education reform of the late-1990s - California's CSR program. Using the grade-specific timing of the reform, we first showed that CSR caused a significant decrease in private school shares and marked compositional changes in the public school system. Then, applying our differencing strategy, we estimated an indirect sorting effect of the policy at least as important (in our education setting) as the direct policy effect, which has been the focus of careful measurement in the prior literature.

We were also able to recover the persistence of the direct and indirect effects of the reform. Once these are accounted for, we showed how the combined benefits of CSR in the short term are almost one and a half times greater than the direct effect; in the longer term, the combined benefits are even greater. On the cost side, we then showed that indirect sorting leads to recurrent expenditures that are a fifth higher than in the state's own projections. Combining the two for the duration of the class size reduction program, a suggestive net benefit calculation points to a benefit-cost ratio double the ratio if the indirect effect are ignored.

Beyond class size reduction policies, our approach and estimates are relevant when assessing the effects of major reforms in other contexts. Alternative education reforms with different cost implications - incentive-based policies, for instance - that boost public school quality are also likely to change the mix of students across public and private systems, with consequences for education production of the kind our framework can accommodate. Applications of the approach to estimate indirect sorting effects elsewhere in response to other major policies are for future work. 


\section{References}

Altonji, Joseph G., Todd E. Elder, and Christopher R. Taber. 2005. "Selection on observed and unobserved variables: Assessing the effectiveness of Catholic schools." Journal of Political Economy, 113(1): 151-184.

Angrist, Joshua D, and Kevin Lang. 2004. "Does school integration generate peer effects? Evidence from Boston's Metco Program." American Economic Review, 94(5): 1613-1634.

Angrist, Joshua D, and Victor Lavy. 1999. "Using Maimonides' rule to estimate the effect of class size on scholastic achievement." Quarterly Journal of Economics, 114(2): 533-575.

Angrist, Joshua D., Erich Battistin, and Daniela Vuri. 2017. "In a small moment: Class size and moral hazard in the Italian Mezzogiorno." American Economic Journal: Applied Economics, $9(4): 216-49$.

Bayer, Patrick, Fernando Ferreira, and Robert McMillan. 2004. "Tiebout sorting, social multipliers and the demand for school quality." National Bureau of Economic Research Working Paper 10871.

Bianchi, Nicola. 2020. "The Indirect Effects of Educational Expansions: Evidence from a Large Enrollment Increase in University Majors." Journal of Labor Economics, 38(3): 767-804.

Bohrnstedt, George W., and Brian M. Stecher. 2002. "What we have learned about class size reduction in California. Capstone report." Unpublished manuscript.

Brewer, Dominic J., Cathy Krop, Brian P. Gill, and Robert Reichardt. 1999. "Estimating the cost of national class size reductions under different policy alternatives." Educational Evaluation and Policy Analysis, 21(2): pp. 179-192.

Buddin, Richard. 2012. "The impact of charter schools on public and private school enrollments." Cato Institute Policy Analysis, 707.

Chetty, Raj, John N. Friedman, and Jonah E. Rockoff. 2014. "Measuring the impacts of teachers II: Teacher value-added and student outcomes in adulthood." American Economic Review, 104(9): 2633-2679.

Chetty, Raj, John N. Friedman, Nathaniel Hilger, Emmanuel Saez, Diane WhitmoreSchanzenbach, and Danny Yagan. 2011. "How does your kindergarten classroom affect your earnings? Evidence from Project STAR." Quarterly Journal of Economics, 126(4): 1593-1660.

Dinerstein, Michael, and Troy Smith. 2016. "Quantifying the supply response of private schools to public policies." Unpublished manuscript.

Ding, Weili, and Steven F. Lehrer. 2010. "Estimating Context-Independent Treatment Effects in Education Experiments." Unpublished manuscript.

Epple, Dennis, and Richard E. Romano. 1998. "Competition between private and public schools, vouchers, and peer-group effects." American Economic Review, 33-62.

Finn, Jeremy D, and Charles M Achilles. 1990. "Answers and questions about class size: A statewide experiment." American Educational Research Journal, 27(3): 557-577. 
Gilraine, Michael. 2020. "A Method for Disentangling Multiple Treatments from a Regression Discontinuity Design." Journal of Labor Economics, forthcoming.

Graham, Bryan S. 2008. "Identifying social interactions through conditional variance restrictions." Econometrica, 76(3): 643-660.

Hoxby, Caroline M. 2000. "The effects of class size on student achievement: New evidence from population variation." Quarterly Journal of Economics, 115(4): 1239-1285.

Jackson, C. Kirabo. 2012. "School competition and teacher labor markets: Evidence from charter school entry in North Carolina." Journal of Public Economics, 96(5-6): 431-448.

Jackson, C. Kirabo, Rucker C. Johnson, and Claudia Persico. 2015. "The Effects of School Spending on Educational and Economic Outcomes: Evidence from School Finance Reforms." Quarterly Journal of Economics, 131(1): 157-218.

Jacob, Brian A., Lars Lefgren, and David P. Sims. 2010. "The persistence of teacher-induced learning." Journal of Human Resources, 45(4): 915-943.

Jepsen, Christopher, and Steven Rivkin. 2009. "Class size reduction and student achievement: The potential tradeoff between teacher quality and class size." Journal of Human Resources, $44(1): 223-250$.

Kinsler, Josh. 2012. "Beyond levels and growth estimating teacher value-added and its persistence." Journal of Human Resources, 47(3): 722-753.

Krueger, Alan B. 1999. "Experimental estimates of education production functions." Quarterly Journal of Economics, 114(2): 497-532.

Krueger, Alan B., and Diane M. Whitmore. 2001. "The effect of attending a small class in the early grades on college-test taking and middle school test results: Evidence from Project STAR." Economic Journal, 111(468): 1-28.

Lafortune, Julien, Jesse Rothstein, and Diane Whitmore Schanzenbach. 2018. "School finance reform and the distribution of student achievement." American Economic Journal: Applied Economics, 10(2): 1-26.

Lucas, Greg. 1996. "Sacramento Surprise - Extra Funds / Governor wants to use money to cut class size." San Francisco Chronicle.

Rivkin, Steven G., Eric A. Hanushek, and John F. Kain. 2005. "Teachers, schools, and academic achievement." Econometrica, 73(2): 417-458.

Schrag, Peter. 2006. "Policy from the Hip: Class size reduction in California." Brookings Papers on Education Policy, 2006(1): 229-243.

Unlu, Fatih. 2005. "California class size reduction reform: New findings from the NAEP." Unpublished manuscript.

Yun, John T., and Sean F. Reardon. 2005. "Private school racial enrollments and segregation." School choice and diversity: What the evidence says, 42-58. 
Figure 1: Policy Coverage and Data Availability

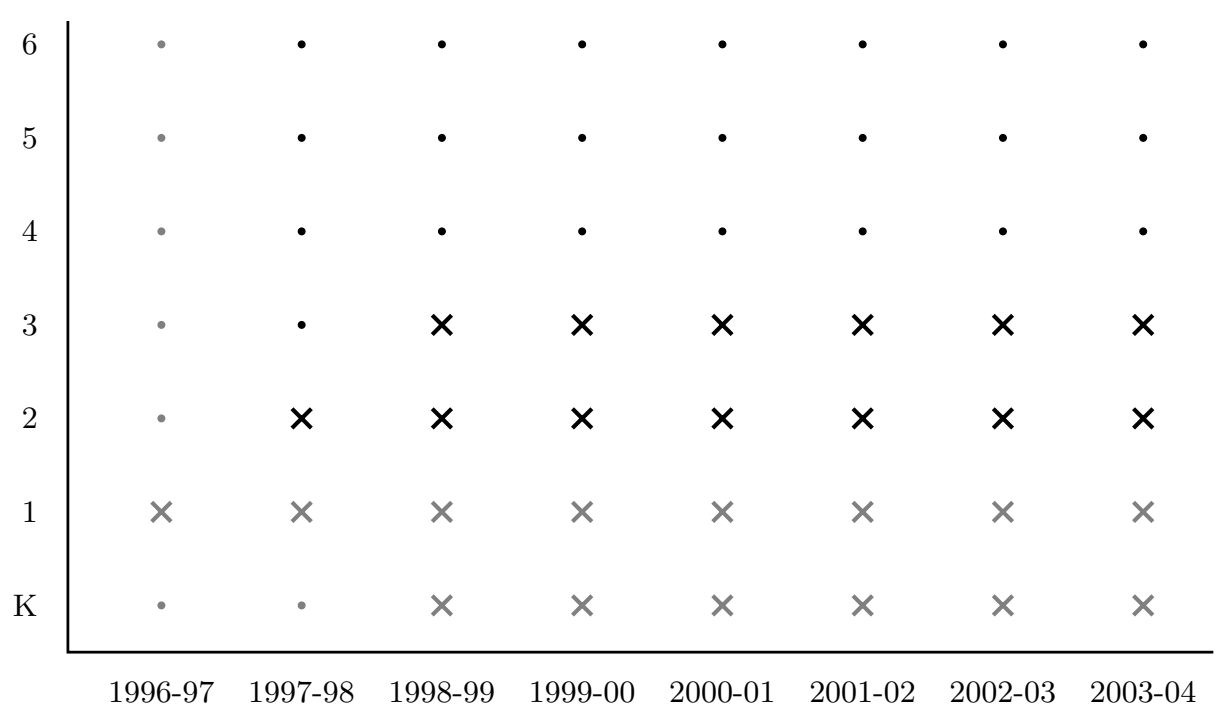

Notes: The reform is in effect for a particular year (horizontal axis) and grade (vertical axis) combination if the corresponding cell contains a ' $X$ ' symbol and it is not if it contains a '.' symbol. While the earliest grade of implementation is kindergarten (K), test score data are only available for grades two and above and from 1997-98 onward. The bottom two rows and leftmost column use a lighter shading to reflect this.

Figure 2: Class Sizes in California over Time

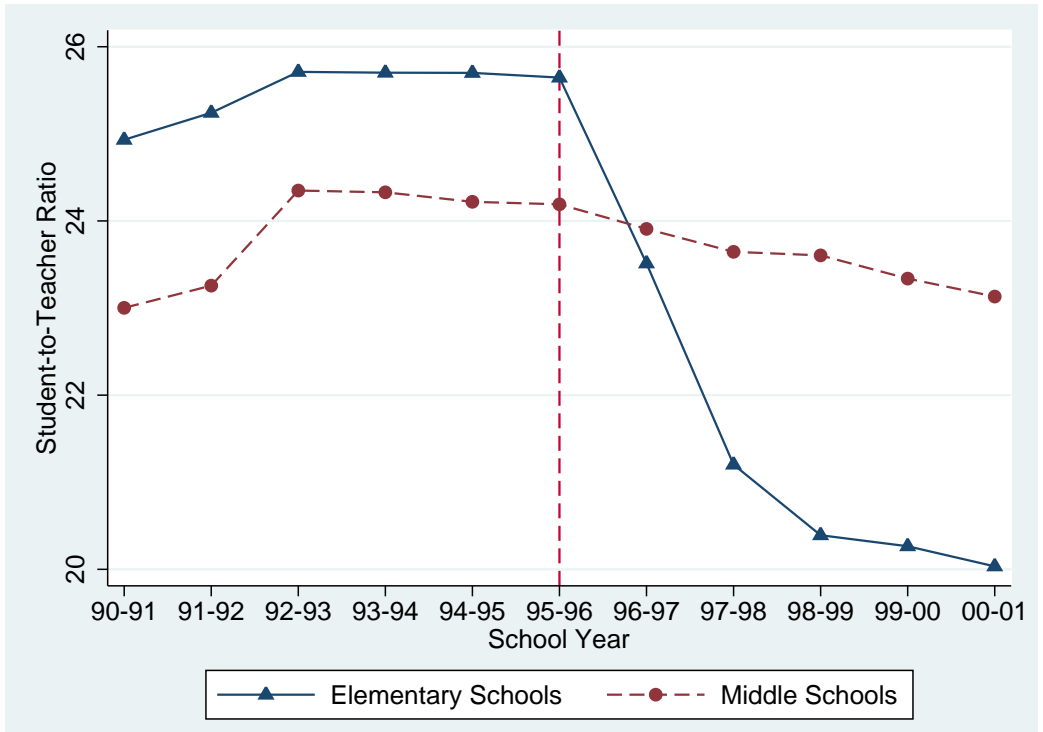

Notes: This figure shows student-to-teacher ratios by year for school years 1990-91 through 2000-01. The student-toteacher ratio is defined as the number of students in a school divided by the number of teachers at that school. Given that CSR only affects grades K-3, we expect that this will substantially underestimate the change in K-3 class sizes induced by CSR. Elementary schools are defined as any school that includes grades K-3 and whose highest grade is 6 or below. Middle schools are schools that do not have a K-3 grade and whose highest grade is 9 or below. The vertical dashed line represents the start of the 1995-96 school year, the last year before CSR was implemented in the 1996-97 school year. 
Figure 3: Private School Share Trends by Grade

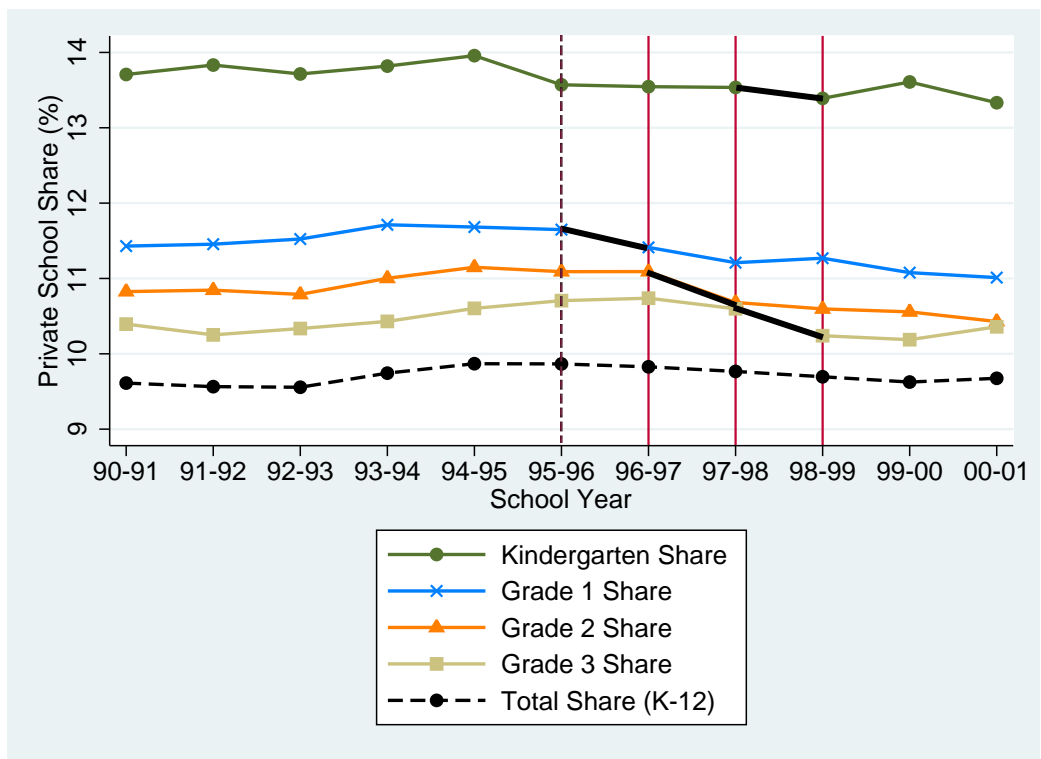

Notes: This figure shows aggregate private school share trends by grade over the years surrounding CSR. 'Private School Share' is defined as the aggregate number of students in private school in each grade in the state divided by the total number of public and private school students in that grade. The vertical dashed line represents the start of the 1995-96 school year, the last year before CSR was implemented in the 1996-97 school year, while the solid vertical lines represent the start of school years 1996-97, 1997-98 and 1998-99 respectively, when different grades became eligible for CSR. Specifically, first grade became eligible for the 1996-97 school year, second grade for the 1997-98 school year, and third grade and kindergarten for the 1998-99 school year. The darkened thick line segments indicate the effect of CSR on the grade-level private school share when CSR was first implemented for that particular grade.

Figure 4: Number of Private Schools per 1000 School-Aged Children by Year

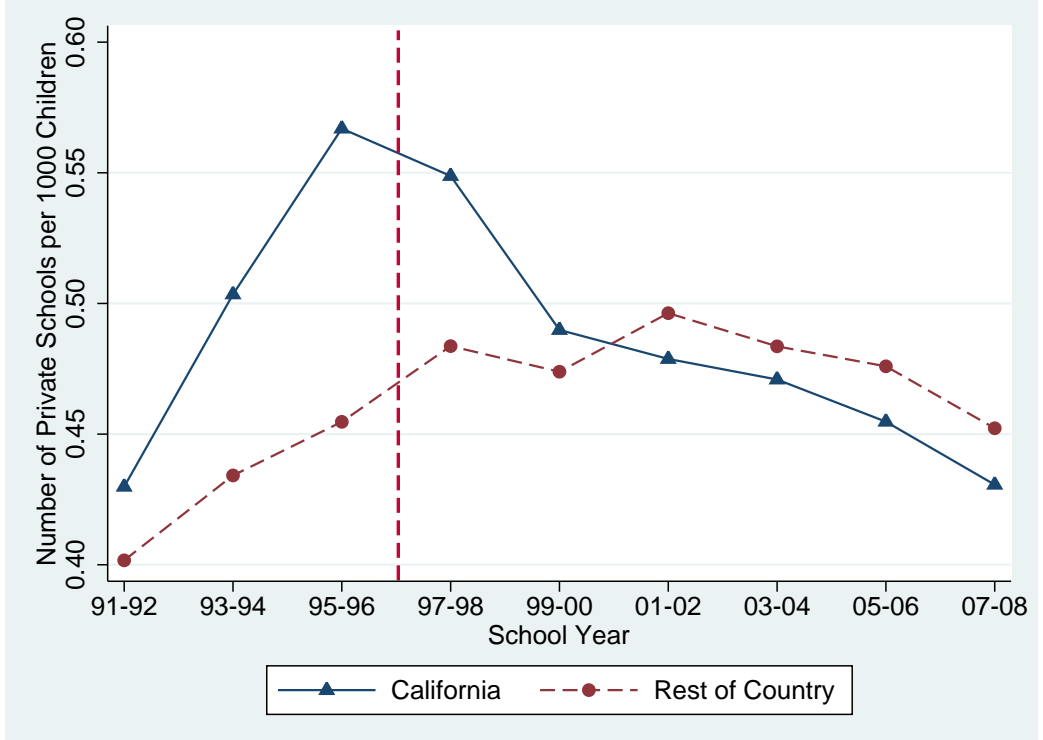

Notes: The dashed vertical line indicates the 1996-97 introduction of the CSR reform. Data on the number of private schools come from the Private School Universe Survey and are available only every two years (see Table A.1). The figure only includes private schools that primarily serve CSR grades. A private school is determined to serve CSR grades if, on average, at least twenty percent of its student body is in K-3 grades in the 1989-90 through 2013-14 school years. The population of children are defined as all individuals aged 5-17 living in a state. 
Figure 5: Reduced-Form Identification of the Indirect Effect

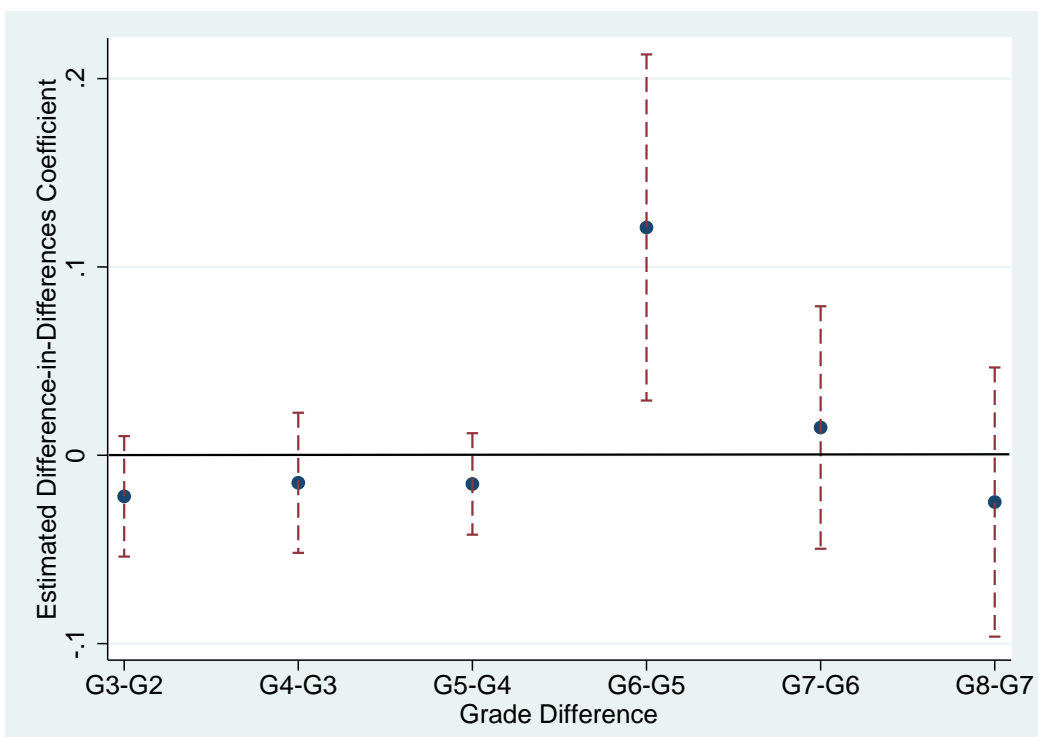

Notes: This figure shows point estimates of a triple-differences regression using grade $g$ vs. $g-1$, K6 vs. K5 schools and cohorts affected vs. unaffected by CSR as the three layers of differencing. The figure highlights the identification of the indirect effect in our model in a reduced-form way. Specifically, we expect that the only grade $g$ vs. $g-1$ differences in mathematics test scores that should appear are for the grade 6 vs. grade 5 comparison, as that is when students who switched into the public system due to CSR return to the private system upon transitioning to middle school. The outcome variable is the mathematics test score, normalized by grade-year to have mean zero and standard deviation one. Vertical dashed bands represent $95 \%$ confidence intervals for each point estimate, while the horizontal line indicates an estimate of zero. Standard errors are clustered at the district level. These results include grade, school, and year fixed effects and so are the same as those reported in column (2) of Table A.6.

Figure 6: Differencing Variation - Identifying the Direct Effect

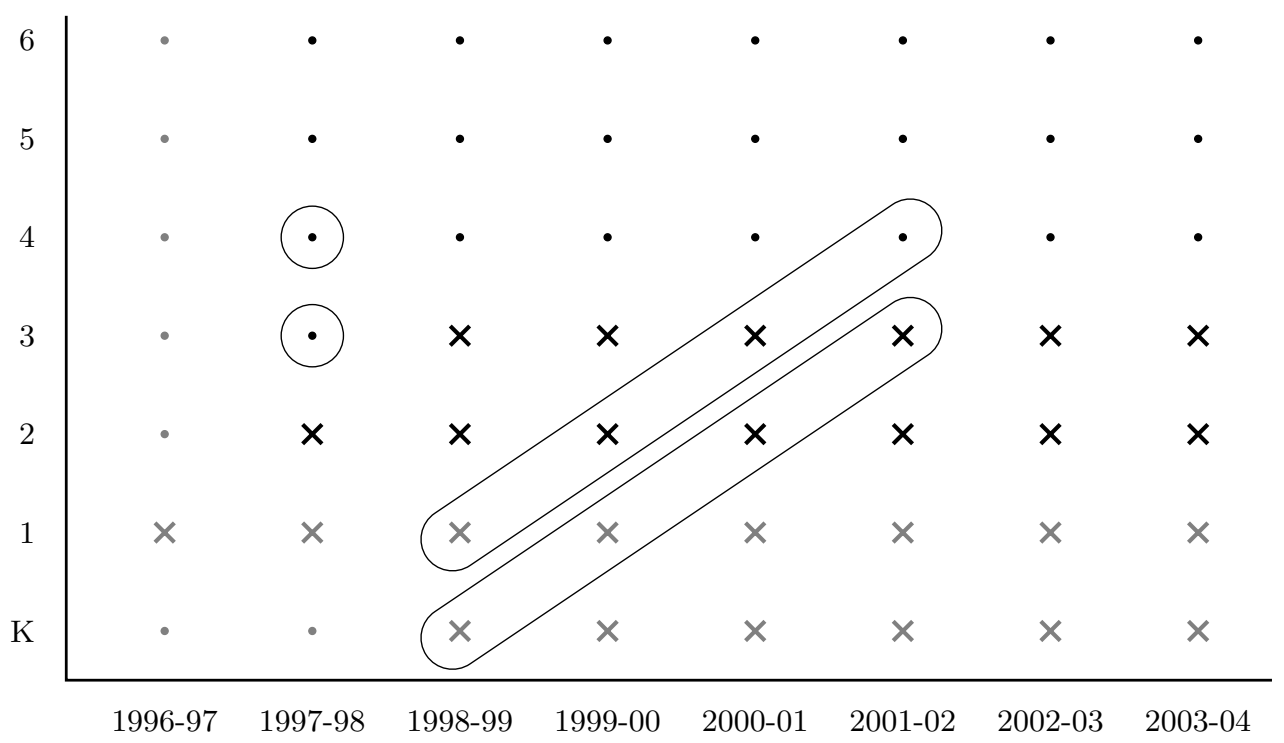

Notes: Policy coverage and data availability are as described in the notes to Figure 1. The variation used to recover the direct effect through differencing is highlighted using four different outlines, applying the differencing procedure described in Section 5.1. 
Figure 7: Differencing Variation - Identifying the Indirect Effect

(a) K-6 Grade Configuration

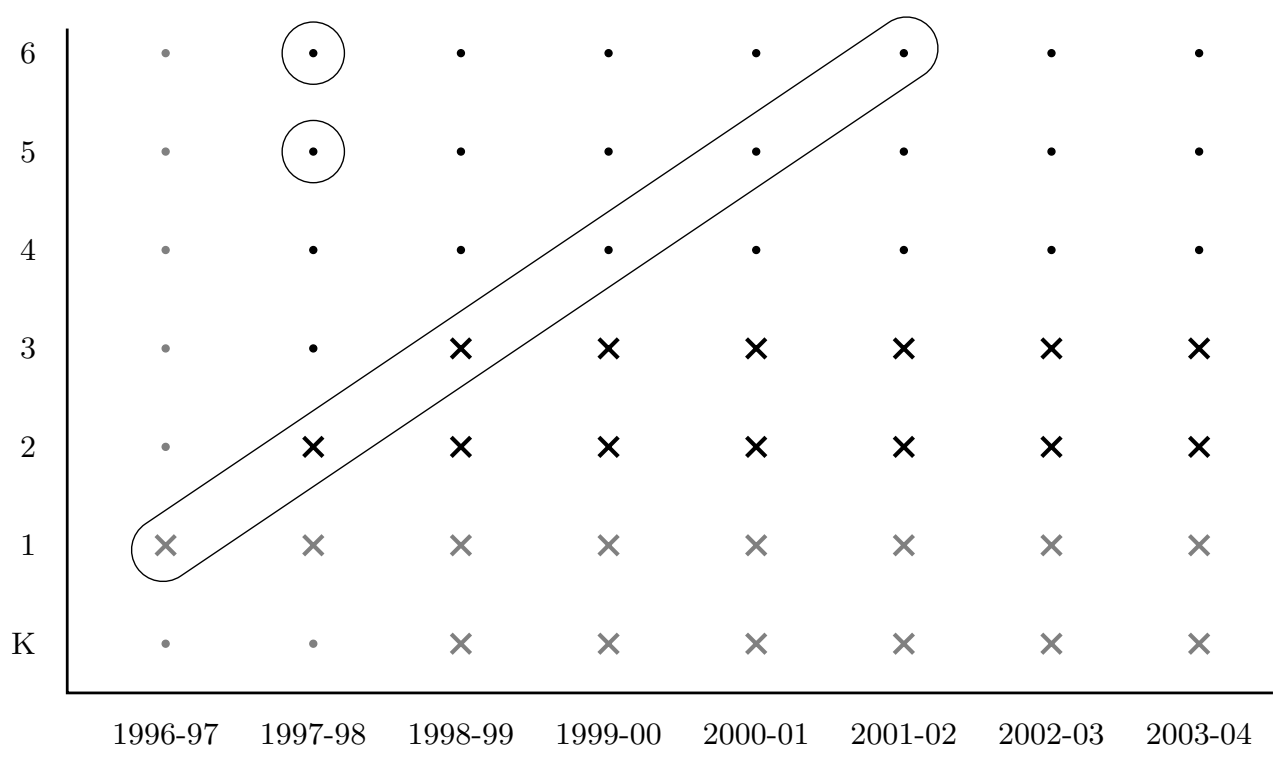

(b) K-5 Grade Configuration

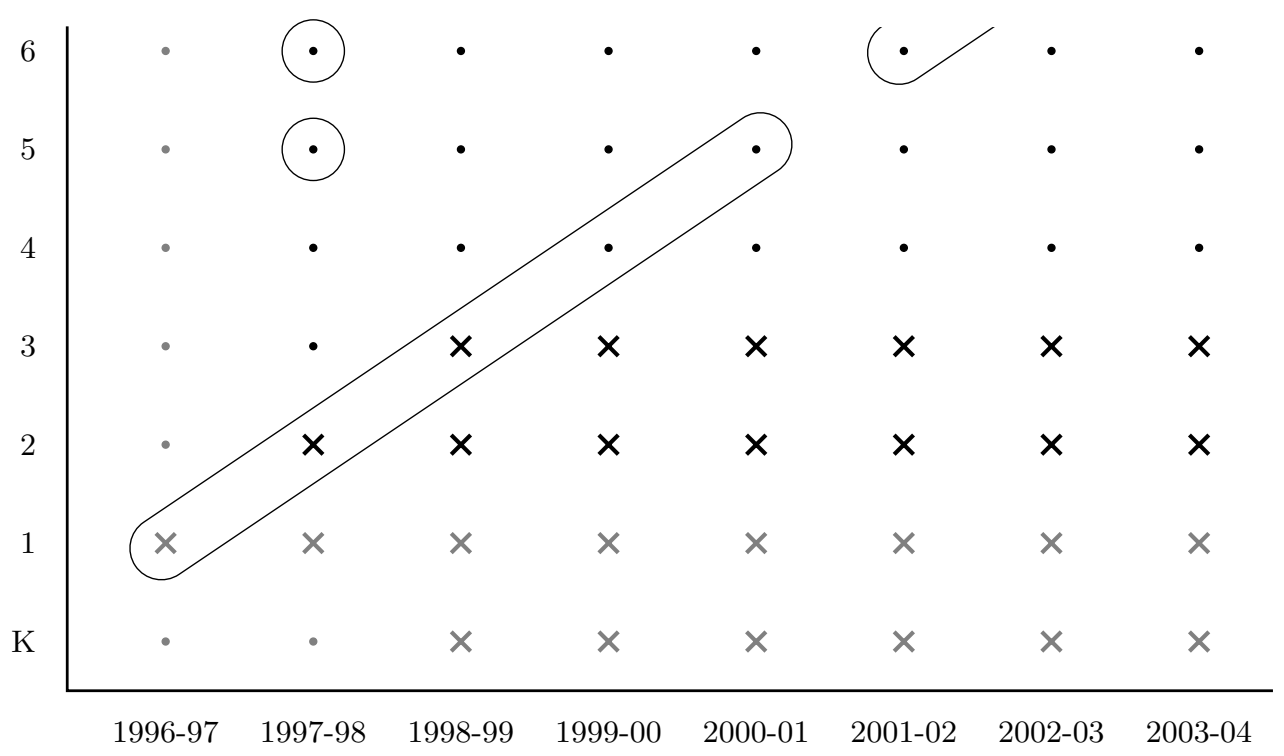

Notes: Policy coverage and data availability are as described in the notes to Figure 1. The variation used to recover the indirect effect through differencing is highlighted using the outlines in each panel (contrasting K-6 and K-5 grade configurations), applying the differencing procedure described in Section 5.1. 
Table 1: Summary Statistics: Enrollment and Demographics

\begin{tabular}{|c|c|c|c|c|}
\hline & $\begin{array}{c}\text { Overall Mean } \\
(1990-91 \text { to } 2008-09)\end{array}$ & $\begin{array}{c}\text { Pre-CSR } \\
(90-91 \text { to } 95-96)\end{array}$ & $\begin{array}{c}\text { CSR } \\
(96-97 \text { to } 99-00)\end{array}$ & $\begin{array}{c}\text { Post-CSR } \\
(00-01 \text { to } 08-09)\end{array}$ \\
\hline \multicolumn{5}{|l|}{ School Data } \\
\hline Elementary Student-to-Teacher Ratio ${ }^{1}$ & 22.7 & 24.9 & 22.6 & 21.6 \\
\hline Private School Share (\%) & $\begin{array}{c}9.3 \\
(8.5)\end{array}$ & $\begin{array}{c}9.9 \\
(8.5)\end{array}$ & $\begin{array}{c}9.9 \\
(8.5)\end{array}$ & $\begin{array}{c}8.8 \\
(8.4)\end{array}$ \\
\hline CSR Intensity $^{2}$ & $\begin{array}{c}89.9 \\
(17.1)\end{array}$ & $\begin{array}{c}90.2 \\
(16.4)\end{array}$ & $\begin{array}{c}90.0 \\
(17.0)\end{array}$ & $\begin{array}{c}89.7 \\
(17.4)\end{array}$ \\
\hline$\%$ English Learner ${ }^{3}$ & $\begin{array}{c}35.8 \\
(19.8)\end{array}$ & $\begin{array}{c}32.1 \\
(19.8)\end{array}$ & $\begin{array}{c}34.3 \\
(20.0)\end{array}$ & $\begin{array}{c}38.1 \\
(19.5)\end{array}$ \\
\hline$\%$ White & $\begin{array}{c}36.1 \\
(25.2)\end{array}$ & $\begin{array}{c}42.6 \\
(26.2)\end{array}$ & $\begin{array}{l}38.6 \\
(25.7)\end{array}$ & $\begin{array}{c}32.2 \\
(23.8)\end{array}$ \\
\hline$\%$ Hispanic & $\begin{array}{c}42.3 \\
(24.6)\end{array}$ & $\begin{array}{c}36.6 \\
(23.4)\end{array}$ & $\begin{array}{c}40.3 \\
(24.1)\end{array}$ & $\begin{array}{l}45.8 \\
(24.8)\end{array}$ \\
\hline$\%$ Black & $\begin{array}{c}8.3 \\
(8.5)\end{array}$ & $\begin{array}{c}8.7 \\
(9.4)\end{array}$ & $\begin{array}{c}8.7 \\
(9.0)\end{array}$ & $\begin{array}{c}8.0 \\
(7.9)\end{array}$ \\
\hline$\%$ Asian & $\begin{array}{c}8.3 \\
(9.9)\end{array}$ & $\begin{array}{c}8.3 \\
(9.0)\end{array}$ & $\begin{array}{c}8.4 \\
(9.6)\end{array}$ & $\begin{array}{c}8.3 \\
(10.5)\end{array}$ \\
\hline Enrollment & $\begin{array}{c}578 \\
(2260)\end{array}$ & $\begin{array}{c}533 \\
(2135)\end{array}$ & $\begin{array}{c}572 \\
(2249)\end{array}$ & $\begin{array}{c}606 \\
(2331)\end{array}$ \\
\hline$\%$ Free and Reduced Price Meals ${ }^{4}$ & $\begin{array}{c}47.7 \\
(23.1)\end{array}$ & $\begin{array}{c}41.9 \\
(21.6)\end{array}$ & $\begin{array}{c}48.0 \\
(23.1)\end{array}$ & $\begin{array}{c}50.6 \\
(23.3)\end{array}$ \\
\hline Observations (District-Grade-Year) & 208,285 & 63,983 & 32,761 & 111,541 \\
\hline
\end{tabular}

Notes: This table shows descriptive statistics of outcome variables along with student demographics before, during and after CSR implementation. All variables are weighted by district-grade-year enrollment with the exception of enrollment. Demographic data only include public school students.

${ }^{1}$ Elementary Student-to-Teacher Ratio is calculated as the number of students in a school divided by the number of teachers in that elementary school. Elementary schools are defined as any school that includes grades K-3 and whose highest grade is 6 or below.

2 'CSR Intensity' measures the proportion of K-3 students in CSR school-grades in the 1998-99 school year. The measure varies slightly year-to-year due to district closures and missing data from some districts in some years ( $87 \%$ of observations are from districts with at least 20 years of data).

${ }^{3}$ Some observations are missing values for this variable. There are a total of 185,249 observations with non-missing values.

${ }^{4}$ This variable is only available at the district-year level and has 19,311 observations. 
Table 2: Difference-in-Differences Estimates of CSR on Private School Share

\begin{tabular}{lcccc}
\hline Outcome Variable: Private School Share $(\%)$ & & & \\
\hline & $(1)$ & $(2)$ & $(3)$ & $(4)$ \\
\hline Treatment*Post & $-1.11^{* * *}$ & $-1.04^{* * *}$ & $-0.99^{* * *}$ & $-1.40^{* * *}$ \\
& $(0.17)$ & $(0.18)$ & $(0.27)$ & $(0.27)$ \\
Post & $-0.45^{* * *}$ & 0.24 & 0.10 & $0.38^{* *}$ \\
& $(0.14)$ & $(0.15)$ & $(0.16)$ & $(0.18)$ \\
Treatment & $2.87^{* * *}$ & - & - & - \\
Year/Grade FE & $(0.25)$ & & & Yes \\
Demographic Controls & No & Yes & Yes & Yes \\
District FE & No & No & Yes & Yes \\
Observations & No & No & No & 173,129 \\
\hline
\end{tabular}

Notes: This table shows results from the difference-in-differences regression given by equation (4.1) with varying levels of controls. Observations are at the district-grade-year level and cover the 1990-91 through 2008-09 school years. Demographic controls include student race, gender, English second language, enrollment and enrollment squared. The 'treatment' variable is omitted for columns (2)-(4) since it is collinear with the grade fixed effects. All regressions are weighted by district-grade-year enrollment. Standard errors are clustered at the district level. $* * *, * *$ and ${ }^{*}$ denote significance at the $1 \%, 5 \%$ and $10 \%$ levels, respectively.

Table 3: Regression-Discontinuity Estimates by Grade Span

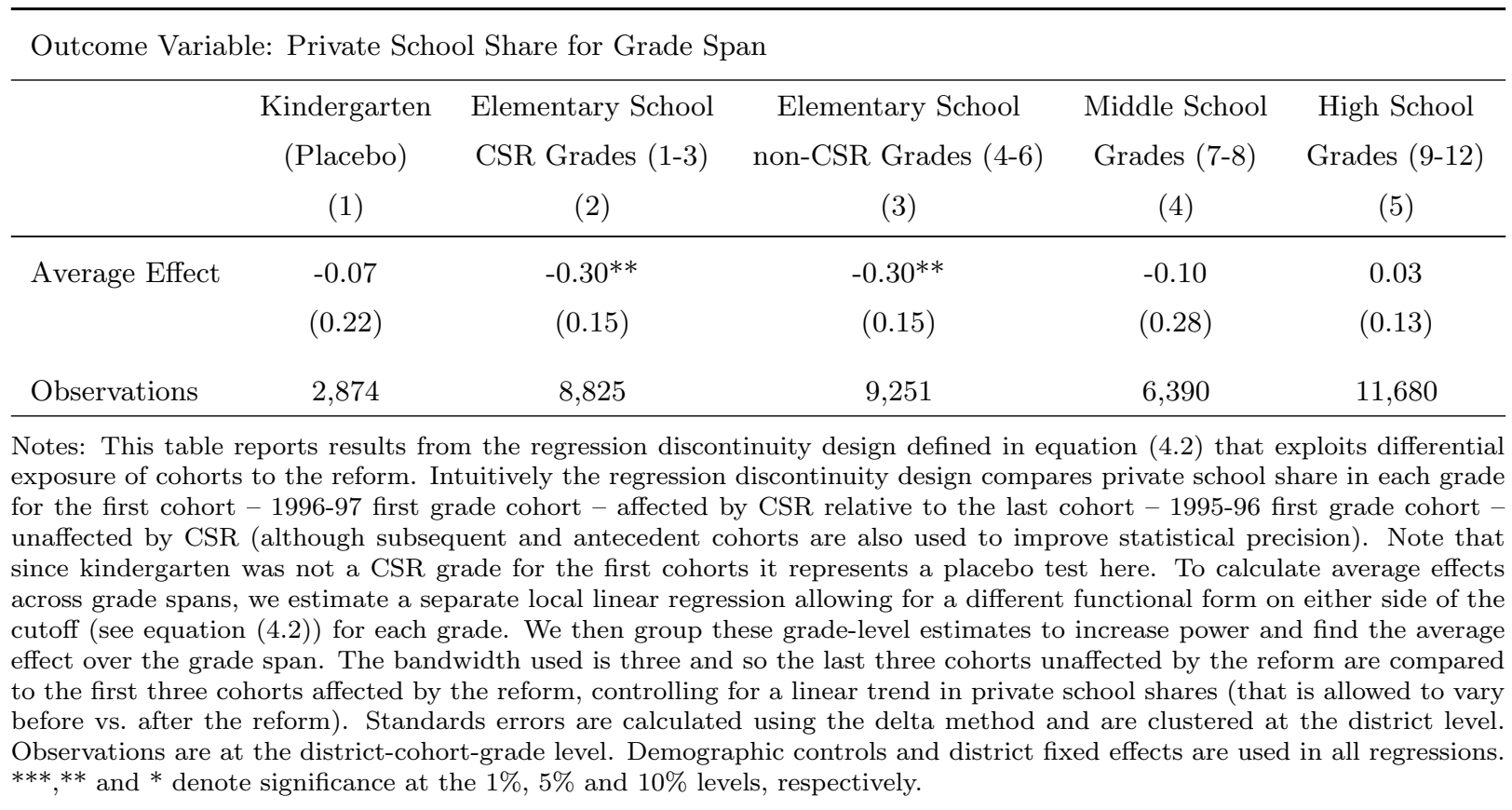


Table 4: Model Estimates

\begin{tabular}{|c|c|c|c|c|}
\hline & \multicolumn{2}{|c|}{ With $\psi=\frac{2}{3}$} & \multicolumn{2}{|c|}{ With $\psi=1$} \\
\hline & (1) & $(2)$ & (3) & (4) \\
\hline$\gamma_{R}$ & $\begin{array}{c}2.10^{* * *} \\
(0.20)\end{array}$ & $\begin{array}{c}2.22 * * * \\
(0.20)\end{array}$ & $\begin{array}{c}2.10^{* * *} \\
(0.20)\end{array}$ & $\begin{array}{c}2.22^{* * * *} \\
(0.20)\end{array}$ \\
\hline$\gamma_{X}$ & $\begin{array}{c}2.27 \\
(1.69)\end{array}$ & $\begin{array}{c}3.26^{* *} \\
(1.54)\end{array}$ & $\begin{array}{c}1.63 \\
(1.24)\end{array}$ & $\begin{array}{c}2.42^{* *} \\
(1.13)\end{array}$ \\
\hline$\delta_{R}$ & $\begin{array}{l}0.49^{*} \\
(0.26)\end{array}$ & $\begin{array}{c}0.45^{* *} \\
(0.21)\end{array}$ & $\begin{array}{l}0.50^{*} \\
(0.26)\end{array}$ & $\begin{array}{c}0.46^{* *} \\
(0.21)\end{array}$ \\
\hline$\delta_{X}$ & $\begin{array}{c}0.64^{* *} \\
(0.30)\end{array}$ & $\begin{array}{c}0.57^{* *} \\
(0.27)\end{array}$ & $\begin{array}{c}0.70^{* *} \\
(0.31)\end{array}$ & $\begin{array}{c}0.62^{* *} \\
(0.30)\end{array}$ \\
\hline County FE & No & Yes & No & Yes \\
\hline Observations & 147,636 & 147,636 & 147,636 & 147,636 \\
\hline
\end{tabular}

Notes: This table shows estimates of the parameters described in Section 6. Observations are at the school-grade-year level, and cover the 1997-98 through 2001-02 school years. Mathematics test scores are shown in percentile ranks relative to a national norming sample, where one percentile rank roughly equates to $0.05 \sigma$ in the distribution of school-grade level test scores. All parameter estimates include controls for teacher quality. Standard errors for $\gamma_{R}$ and $\gamma_{X}$ are computed using the delta method and are clustered at the school level. Standard errors for $\delta_{R}$ and $\delta_{X}$ are bootstrapped. $* * *, * *$ and ${ }^{*}$ denote significance at the $1 \%, 5 \%$ and $10 \%$ levels, respectively.

Table 5: Compositional and Spillover Effects by Private-Public School Switcher Percentile

Average Test Score Percentile of Private-Public Switchers

\begin{tabular}{lccccc} 
& $90^{t h}$ & $75^{t h}$ & Mean & $50^{t h}$ & $25^{t h}$ \\
& $(1)$ & $(2)$ & $(3)$ & 0.79 & 0.21 \\
\hline Average 'Switcher' Test Score & 1.88 & 1.42 & 0.82 & 0.03 & 0.01 \\
Compositional Effect & 0.08 & 0.06 & 0.03 & 0.13 & 0.15 \\
Spillover Effect & 0.08 & 0.10 & 0.13 & 3.91 & 17.47 \\
Implied Social Multiplier & 1.06 & 1.73 & 3.73 & \\
\hline
\end{tabular}

Notes: This table decomposes the $0.16 \sigma$ spillover effect estimated in Section 6 into compositional and spillover components (noting rows 2 and 3 sum to 0.16). Given that the test score of the marginal private-public switcher is not observed, each column reports a different percentile of the private school test score distribution the average private-public switcher could be drawn from. Public and private school test score distributions are taken from the 1996 California NAEP fourth grade results (see Table 2.7A in https://files.eric.ed.gov/fulltext/ED425943.pdf). The relevant calculations start from the 1.4 percent decline in private school share estimated in Column (4) of Table 2. Based on this, we expect that an average school-grade with enrollment of fifty-five students will (in expectation) receive 0.77 of a private school student entering their school (noting that many public schools have no private schools nearby). The average switcher at the $75^{\text {th }}$ percentile of the private school distribution, using the column (2) scenario for illustration, leads to a $0.02\left(=\frac{1.42 * 0.77}{55}\right)$ increase in the student-level distribution. We then multiply by three to convert this increase in the student-level distribution to the school-grade-level distribution. This gives the 'Compositional Effect' entry of 0.06 in the second row of the third column. The 'Spillover Effect' entry on the third row, of $0.10=0.16-0.06$, is the total indirect effect minus the compositional effect. The implied social multiplier in the fourth row is then given by the ratio of the spillover effect to the compositional effect (in the second column, 1.73 =0.10/0.06). All effect sizes are normalized at the school-grade level to be mean zero and standard deviation one in the public school system. 


\section{Appendix A California State Testing - a Quick Primer}

Statewide testing in California started in 1961 for mathematics, reading and writing in grades 5, 8 and 10. In 1972, the California Assessment Program was created, which tested reading in grades 2 and 3 and mathematics, reading and writing in grades 6 and 12. It lasted (with a few test additions) until 1991, when it was replace by the California Learning Assessment System (CLAS), which covered reading, writing and mathematics in grades 4, 5, 8 and 10.

In 1994, under public pressure from civil rights groups that the CLAS was inaccurate and intruded upon students' privacy (due to numerous race-based questions on the test), the Governor vetoed a Senate bill to extend CLAS. ${ }^{62}$ As a consequence, there were no statewide tests for the 1994-95 and 1995-96 school years, although districts often did conduct standardized tests during this time; the state even provided funding for this through the Pupil Testing Incentive Program.

In the 1996-97 school year, the Standardized Testing and Reporting program (STARP) - an initiative of the Governor - was implemented, which tested reading, writing and math in grades 2-8 and reading, writing, mathematics, history, and science in grades 9-11. The test used by STARP was the Stanford 9, a nationally normed multiple-choice achievement test. Additional test items in language arts and in mathematics were included in the 1999-00 through 2002-03 tests to cover material in the California content standards that were not addressed by the Stanford 9. Besides this small addition, the STARP program was relatively unchanged until 2002-03 (see below). These are the tests we use in this study.

In time for the 2002-03 school year, California's STARP program was reauthorized and the State Board of Education issued a request for potential contractors to submit proposals for administering STARP. The contract was won by CTB/McGraw-Hill, and led to the test being changed from the Stanford Achievement Test (run by Harcourt Educational Measurement) to the California Achievement Tests. Test scores reported by the two tests differed dramatically, with no systematic linking of scores between the two tests being conducted. Given this test change, we focus on the 1996-97 through 2001-02 (inclusive) test scores in this paper. California's STARP testing program was officially terminated after the 2012-13 school year and was replaced by the California Assessment of Student Performance and Progress.

\footnotetext{
${ }^{62}$ The Governor stated that his veto was due to the fact that it did not give teachers and parents individual student achievement scores (scores were available at the school level only).
} 


\section{Appendix B Private School Evidence: Robustness}

In this appendix, we explore the robustness of our estimates of the impact of CSR on private school share described in Section 4.1. We do so in two ways: (i) we extend our difference-in-differences design to a triple-differences design using district-level CSR participation intensity as an additional dimension of differencing, and (ii) we provide support for the 'parallel trends' assumption by plotting coefficient estimates by year and looking for any significant pre-trends in outcomes. We also present the estimating equation we use to identify the effect of CSR on the number of private schools.

To extend our difference-in-differences design in Section 4.1 to a triple-differences design, we calculate a measure of the intensity of CSR implementation by school district. This takes advantage of the fact that, while most districts opted into CSR, ${ }^{63}$ the school-grade level implementation was uneven across them. As school-level CSR participation data are only available for the 1998-99 through 2003-04 school years, we define our 'local intensity' measure $\left(C S R_{d}\right)$ as the percentage of K-3 students in a CSR participating school-grade within a district for the 1998-99 school year. ${ }^{64}$ Formally,

$$
C S R_{d}=\frac{\sum_{s \in d} \sum_{g=0}^{3} \mathbb{1}\left\{C S R_{s g}\right\} *\left(\text { enroll }_{s g}\right)}{\sum_{s \in d} \sum_{g=0}^{3} \text { enroll }_{s g}},
$$

where enroll $_{s g}$ is the enrollment of grade $g$ students in school $s$ and district $d$ (kindergarten is defined as $g=0)$, and $\mathbb{1}\left\{C S R_{s g}\right\}$ is an indicator for whether the school implemented CSR for the particular grade in the 1998-99 school year.

Using this local intensity measure, the triple-differences analysis is implemented by estimating the following weighted regression:

$$
\begin{aligned}
\text { share }_{d g t} & =\beta_{0}+\beta_{1} \text { post }_{g t}+\beta_{2}\left(\text { post }_{g t} * \text { treat }_{g}\right)+\beta_{3}\left(\text { post }_{g t} * C S R_{d}\right)+\beta_{4}\left(\text { treat }_{g} * C S R_{d}\right) \\
& +\beta_{5}\left(\text { post }_{g t} * \text { treat }_{g} * C S R_{d}\right)+\eta_{d}+\theta_{t}+\delta_{g}+\phi X_{d g t}+\epsilon_{d g t},
\end{aligned}
$$

where all variables other than the intensity measure $C S R_{d}$ are identical to those in equation (4.1). The triple-differences coefficient of interest is $\beta_{5}$. Identification of the parameter depends on a less restrictive variant of the parallel trends assumption in Section 4.1: the difference in the evolution of private school share between CSR and non-CSR grades would have been the same for low- and high-share CSR districts in the absence of the reform.

\footnotetext{
${ }^{63}$ In the first year of CSR, only 56 of 895 districts in California did not opt-in. In the following year, twenty districts remained non-participating districts. For every year thereafter in our sample period, the number of non-participating districts was about ten.

${ }^{64}$ Results are similar if this variable is averaged over the 1998-99 through 2003-04 school years.
} 
Given that our triple-differences identification strategy exploits variation in the local intensity of adoption, Figure A.1 shows the spatial variation in our district-level CSR adoption intensity measure, $C S R_{d}$. There substantial geographic variation in our CSR intensity measure, with high levels of CSR adoption in regions such as San Diego and the Bay Area and low levels in regions such as the southern end of the Central Valley.

Using district-level CSR participation intensity as an additional dimension of differencing, our preferred triple-differences analysis from equation (B.2) yields similar findings to the difference-indifferences estimates from Section 4.1. ${ }^{65}$ With all controls, column (4) of Table A.3 shows that CSR is associated with a 1.3 percentage point decline in private school share. Thus, private school share experienced a substantial reduction as a result of the reform, concentrated precisely in the grades that were treated and in school districts that implemented the reform in a faithful way.

Finally, we provide support for the 'parallel trends' assumption that underlies these results by plotting coefficient estimates by year. Figure A.2(a) does so for the main difference-in-differences specification defined by equation (4.1), while Figure A.2(a) does the same for the triple-differences specification given by equation (B.2). Both figures show that there is no effect on private school share prior to the implementation of the reform,${ }^{66}$ followed by a clear decline afterwards.

Number of Private Schools: We also conduct an analysis of the effect of CSR on the number of private schools. To do so, we rely on data from the Private School Universe Survey and the U.S. Census (see Table A.1 for more details) and implement a difference-in-differences approach, comparing the number of private schools in California to the rest of the United States before and after the CSR reform came into effect. We then add an additional layer of differencing by comparing private schools that predominantly serve students in CSR grades to those predominantly serving students in non-CSR grades. ${ }^{67}$ Specifically, we run the following triple-differences regression:

$$
\begin{aligned}
\text { private }_{c s t} & =\beta_{0}+\beta_{1} C S R_{c}+\beta_{2}\left(C S R_{c} * C A_{s}\right)+\beta_{3}\left(C S R_{c} * \text { post }_{t}\right)+\beta_{4}\left(C A_{s} * \text { post }_{t}\right) \\
& +\beta_{5}\left(C S R_{c} * C A_{s} * \text { post }_{t}\right)+\gamma_{s}+\theta_{t}+\epsilon_{c s t},
\end{aligned}
$$

where private $_{\text {cst }}$ is the number of private schools per one thousand 5-17 year old children with grade configuration $c$ in state $s$ in year $t, C S R_{c}$ is an indicator equal to one if more than twenty percent of the private school's student body is in CSR grades, $C A_{s}$ is an indicator for the state of

\footnotetext{
${ }^{65} \mathrm{It}$ is important to note that the difference-in-differences and triple-differences estimates are not directly comparable, since almost all districts have some level of CSR implementation. Thus, the triple-differences coefficient cannot be interpreted as the effect of CSR relative to a non-CSR baseline, as such a comparison extends beyond the support of the data.

${ }^{66}$ More formally, a chi-squared test finds that the impacts before the reform are not jointly significant.

${ }^{67}$ We define a school as 'predominantly serving students in CSR grades' if more than twenty percent of their student body is in a K-3 grade.
} 
California, post $t_{t}$ indicates whether or not CSR has been implemented and $\gamma_{s}$ and $\theta_{t}$ are state and year fixed effects, respectively. The triple-differences coefficient of interest is $\beta_{5}$, which identifies the impact of CSR on the number of private schools under the assumption that the difference in the evolution of the number of private schools serving CSR and non-CSR grades would have been the same for California and the rest of the United States in the absence of the reform. Results from this regression are reported in Table A.4.

\section{Appendix C Public School Composition}

In this appendix, we describe our econometric approach (alluded to in Section 4.2) for assessing the extent to which re-sorting between private and public schools altered the composition of students in public school. To do so, we implement a triple-differences design that starts with the first two layers of differencing from (4.1) whereby CSR grades are compared to non-CSR grades before and after the reform was implemented. We then add a third dimension of differencing that takes into account whether a private school is nearby (which we discretize). The weighted estimating equation is:

$$
\begin{aligned}
\text { demo }_{\text {sgt }} & =\beta_{0}+\beta_{1}\left(\text { post }_{t} * \text { treat }_{g}\right)+\beta_{2}\left(\text { post }_{t} * \mathbb{1}\{\text { Buffer }<x k m\}_{s}\right)+\beta_{3}\left(\text { treat } _ { g } * \mathbb { 1 } \left\{{\text { Buffer } \left.<x k m\}_{s}\right)}\right.\right. \\
& +\beta_{4}\left(\text { post }_{t} * \text { treat }_{g} * \mathbb{1}\{\text { Buffer }<x k m\}_{s}\right)+\eta_{s}+\theta_{t}+\delta_{g}+\phi X_{\text {sgt }}+\epsilon_{\text {sgt }},
\end{aligned}
$$

where demo $_{s g}$ is the demographic share of interest for grade $g$ student in school $s$ at time $t$, post indicates whether CSR had been implemented, treat $_{g}$ indicates whether grade $g$ was subject to the CSR reform, $\mathbb{1}\{\text { Buffer }<x k m\}_{s}$ ) is an indicator for whether a private school serving CSR grades ${ }^{68}$ is within a $x \mathrm{~km}$ radius of school $s,{ }^{69} X_{s g t}$ is a set of school-grade-year covariates, and $\eta_{s}, \theta_{t}$ and $\delta_{g}$ are school, time and grade fixed effects, respectively.

The triple-differences coefficient of interest is $\beta_{4}$. To identify it, we assume that the difference in the change in demographic share between CSR and non-CSR grades would have been the same for public schools within $x \mathrm{~km}$ of a private school and those farther away in the absence of the reform. Results from this regression are reported in Table A.5.

Similar to Appendix B, we provide support for the 'parallel trends' assumption by computing difference-in-differences estimates by year, using the treatment of grades (CSR versus non-CSR) and the distance to the nearest private school competitor (within 3 kilometres versus more than 3 kilometres) as the two dimensions of differencing. Figure A.4 does this for two public school demographic variables: percent white and percent Hispanic. In both cases, the point estimates are

\footnotetext{
${ }^{68}$ Only private schools with ten or more students in kindergarten through third grade are included.

${ }^{69}$ In Table A.5, we report results for buffers of $1.5 \mathrm{~km}, 3 \mathrm{~km}$ and $5 \mathrm{~km}$.
} 
indistinguishable from zero in the pre-reform years, with the yearly effects becoming statistically and economically significant once CSR is implemented.

\section{Appendix D Estimating Equations for Differencing Approach}

This appendix sets out the main equations used in our differencing approach. It first discusses the identification of the main parameters without teacher effects. We then add teacher effects, discussing the method we use to estimate teacher quality before explaining how we incorporate teacher quality into the main estimating equations.

\section{D.1 Without Teacher Effects}

We take each of the key parameters of the technology in turn:

$\gamma_{\boldsymbol{R}}$ : Identification of $\gamma_{R}$ comes from equation (5.3) in the main text. Here, we derive that equation, which subtracts $\widehat{\Delta y}_{4,01-02}$ from $\widehat{\Delta y}_{3,01-02}$ :

$$
\begin{aligned}
\widehat{\Delta y}_{3,01-02} & -\widehat{\Delta y_{4,01-02}}=\left(\delta_{R}\right)^{3} \gamma_{R} \Delta R_{0,98-99}+\left(\delta_{R}\right)^{2} \gamma_{R} \Delta R_{1,99-00}+\delta_{R} \gamma_{R} \Delta R_{2,00-01}+\gamma_{R} \Delta R_{3,01-02} \\
& +\left(\delta_{X}\right)^{3} \gamma_{X} \Delta X_{0,98-99}+\left(\delta_{X}\right)^{2} \gamma_{X} \Delta X_{1,99-00}+\delta_{X} \gamma_{X} \Delta X_{2,00-01}+\gamma_{X} \Delta X_{3,01-02}+\Delta \epsilon_{3,01-02} \\
& -\left(\left(\delta_{R}\right)^{3} \gamma_{R} \Delta R_{1,98-99}+\left(\delta_{R}\right)^{2} \gamma_{R} \Delta R_{2,99-00}+\delta_{R} \gamma_{R} \Delta R_{3,00-01}\right. \\
& \left.+\left(\delta_{X}\right)^{3} \gamma_{X} \Delta X_{1,98-99}+\left(\delta_{X}\right)^{2} \gamma_{X} \Delta X_{2,99-00}+\delta_{X} \gamma_{X} \Delta X_{3,00-01}+\gamma_{X} \Delta X_{4,01-02}+\Delta \epsilon_{4,01-02}\right) \\
& =\gamma_{R} \Delta R_{01-02}+\left(\Delta \epsilon_{3,01-02}-\Delta \epsilon_{4,01-02}\right),
\end{aligned}
$$

where the final equality comes the fact that CSR affected all grades equally once it was implemented, so that $\Delta R_{g t}=\Delta R_{g^{\prime} t} \equiv \Delta R_{t}$ and $\Delta X_{g t}=\Delta X_{g^{\prime} t} \forall g, g^{\prime}$ (Assumption 3). We then invoke the parallel trends assumption (Assumption 4) and use test score differences between third and fourth grades before the reform to act as a counterfactual for test score differences after the reform. Using this, we have that:

$$
\gamma_{R} \Delta R_{01-02}=y_{3,01-02}-y_{4,01-02}-\left(y_{3,97-98}-y_{4,97-98}\right)
$$

$\gamma_{\boldsymbol{X}}$ : Identification of $\gamma_{X}$ comes from equation (5.5), which is derived fully in the main text. We relax the parallel trends assumption (Assumption 4), using two levels of differencing to act as the counterfactual. First, to account for systematic differences between K-6 and K-5 schools, we use fifth grade test scores in K-5 $\left(y_{5,01-02, K 6}\right)$ and K-6 schools $\left(y_{5,01-02, K 5}\right)$ as our first level of differencing. Then we use the pre-reform test scores for both fifth and sixth grades, $y_{5,97-98}$ and $y_{6,97-98}$, in K-5 and K-6 schools as counterfactuals for the observed test scores in fifth and sixth 
grades in the 2001-02 school year. Therefore, we have: ${ }^{70}$

$$
\begin{aligned}
\psi \gamma_{X} \Delta X_{6,01-02} & =\left[y_{6,01-02, K 6}-y_{5,01-02, K 6}-\left(y_{6,97-98, K 6}-y_{5,97-98, K 6}\right)\right] \\
& -\left[y_{6,01-02, K 5}-y_{5,01-02, K 5}-\left(y_{6,97-98, K 5}-y_{5,97-98, K 5}\right)\right]
\end{aligned}
$$

$\left(\boldsymbol{\delta}_{\boldsymbol{R}}, \boldsymbol{\delta}_{\boldsymbol{X}}\right)$ : Identification of $\delta_{R}$ and $\delta_{X}$ takes the parameters $\gamma_{R}$ and $\gamma_{X}$ to be known and differences the test scores in fourth grade and third grade in the $2000-01$ school year, which yields: ${ }^{71}$

$$
\begin{aligned}
\widehat{\Delta y}_{4,00-01} & -\widehat{\Delta y}_{3,00-01}=\left(\delta_{R}\right)^{3} \gamma_{R} \Delta R_{1,97-98}+\left(\delta_{R}\right)^{2} \gamma_{R} \Delta R_{2,98-99}+\delta_{R} \gamma_{R} \Delta R_{3,99-00} \\
& +\left(\delta_{X}\right)^{3} \gamma_{X} \Delta X_{1,97-98}+\left(\delta_{X}\right)^{2} \gamma_{X} \Delta X_{2,98-99}+\delta_{X} \gamma_{X} \Delta X_{3,99-00}+\gamma_{X} \Delta X_{4,00-01}+\Delta \epsilon_{4,01-02} \\
& -\left(\left(\delta_{R}\right)^{2} \gamma_{R} \Delta R_{1,98-99}+\delta_{R} \gamma_{R} \Delta R_{2,99-00}+\gamma_{R} \Delta R_{3,00-01}\right. \\
& \left.+\left(\delta_{X}\right)^{2} \gamma_{X} \Delta X_{1,98-99}+\delta_{X} \gamma_{X} \Delta X_{2,99-00}+\gamma_{X} \Delta X_{3,00-01}+\Delta \epsilon_{3,01-02}\right) \\
& =\left(\delta_{R}\right)^{3} \gamma_{R} \Delta R_{1,97-98}-\gamma_{R} \Delta R_{3,00-01}+\left(\delta_{X}\right)^{3} \gamma_{X} \Delta X_{1,97-98}+\left(\Delta \epsilon_{4,01-02}-\Delta \epsilon_{3,01-02}\right) .(\mathrm{D} .4)
\end{aligned}
$$

Similarly, comparing test scores between fourth and fifth grade in the 2000-01 school year yields:

$$
\begin{aligned}
\widehat{\Delta y}_{5,00-01} & -\widehat{\Delta y}_{4,00-01}=\left(\delta_{R}\right)^{4} \gamma_{R} \Delta R_{1,96-97}+\left(\delta_{R}\right)^{3} \gamma_{R} \Delta R_{2,97-98}+\left(\delta_{R}\right)^{2} \gamma_{R} \Delta R_{3,98-99}+\left(\delta_{X}\right)^{4} \gamma_{X} \Delta X_{1,96-97} \\
& +\left(\delta_{X}\right)^{3} \gamma_{X} \Delta X_{2,97-98}+\left(\delta_{X}\right)^{2} \gamma_{X} \Delta X_{3,98-99}+\delta_{X} \gamma_{X} \Delta X_{4,99-00}+\gamma_{X} \Delta X_{5,00-01}+\Delta \epsilon_{5,00-01} \\
& -\left(\left(\delta_{R}\right)^{3} \gamma_{R} \Delta R_{1,97-98}+\left(\delta_{R}\right)^{2} \gamma_{R} \Delta R_{2,98-99}+\delta_{R} \gamma_{R} \Delta R_{3,99-00}\right. \\
& \left.+\left(\delta_{X}\right)^{3} \gamma_{X} \Delta X_{1,97-98}+\left(\delta_{X}\right)^{2} \gamma_{X} \Delta X_{2,98-99}+\delta_{X} \gamma_{X} \Delta X_{3,99-00}+\gamma_{X} \Delta X_{4,00-01}+\Delta \epsilon_{4,00-01}\right) \\
& =\left(\delta_{R}\right)^{4} \gamma_{R} \Delta R_{1,96-97}-\delta_{R} \gamma_{R} \Delta R_{3,99-00}+\left(\delta_{X}\right)^{4} \gamma_{X} \Delta X_{1,96-97}+\left(\Delta \epsilon_{5,00-01}-\Delta \epsilon_{4,00-01}\right) .(\mathrm{D} .5)
\end{aligned}
$$

Since CSR affected all grades equally, we have that $\Delta R_{1,96-97}=\Delta R_{1,97-98}=\Delta R_{3,99-00}=$ $\Delta R_{3,00-01}$ and $\Delta X_{1,96-97}=\Delta X_{3,97-98}$. This is effectively Assumption 3 (grade-invariant input levels), although there is an additional component here that the input levels were also time-invariant once CSR was implemented. Suppressing the grade and year notation on the $\Delta R_{g t}$ and $\Delta X_{g t}$ variables and invoking Assumption 4 (parallel trends) yields the following two equations with two unknowns $\left(\delta_{R}, \delta_{X}\right)$ :

$$
\begin{aligned}
& y_{4,00-01}-y_{3,00-01}-\left(y_{4,97-98}-y_{3,97-98}\right)=\gamma_{R} \Delta R\left(\left(\delta_{R}\right)^{3}-1\right)+\left(\delta_{X}\right)^{3} \gamma_{X} \Delta X \\
& y_{5,00-01}-y_{4,00-01}-\left(y_{5,97-98}-y_{4,97-98}\right)=\delta_{R} \gamma_{R} \Delta R\left(\left(\delta_{R}\right)^{3}-1\right)+\left(\delta_{X}\right)^{4} \gamma_{X} \Delta X \text {. }
\end{aligned}
$$

\footnotetext{
${ }^{70}$ Here, we are over-identified since we could use 1997-98, 1998-99 and 1999-00 as counterfactuals: those cohorts in fifth and sixth grades were not subject to CSR in those three years. In practice, we use all three and take an average of the estimates, although estimates are quantitatively similar regardless which counterfactual year is used.

${ }^{71} \Delta y_{3,99-00}-\Delta y_{4,99-00}$ yields the same structural equation as $\Delta y_{3,00-01}-\Delta y_{4,00-01}$ and $\Delta y_{5,01-02}-\Delta y_{4,01-02}$ yields the same structural equation as $\Delta y_{5,00-01}-\Delta y_{4,00-01}$. This equation is therefore over-identified. Once again, we use all both equations and take an average of the estimates, although estimates are quantitatively similar regardless which structural equation is used.
} 


\section{D.2 Estimating Teacher Quality}

This subsection explains in detail how we incorporate the estimation of teacher quality into our multiple differencing approach.

Let $Q_{C S R, t}^{l}$ and $Q_{n o n, t}^{l}$ denote the effect of teacher quality in year $t$ for students in a CSR and non-CSR grade, respectively. We allow these effects to persist by using the $l$ superscript, which represents the effect of being treated to a CSR or non-CSR teacher $l \geq 0$ periods ago (where 0 is the contemporaneous effect). Note that we do not look at teacher quality at the grade level, but rather distinguish between CSR and non-CSR grades, since CSR should affect teachers across all CSR grades equally.

Our data begin in 1997-98, after the initial increase in the share of inexperienced teachers due to CSR's sudden introduction. The proportion of inexperienced teachers is similar across CSR (second and third) and non-CSR (fourth) grades for that first year. ${ }^{72}$ An interesting pattern emerges over the next three years once the CSR program expands to kindergarten and third grade: teacher inexperience falls substantially for CSR grades and rises for non-CSR grades. Inexperience then falls for all grades thereafter. ${ }^{73}$

We incorporate variation in teacher inexperience into our strategy by estimating the teacher quality parameters $Q_{C S R, t}^{l}$ and $Q_{n o n, t}^{l}$ for each lag $l$ according to the following two-step procedure. First, we regress test scores in 1997-98 $+l\left(y_{s, g, 97-98+l}\right)$ on the share of teacher inexperience in 1997-98 $\left(X_{s, g, 97-98}\right)$, including grade fixed effects $\left(\phi_{g}\right)$ :

$$
y_{s, g, 97-98+l}=\kappa_{l} X_{s, g, 97-98}+\phi_{g}+\epsilon_{s, g, 97-98} .
$$

Second, we use the resulting estimate $\hat{\kappa}_{l}$ to compute teacher quality relative to the $1997-98$ baseline: ${ }^{74}$

$$
\begin{aligned}
& Q_{C S R, t}^{l}=\hat{\kappa}_{l} \times\left(X_{3, t}-X_{3,97-98}\right) \\
& Q_{n o n, t}^{l}=\hat{\kappa}_{l} \times\left(X_{4, t}-X_{4,97-98}\right),
\end{aligned}
$$

where CSR and non-CSR values of $Q$ use variation in third- and fourth-grade inexperience, respectively. Thus, the relevant parameters to compute $\hat{\kappa}_{R}$, are $Q_{C S R, 01-02}^{0}=\hat{\kappa}_{0} \times\left(X_{3,2001-02}-X_{3,97-98}\right)$, $Q_{\text {non }, 01-02}^{0}=\hat{\kappa}_{0} \times\left(X_{4,01-02}-X_{4,97-98}\right)$ and $Q_{C S R, 97-98}^{4}=\hat{\kappa}_{4} \times\left(X_{4,97-98}-X_{4,97-98}\right)=0$. The necessary

\footnotetext{
${ }_{72}^{7 n e x p e r i e n c e ~ i n ~ f i f t h ~ a n d ~ s i x t h ~ g r a d e s ~ i s ~ c l o s e ~ t o ~ b u t ~ s l i g h t l y ~ l o w e r ~ t h a n ~ f o r ~ s e c o n d ~ t h r o u g h ~ f o u r t h ~ g r a d e s . ~}$

${ }^{73}$ It may seem puzzling why schools would maintain teacher quality for CSR grades at the expense of non-CSR grades, since formal incentives under the 1999 Public Schools Accountability Act were not provided differentially by grade. Schools perhaps believed policymakers were paying closer attention to CSR grades or schools may have worked to ensure the success of a promising reform.

${ }^{74}$ Defining teacher quality relative to 1997-98 controls for preexisting differences between grades that are unrelated to the implementation of the CSR program. Using 1997-98 as a baseline is justified given that CSR had yet to apply to third grade in that year. Indeed, Table A.11 shows that the share of teacher inexperience is essentially identical across third and fourth grades in 1997-98.
} 
parameters to compute $\hat{\gamma}_{X}$ are estimated analogously. ${ }^{75}$

\section{D.3 Estimating Equations with Teacher Effects}

We incorporate general equilibrium teacher effects by controlling for differences in observed teacher quality proxies. Given the teacher effects (as defined in Appendix D.2), we express differences between observed and counterfactual test scores allowing for differences in teacher quality according to whether students were in a CSR or non-CSR grade. For example, the difference between observed and counterfactual third grade test scores in 2001-02 can be expressed as:

$$
\begin{aligned}
\widehat{\Delta y_{3,01-02}} & =\left(\delta_{R}\right)^{3} \gamma_{R} \Delta R_{0,98-99}+\left(\delta_{R}\right)^{2} \gamma_{R} \Delta R_{1,99-00}+\delta_{R} \gamma_{R} \Delta R_{2,00-01}+\gamma_{R} \Delta R_{3,01-02} \\
& +\left(\delta_{X}\right)^{3} \gamma_{X} \Delta X_{0,98-99}+\left(\delta_{X}\right)^{2} \gamma_{X} \Delta X_{1,99-00}+\delta_{X} \gamma_{X} \Delta X_{2,00-01}+\gamma_{X} \Delta X_{3,01-02} \\
& +\gamma_{Q}\left(Q_{C S R, 98-99}^{3}+Q_{C S R, 99-00}^{2}+Q_{C S R, 00-01}^{1}+Q_{C S R, 01-02}^{0}+\Delta \epsilon_{3,01-02}\right.
\end{aligned}
$$

$\gamma_{\boldsymbol{R}}$ : Incorporating general equilibrium teacher effects, the differences between observed and counterfactual test scores that yield $\gamma_{R}$ can be expressed in terms of the parameters as followings:

$$
\begin{aligned}
y_{3,01-02} & -y_{4,01-02}-\left(y_{3,97-98}-y_{4,97-98}\right)=\gamma_{R} \Delta R_{3,01-02} \\
& +\gamma_{Q}\left(Q_{C S R, 98-99}^{3}+Q_{C S R, 99-00}^{2}+Q_{C S R, 00-01}^{1}+Q_{C S R, 01-02}^{0}\right) \\
& -\gamma_{Q}\left(Q_{n o n, 97-98}^{4}+Q_{C S R, 98-99}^{3}+Q_{C S R, 99-00}^{2}+Q_{C S R, 00-01}^{1}+Q_{n o n, 01-02}^{0}\right) \\
& =\gamma_{R} \Delta R_{3,01-02}+\gamma_{Q}\left(Q_{C S R, 01-02}^{0}-Q_{n o n, 01-02}^{0}-Q_{n o n, 97-98}^{4}\right) .
\end{aligned}
$$

$\gamma_{\boldsymbol{X}}$ : Similarly, the differences between observed and counterfactual test scores that yield $\gamma_{X}$ can be expressed in terms of the parameters in the following way:

$$
\begin{aligned}
& {\left[y_{6,01-02, K 6}-y_{5,01-02, K 6}-\left(y_{6,97-98, K 6}-y_{5,97-98, K 6}\right)\right]} \\
& -\left[y_{6,01-02, K 5}-y_{5,01-02, K 5}-\left(y_{6,97-98, K 5}-y_{5,97-98, K 5}\right)\right]=\psi \gamma_{X} \Delta X_{6,01-02, K 6} \\
& +\gamma_{Q}\left(Q_{C S R, 96-97, K 6}^{5}+Q_{C S R, 97-98, K 6}^{4}+Q_{C S R, 98-99, K 6}^{3}+Q_{n o n, 99-00, K 6}^{2}+Q_{n o n, 00-01, K 6}^{1}+Q_{n o n, 01-02, K 6}^{0}\right) \\
& -\gamma_{Q}\left(Q_{C S R, 97-98, K 6}^{4}+Q_{C S R, 98-99, K 6}^{3}+Q_{C S R, 99-00, K 6}^{2}+Q_{n o n, 00-01, K 6}^{1}+Q_{n o n, 01-02, K 6}^{0}\right) \\
& -\left[\gamma_{Q}\left(Q_{C S R, 96-97, K 5}^{5}+Q_{C S R, 97-98, K 5}^{4}+Q_{C S R, 98-99, K 5}^{3}+Q_{n o n, 99-00, K 5}^{2}+Q_{n o n, 00-01, K 5}^{1}+Q_{n o n, 01-02, K 5}^{0}\right)\right. \\
& \left.-\gamma_{Q}\left(Q_{C S R, 97-98, K 5}^{4}+Q_{C S R, 98-99, K 5}^{3}+Q_{C S R, 99-00, K 5}^{2}+Q_{n o n, 00-01, K 5}^{1}+Q_{n o n, 01-02, K 5}^{0}\right)\right] \\
& =\psi \gamma_{X} \Delta X_{6,01-02, K 6}+\gamma_{Q}\left(Q_{C S R, 96-97, K 6}^{5}+Q_{n o n, 99-00, K 6}^{2}-Q_{C S R, 99-00, K 6}^{2}\right) \\
& -\left[\gamma_{Q}\left(Q_{C S R, 96-97, K 5}^{5}+Q_{n o n, 99-00, K 5}^{2}-Q_{C S R, 99-00, K 5}^{2}\right)\right] .
\end{aligned}
$$

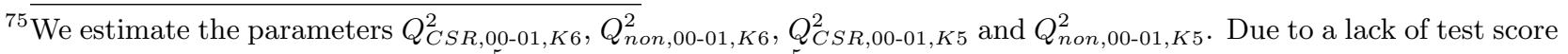
data in 1996-97, the parameters $Q_{C S R, 96-97, K 5 / K 6}^{5}$ and $Q_{n o n, 96-97, K 5 / K 6}^{5}$ cannot be estimated and are thus omitted from our estimating equations. However, as with $Q_{C S R, 97-98}^{4}$, we can assume that they are negligible since teacher quality across grades is likely to be similar in 1996-97 and 1997-98 across K5 and K6 schools. 
$\left(\boldsymbol{\delta}_{\boldsymbol{R}}, \boldsymbol{\delta}_{\boldsymbol{X}}\right)$ : Finally, to solve for $\delta_{R}$ and $\delta_{X}$, we incorporate teacher effects into the final two regressions:

$$
\begin{aligned}
y_{4,00-01} & -y_{3,00-01}-\left(y_{4,97-98}-y_{3,97-98}\right)=\gamma_{R} \Delta R\left(\left(\delta_{R}\right)^{3}-1\right)+\left(\delta_{X}\right)^{3} \gamma_{X} \Delta X \\
& +\gamma_{Q}\left(Q_{\text {non }, 96-97}^{4}+Q_{C S R, 97-98}^{3}+Q_{C S R, 98-99}^{2}+Q_{C S R, 99-00}^{1}+Q_{n o n, 00-01}^{0}\right) \\
& -\gamma_{Q}\left(Q_{n o n, 97-98}^{3}+Q_{C S R, 98-99}^{2}+Q_{C S R, 99-00}^{1}+Q_{C S R, 00-01}^{0}\right) \\
& =\gamma_{R} \Delta R\left(\left(\delta_{R}\right)^{3}-1\right)+\left(\delta_{X}\right)^{3} \gamma_{X} \Delta X \\
& +\gamma_{Q}\left(Q_{\text {non }, 96-97}^{4}+Q_{C S R, 97-98}^{3}-Q_{\text {non, }, 97-98}^{3}+Q_{\text {non }, 00-01}^{0}-Q_{C S R, 00-01}^{0}\right) .
\end{aligned}
$$

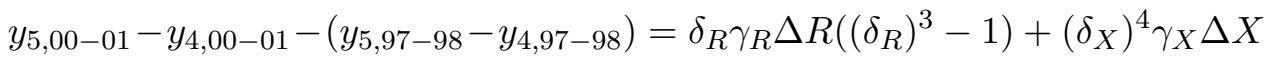

$$
\begin{aligned}
& +\gamma_{Q}\left(Q_{C S R, 96-97}^{4}+Q_{C S R, 97-98}^{3}+Q_{C S R, 98-99}^{2}+Q_{n o n, 99-00}^{1}+Q_{n o n, 00-01}^{0}\right) \\
& -\gamma_{Q}\left(Q_{n o n, 96-97}^{4}+Q_{C S R, 97-98}^{3}+Q_{C S R, 98-99}^{2}+Q_{C S R, 99-00}^{1}+Q_{n o n, 00-01}^{0}\right) \\
& =\delta_{R} \gamma_{R} \Delta R\left(\left(\delta_{R}\right)^{3}-1\right)+\left(\delta_{X}\right)^{4} \gamma_{X} \Delta X \\
& +\gamma_{Q}\left(Q_{C S R, 96-97}^{4}-Q_{\text {non }, 96-97}^{4}+Q_{n o n, 99-00}^{1}-Q_{C S R, 99-00}^{1}\right) \text {, }
\end{aligned}
$$

where the time and grade subscripts on $\Delta X$ and $\Delta R$ have been dropped (as in equation (D.6)). 


\section{APPENDIX FIGURES AND TABLES}

Figure A.1: K-3 CSR Participation by District in 1998-99 ('CSR Intensity' Measure)

(a) California

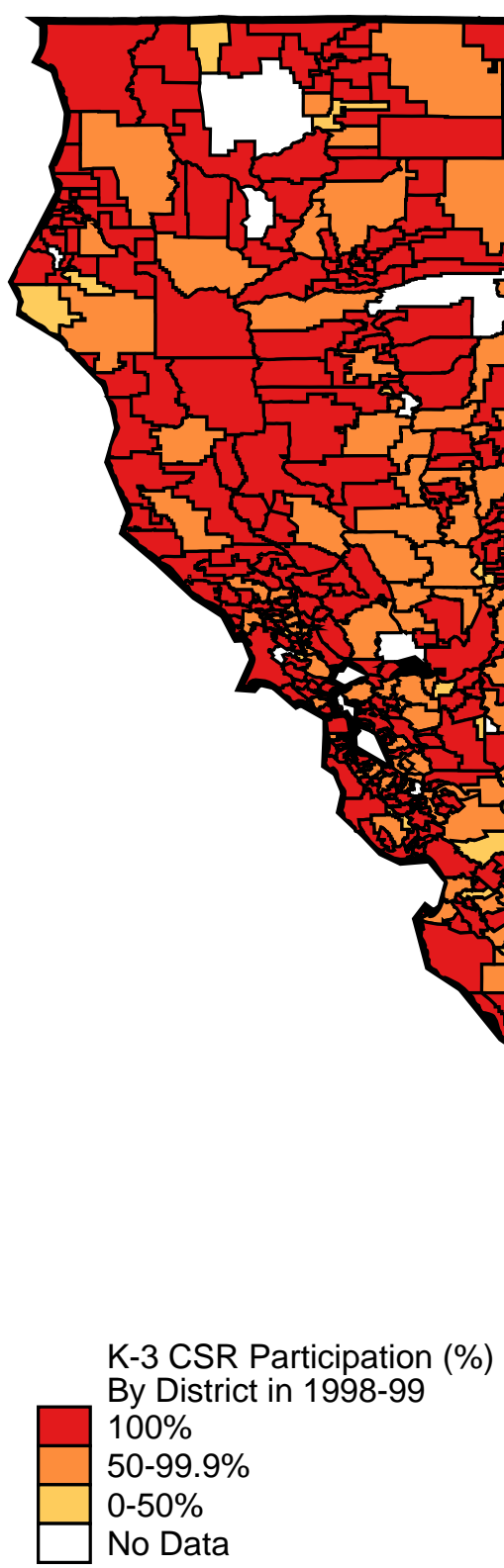

(b) Los Angeles and Orange Counties

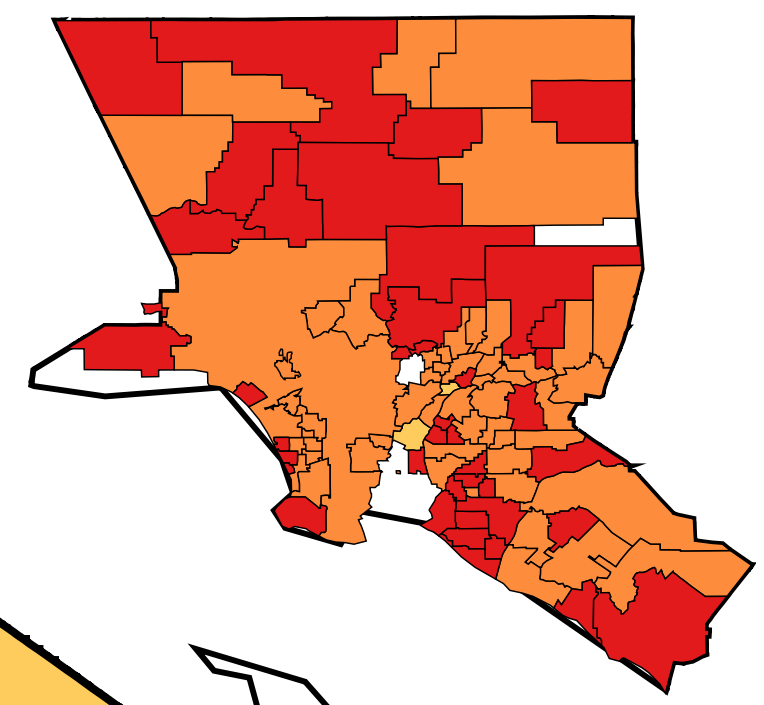

Notes: The above figure shows the percentage of district-level K-3 enrollment in a CSR-participating school-grade for the 1998-99 school year. Los Angeles and Orange Counties combined are shown separately for better visualization of that region. White areas denote regions that cannot be assigned to a school district. 
Figure A.2: The Effect of CSR on Private School Share by Year

(a) Difference-in-Differences

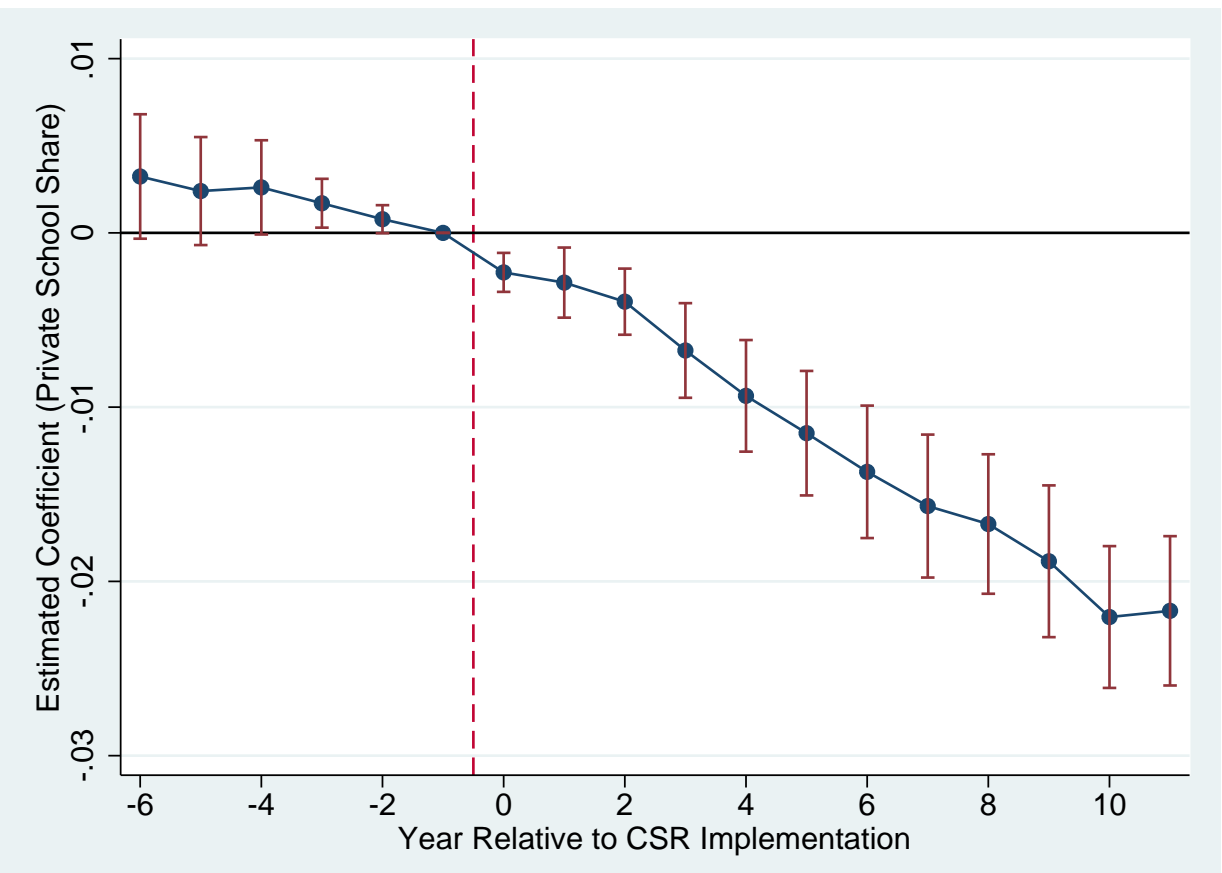

(b) Triple-Differences

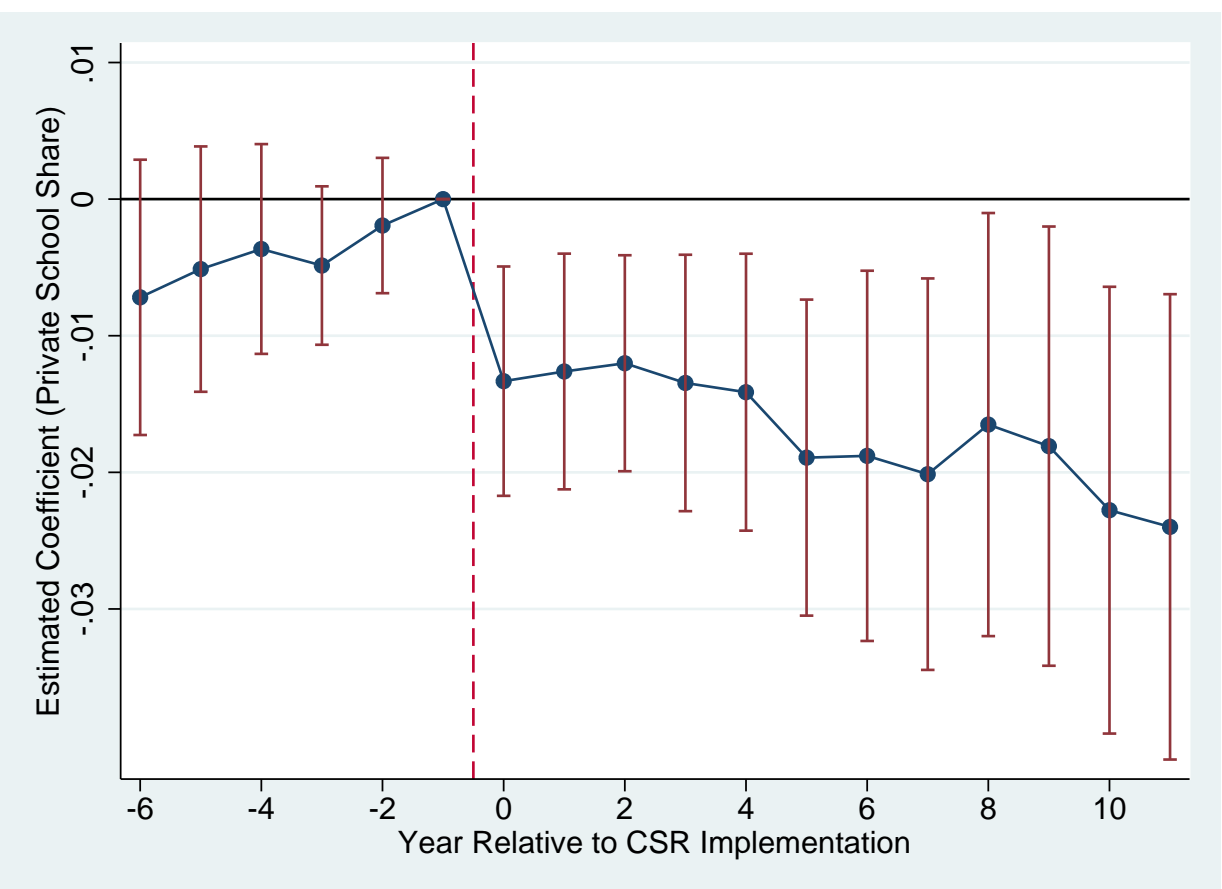

Notes: Figure A.2(a) shows the estimated change in private school share by year in 'treated' CSR grades (K-3) relative to 'untreated' non-CSR grades (4-12). Figure A.2(b) adds district-level CSR participation intensity as an additional layer of differencing. In both figures, the dashed vertical line represents the start of CSR implementation while the horizontal line indicates an estimate of zero. The estimated coefficient for the year prior to the start of CSR implementation is normalized to zero. Vertical bands represent $95 \%$ confidence intervals for each point estimate. Covariates and grade, year and district fixed effects are included. Standard errors are clustered at the district level. 
Figure A.3: Biennial Private School Entry and Exit Rates

(a) Private School Exit Rates

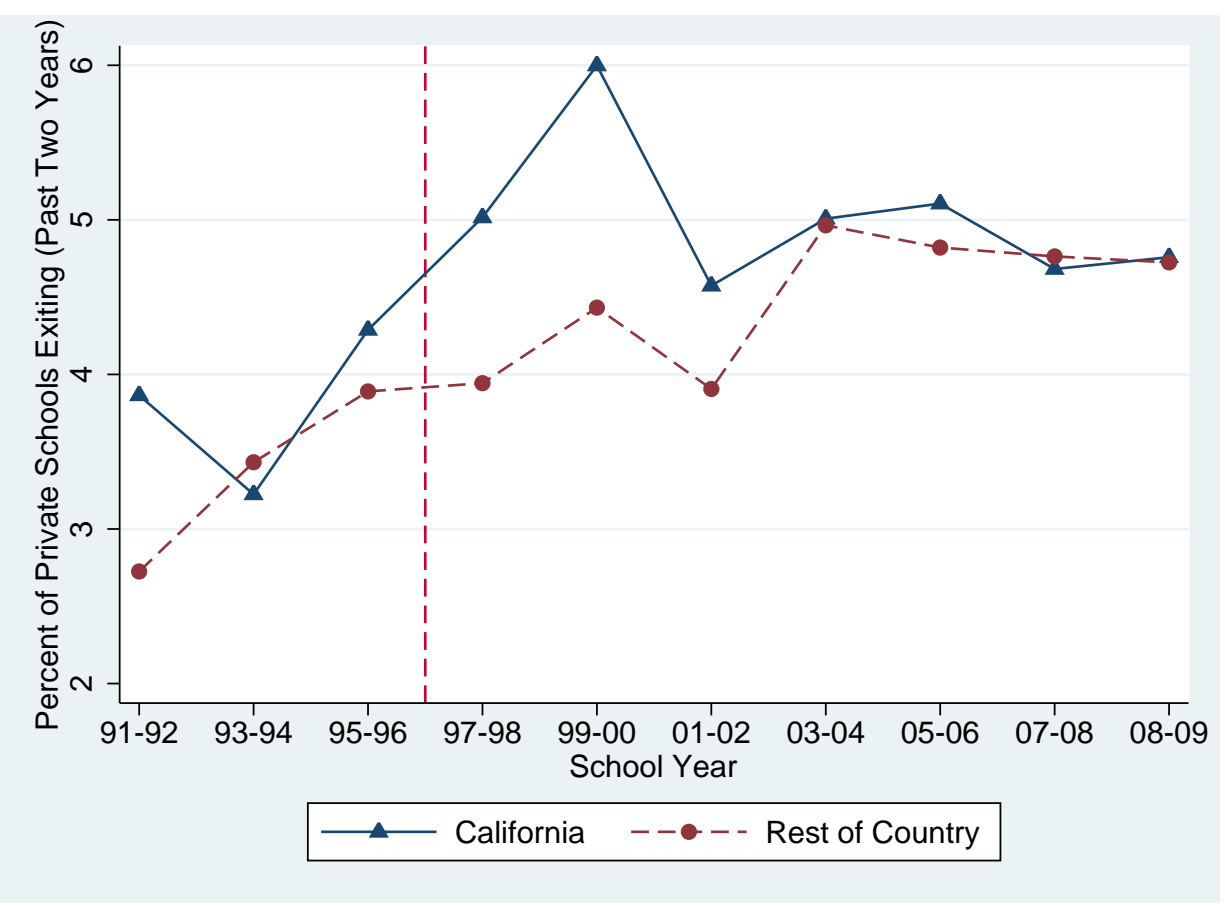

(b) Private School Entry Rates

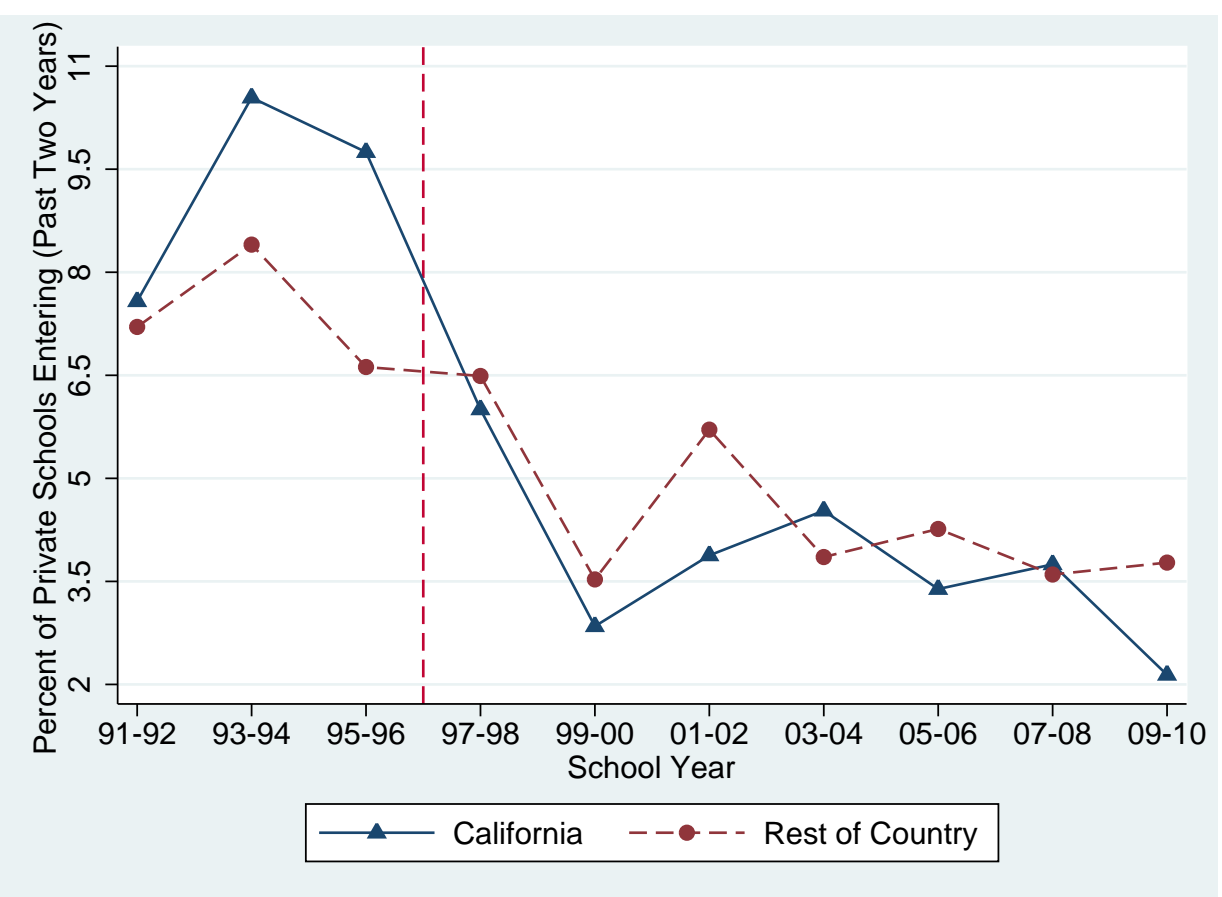

Notes: The above figures display the percent of private schools that have exited or entered the private school market within the last two years. Data on the number of private schools come from the Private School Universe Survey and are available only every two years (see Table A.1). The dashed vertical lines indicate the 1996-97 introduction of the CSR reform. Figures only include private schools that serve CSR grades - that is, if (on average) the school consists of twenty percent or more students in K-3 in the 1989-90 through 2009-10 school years. 
Figure A.4: The Effect of CSR on Public School Composition by Year

(a) Percent White

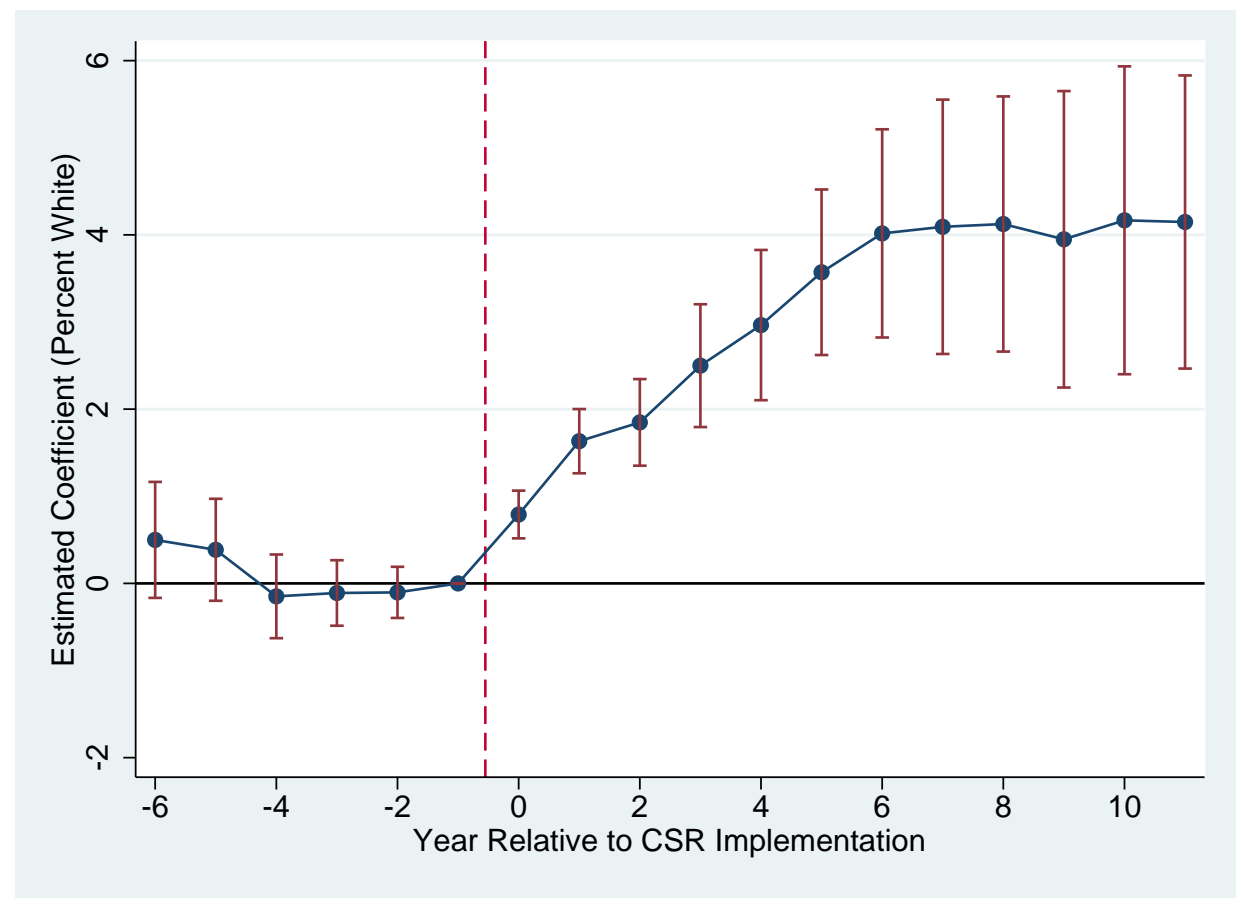

(b) Percent Hispanic

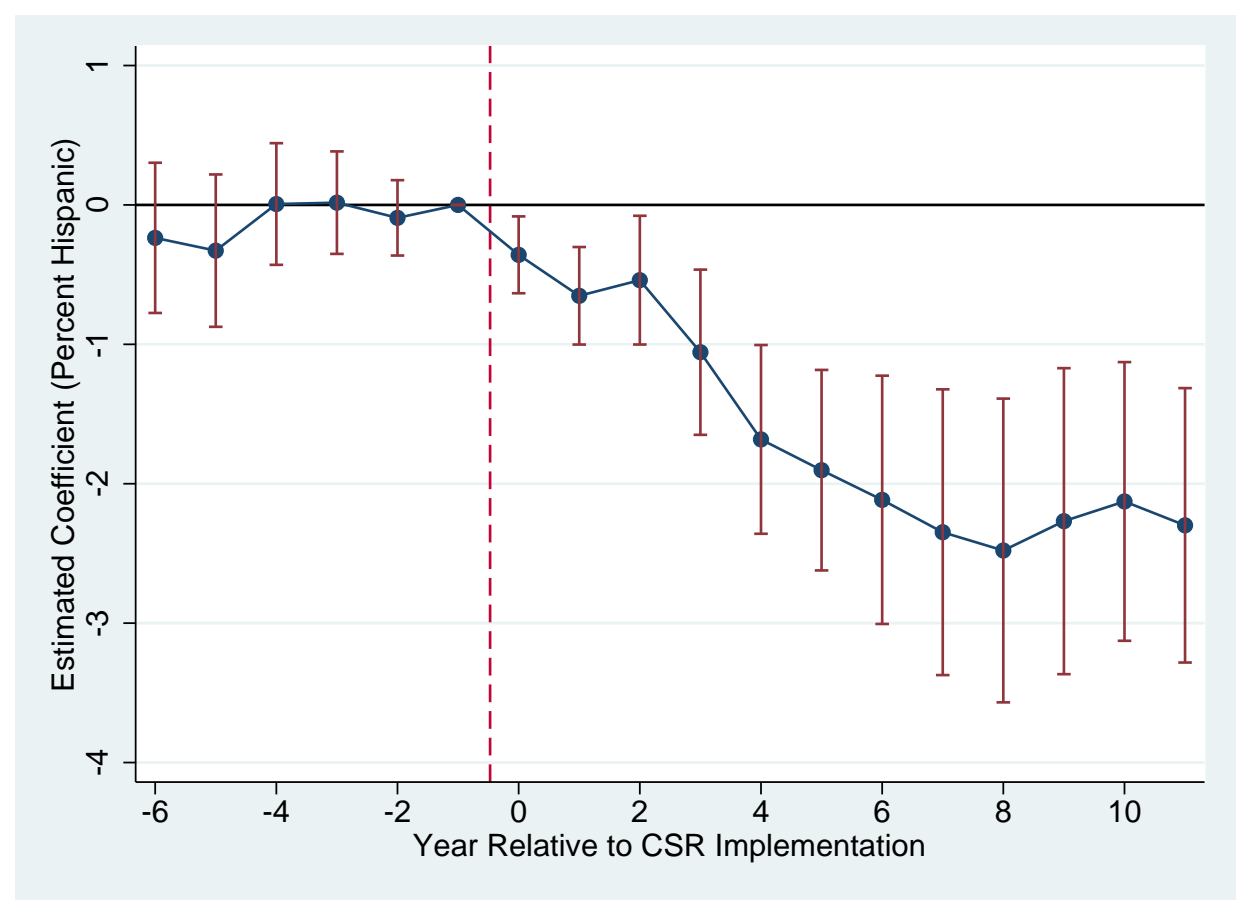

Notes: Figures show the estimated change in public school demographics by year using grade (CSR vs. non-CSR) and closeness to a private school (close vs. far) as the two layers of differencing. 'Close' is defined as any public school within $3 k m$ of a private school serving ten or more students in grades K-3, while all other public schools are categorized as being 'far.' The dashed vertical line represents the start of CSR implementation while the horizontal line indicates an estimate of zero. The estimated coefficient for the year prior to the start of CSR implementation is normalized to zero. Vertical bands represent 95\% confidence intervals for each point estimate. Covariates and grade, year and school fixed effects are included. Standard errors are clustered at the district level. 
Figure A.5: The Effect of CSR on Private School Share by Grade

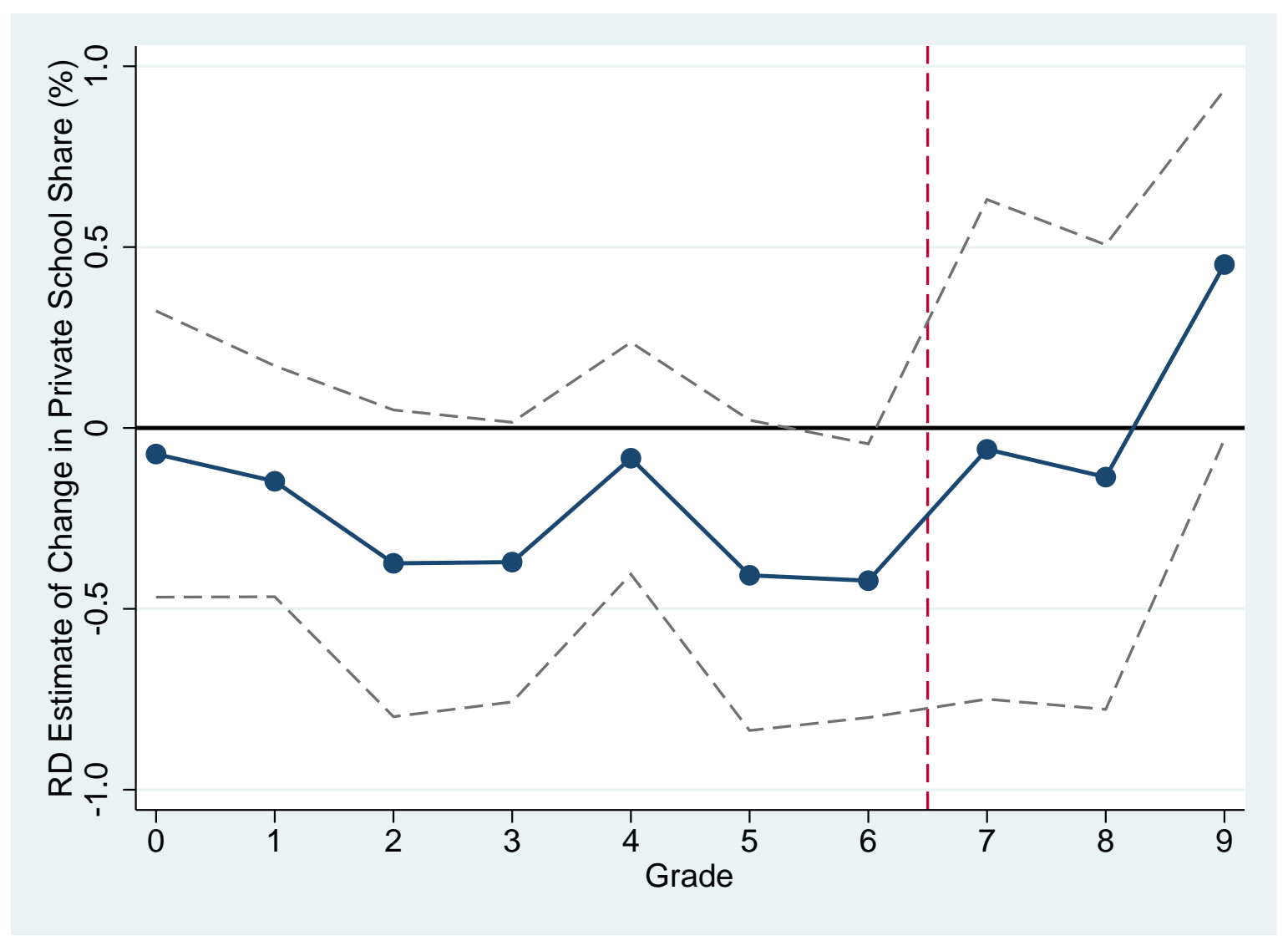

Notes: This figure shows the estimated effect of CSR on private school share for each grade using the RD design described in Section 4.3. Intuitively the regression discontinuity design compares private school share in each grade for the first cohort - 1996-97 first grade cohort - affected by CSR relative to the last cohort - 1995-96 first grade cohort - unaffected by CSR (although subsequent and antecedent cohorts are also used to improve statistical precision). Note that since kindergarten was not a CSR grade for the first cohorts it represents a placebo test here. The vertical dashed line between sixth and seventh grade indicates the first grade where (almost) all students have transitioned to middle school from their elementary school. The horizontal line represents an estimate of zero. The effect for each grade is estimated using a local linear regression allowing for a different functional form on either side of the cutoff. The bandwidth used is three and so the last three cohorts unaffected by the reform are compared to the first three cohorts affected by the reform, controlling for a linear trend in private school shares (that is allowed to vary before vs. after the reform). Demographic controls and district fixed effects are used in all regressions. The dashed lines represent $95 \%$ confidence intervals with standards errors are clustered at the district level. 
Table A.1: Data Sources and Availability

\begin{tabular}{|c|c|c|c|c|}
\hline Data & $\begin{array}{c}\text { Observation } \\
\text { Level } \\
(1)\end{array}$ & $\begin{array}{c}\text { Years } \\
\text { Covered } \\
(2)\end{array}$ & $\begin{array}{c}\text { Number of } \\
\text { Observations } \\
\text { (3) }\end{array}$ & $\begin{array}{l}\text { Data } \\
\text { Source } \\
(4)\end{array}$ \\
\hline \multicolumn{5}{|c|}{ Data Type: California Department of Education Data (publicly available) } \\
\hline $\begin{array}{l}\text { Public School Enrollment } \\
\text { Data (includes race) }\end{array}$ & School-Grade-Year & $\begin{array}{l}1990-91 \text { to } \\
2008-09\end{array}$ & $914,514^{\mathrm{a}}$ & www.cde.ca.gov/ds/sd/sd/filesenr.asp \\
\hline $\begin{array}{l}\text { Private School } \\
\text { Enrollment Data }^{\mathrm{b}}\end{array}$ & District-Grade-Year & $\begin{array}{l}1990-91 \text { to } \\
2008-09\end{array}$ & 261,573 & www.cde.ca.gov/ds/si/ps/index.asp \\
\hline $\begin{array}{l}\text { Public School } \\
\text { ESL Data }^{c}\end{array}$ & School-Grade-Year & $\begin{array}{l}1990-91 \text { to } \\
2008-09\end{array}$ & 914,514 & www.cde.ca.gov/ds/sd/sd/fileselsch.asp \\
\hline $\begin{array}{l}\text { Public School Free or } \\
\text { Reduced-Price Meal Data }\end{array}$ & School-Year & $\begin{array}{l}1990-91 \text { to } \\
2008-09\end{array}$ & 200,848 & www.cde.ca.gov/ds/sh/cw/filesafdc.asp \\
\hline $\begin{array}{l}\text { CSR Implementation } \\
\text { Data }\end{array}$ & $\begin{array}{l}\text { School-Grade-Year } \\
\text { (grades K-3 only) }\end{array}$ & $\begin{array}{l}1998-99 \text { to } \\
2003-04\end{array}$ & 130,011 & www.cde.ca.gov/ds/si/ps/index.asp \\
\hline $\begin{array}{l}\text { Standardized Testing and } \\
\text { Reporting Data }\end{array}$ & $\begin{array}{l}\text { School-Grade-Year } \\
\text { (grades 2-11 only) }\end{array}$ & $\begin{array}{l}1997-98 \text { to } \\
2001-02\end{array}$ & $231,129^{\mathrm{d}}$ & star.cde.ca.gov \\
\hline $\begin{array}{l}\text { Teacher Assignment and } \\
\text { Demographic Data }\end{array}$ & School-Grade-Year & $\begin{array}{l}1997-98 \text { to } \\
2001-02\end{array}$ & $222,626^{\mathrm{d}}$ & www.cde.ca.gov/ds/sd/df/filesassign.asp \\
\hline $\begin{array}{l}\text { Teacher Demographic } \\
\text { and Experience Data }\end{array}$ & School-Year & $\begin{array}{l}1994-95 \text { to } \\
2008-09\end{array}$ & 136,935 & www.cde.ca.gov/ds/sd/df/filescertstaff.asp \\
\hline \multicolumn{5}{|c|}{ Data Type: Other Data (publicly available) } \\
\hline $\begin{array}{l}\text { Private School Universe } \\
\text { Survey (State-level) }\end{array}$ & $\begin{array}{l}\text { State-Year } \\
\text { (biannual) }\end{array}$ & $\begin{array}{l}1989-90 \text { to } \\
2009-10\end{array}$ & 561 & nces.ed.gov/surveys/pss/ \\
\hline $\begin{array}{l}\text { U.S. Population Data } \\
\text { (State-level) }\end{array}$ & State-Year & 1989-2009 & 1,122 & seer.cancer.gov/popdata/download.html \\
\hline
\end{tabular}

Notes: All data can be aggregated to higher levels. For instance, 'school-grade-year' observations can be aggregated into 'districtgrade-year' or 'school-year' observations.

${ }^{a}$ Only non-zero grade-level observations are included in this observation count.

b Private school enrollment data for 1990-91 through 1998-99 inclusive are not available on the CDE website. They were provided upon request by the $\mathrm{CDE}$.

c California divides ESL students into English Learners and Fluent English Proficient. Since schools can alter students' ESL designations, we combine these two categories at the observation level into an ESL control, to avoid picking up any endogenous responses in ESL designations following CSR.

d Data are available up to 2008-09, but we only use observations from 1997-98 to 2001-02 due to the switch from the Stanford Achievement Test to the California Achievement Test in the 2002-03 academic year. 
Table A.2: Mathematics Test Score Summary Statistics

\begin{tabular}{lccccc}
\hline \multirow{2}{*}{ School Year } & Grade 2 & Grade 3 & Grade 4 & Grade 5 & Grade 6 \\
\hline \multirow{2}{*}{$1997-98$} & 44.6 & 43.6 & 41.4 & 43.3 & 50.6 \\
& $(19.2)$ & $(19.5)$ & $(19.1)$ & $(19.7)$ & $(19.0)$ \\
$1998-99$ & 44.6 & 43.6 & 41.4 & 43.4 & 50.6 \\
& $(19.2)$ & $(19.5)$ & $(19.1)$ & $(19.7)$ & $(18.9)$ \\
$1999-00$ & 58.5 & 58.2 & 52.4 & 52.2 & 58.8 \\
& $(18.6)$ & $(18.1)$ & $(18.6)$ & $(19.4)$ & $(18.2)$ \\
$2000-01$ & 59.8 & 61.1 & 55.4 & 55.8 & 61.4 \\
& $(18.0)$ & $(17.5)$ & $(18.2)$ & $(18.9)$ & $(17.8)$ \\
$2001-02$ & 62.6 & 63.5 & 58.1 & 58.2 & 63.1 \\
& $(16.9)$ & $(16.8)$ & $(17.5)$ & $(18.1)$ & $(17.3)$ \\
Total Observations & 33,044 & 33,209 & 32,678 & 32,111 & 16,498 \\
(School-Grade-Year) & & & & & \\
\hline
\end{tabular}

Notes: Test scores are from the Stanford 9 test and report the mean percentile ranking of students relative to a nationally representative reference group. The increases in test scores from the 1998-99 school year to the 1999-00 school year were caused by the addition of several test items intended to cover material in California's content standards that were not previously addressed by the Stanford 9. This led causing California students to score higher relative to the norm-referencing group. 
Table A.3: Triple-Differences Estimates of CSR on Private School Share

Outcome Variable: Private School Share (\%)

\begin{tabular}{|c|c|c|c|c|}
\hline & (1) & $(2)$ & $(3)$ & (4) \\
\hline \multirow{2}{*}{ Treatment*Post*CSR } & $-1.34^{* *}$ & $-1.34^{* *}$ & $-1.35^{* *}$ & $-1.29^{* *}$ \\
\hline & $(0.55)$ & $(0.55)$ & $(0.67)$ & $(0.60)$ \\
\hline \multirow{2}{*}{ Treatment*Post } & 0.13 & 0.24 & 0.12 & -0.29 \\
\hline & $(0.47)$ & $(0.47)$ & $(0.53)$ & $(0.46)$ \\
\hline \multirow{2}{*}{ Treatment*CSR } & $2.44^{* *}$ & $2.47^{* *}$ & $2.35^{*}$ & $2.86^{* * *}$ \\
\hline & $(1.09)$ & $(1.09)$ & $(1.32)$ & $(1.00)$ \\
\hline \multirow{2}{*}{ Post*CSR } & $2.00^{* * *}$ & $1.97^{* * *}$ & $1.60^{* *}$ & $1.20^{* *}$ \\
\hline & $(0.60)$ & $(0.60)$ & $(0.64)$ & $(0.54)$ \\
\hline \multirow{2}{*}{ Post } & $-2.32^{* * *}$ & $-1.54^{* * *}$ & $-1.27^{* *}$ & -0.63 \\
\hline & $(0.52)$ & $(0.57)$ & $(0.59)$ & $(0.49)$ \\
\hline \multirow{2}{*}{ CSR } & $5.67^{* *}$ & $5.65^{* *}$ & 1.90 & - \\
\hline & $(2.25)$ & $(2.25)$ & $(1.96)$ & \\
\hline \multirow{2}{*}{ Treatment } & 0.00 & - & - & - \\
\hline & $(1.00)$ & & & \\
\hline Year/Grade FE & No & Yes & Yes & Yes \\
\hline Demographic Controls & No & No & Yes & Yes \\
\hline District FE & No & No & No & Yes \\
\hline Number of Observations & 192,848 & 192,848 & 161,967 & 161,967 \\
\hline
\end{tabular}

Notes: This table shows results from the triple-differences regression described by equation (B.2) with varying levels of controls. Observations are at the district-grade-year level and cover the 199091 through 2008-09 school years. Demographic controls include student race, gender, English second language, enrollment and enrollment squared. The 'treatment' variable is omitted for columns (2)(4) since it is collinear with the grade fixed effects, and CSR is omitted in column (4) as it is collinear with district fixed effects. All regressions are weighted by district-grade-year enrollment. Standard errors are clustered at the district level. $* * *, * *$ and $*$ denote significance at the $1 \%, 5 \%$ and $10 \%$ levels, respectively. 
Table A.4: Triple-Differences Estimates of CSR on Private School Numbers

Outcome Variable: Private Schools per 1000 School-Aged Children

\begin{tabular}{lccc}
\hline & D-in-D & D-in-D & Triple Differences \\
& $(1)$ & $(2)$ & $(3)$ \\
\hline Estimate & $-0.070^{* * *}$ & $-0.011^{* *}$ & $0.059^{* * *}$ \\
& $(0.016)$ & $(0.005)$ & $(0.015)$ \\
State and Year FE & Yes & Yes & Yes \\
Observations & 561 & 561 & 1,122 \\
\hline
\end{tabular}

Notes: This table shows results from difference-in-differences regressions using time (pre- vs. post-CSR) and state (California vs. rest-of-country) as the two layers of differencing and restricts to private schools that do primarily serve CSR grades in column (1) and private schools that do not in column (2). Schools are defined as primarily serving CSR grades if more than twenty percent of their student body is in grades K-3 in the 1995-96 school year. Column (3) then runs the triple-differences regression described by equation (B.3) by adding whether the private school primarily serves CSR grades as an additional layer of differencing. Observations are at the state-by-biennial year level and cover 1989-90 through 2009-10 school years. The number of school-aged children by state is measured as the number of 5-17 year old children in the state according to data given to the National Cancer Institute by the U.S. Census Bureau (available at https://seer.cancer.gov/popdata/download.html). Standard errors are clustered at the state level. ${ }^{*}, * *$ and $* * *$ denote significance at the $10 \%, 5 \%$ and $1 \%$ levels, respectively. 
Table A.5: Triple-Differences Estimates of School Compositional Changes

Outcome Variable: Public School Student Demographic Compositions (\%)

Percent White Percent Hispanic Percent Black Percent Asian

\begin{tabular}{|c|c|c|c|c|}
\hline & $(1)$ & $(2)$ & $(3)$ & $(4)$ \\
\hline Treatment*Post* $\mathbb{1}\{$ Buffer $<1.5 \mathrm{~km}\}$ & $\begin{array}{c}2.94^{* * *} \\
(0.61)\end{array}$ & $\begin{array}{c}-1.52^{* * *} \\
(0.37)\end{array}$ & $\begin{array}{c}-0.68^{* * *} \\
(0.18)\end{array}$ & $\begin{array}{c}0.03 \\
(0.21)\end{array}$ \\
\hline Treatment $*$ Post $* \mathbb{1}\{$ Buffer $<3 \mathrm{~km}\}$ & $\begin{array}{c}2.92^{* * *} \\
(0.62)\end{array}$ & $\begin{array}{c}-1.47^{* * *} \\
(0.39)\end{array}$ & $\begin{array}{c}-0.71^{* * *} \\
(0.18)\end{array}$ & $\begin{array}{c}0.05 \\
(0.23)\end{array}$ \\
\hline Treatment*Post* $* \mathbb{1}\{$ Buffer $<5 \mathrm{~km}\}$ & $\begin{array}{c}2.94^{* * *} \\
(0.62)\end{array}$ & $\begin{array}{c}-1.45^{* * *} \\
(0.39)\end{array}$ & $\begin{array}{c}-0.73^{* * *} \\
(0.18)\end{array}$ & $\begin{array}{c}0.03 \\
(0.23)\end{array}$ \\
\hline \% Share in Private School (1997-98) & 52.9 & 17.2 & 7.1 & 12.3 \\
\hline \% Share in Public School (1997-98) & 38.8 & 40.5 & 8.8 & 11.1 \\
\hline School/Grade/Year FE & Yes & Yes & Yes & Yes \\
\hline
\end{tabular}

Notes: This table shows results from the triple-differences regression using time (pre- vs. post-CSR), grades (CSR vs. non-CSR) and closeness to a private school ('near' vs. 'far') as the three layers of differencing as described in equation (C.1). $\mathbb{1}\{$ Buffer $<x k m\}$ is the distance from a private school that a public school must be to be considered 'treated'. Three alternative buffers are provided for robustness. Observations are at the school-gradeyear level, and cover 1990-91 through 2008-09 school years. There are 914,514 observations. Enrollment and enrollment squared are included as controls. Private and public school demographic shares from the National Center for Education Statistics for the 1997-98 school year are provided in the penultimate two rows for reference. All regressions are weighted by school-grade-year enrollment and standard errors are clustered at the district level. $* * *, * *$ and $*$ denote significance at the $1 \%, 5 \%$ and $10 \%$ levels, respectively. 
Table A.6: Triple-Differences Estimates of CSR Sorting Effects on Test Scores

Outcome Variable: Mathematics Scores, in SD units $(\sigma)$

\begin{tabular}{|c|c|c|c|}
\hline & (1) & $(2)$ & $(3)$ \\
\hline \multicolumn{4}{|c|}{ A. Grade 6 versus Grade 5 (Coefficient of Interest) } \\
\hline$\Phi_{K 6-K 5,6-5, p o s t-p r e}$ & $\begin{array}{l}0.128^{* *} \\
(0.054)\end{array}$ & $\begin{array}{l}0.112^{* *} \\
(0.055)\end{array}$ & $\begin{array}{l}0.099 * * \\
(0.050)\end{array}$ \\
\hline \multicolumn{4}{|c|}{ A. Other Grade Differences (Placebo Tests) } \\
\hline Grade 7 vs. Grade 6 & 0.041 & 0.026 & 0.028 \\
\hline$\left(\Phi_{K 6-K 5,7-6, p o s t-p r e}\right)$ & $(0.032)$ & $(0.028)$ & $(0.026)$ \\
\hline Grade 5 vs. Grade 4 & -0.017 & -0.017 & -0.018 \\
\hline$\left(\Phi_{K 6-K 5,5-4, p o s t-p r e}\right)$ & $(0.014)$ & $(0.014)$ & $(0.015)$ \\
\hline Grade 4 vs. Grade 3 & -0.019 & -0.018 & -0.018 \\
\hline$\left(\Phi_{K 6-K 5,4-3, p o s t-p r e}\right)$ & $(0.017)$ & $(0.018)$ & $(0.018)$ \\
\hline Grade 3 vs. Grade 2 & -0.003 & -0.003 & -0.004 \\
\hline$\left(\Phi_{K 6-K 5,3-2, p o s t-p r e}\right)$ & $(0.016)$ & $(0.016)$ & $(0.016)$ \\
\hline Grade/Year/School FE & No & Yes & Yes \\
\hline Demographic Controls & No & No & Yes \\
\hline
\end{tabular}

Notes: Observations are at the school-grade-year level, and cover the 1997-98 through 2008-09 school years. Test scores are normalized by grade-year to have mean zero and standard deviation one. Demographic controls include student race, enrollment and enrollment squared. Standard errors are clustered at the district level. ${ }^{* * *},{ }^{* *}$ and ${ }^{*}$ denote significance at the $1 \%, 5 \%$ and $10 \%$ levels, respectively. 
Table A.7: Average Class Sizes by Grade and Year

\begin{tabular}{cccccc}
\hline & \multicolumn{5}{c}{ School Year } \\
Grade & $\mathbf{1 9 9 7 - 9 8}$ & $\mathbf{1 9 9 8 - 9 9}$ & $\mathbf{1 9 9 9 - 2 0 0 0}$ & $\mathbf{2 0 0 0 - 0 1}$ & $\mathbf{2 0 0 1 - 0 2}$ \\
\cline { 5 - 6 } & & \multicolumn{4}{c}{ Average Class Size } \\
\cline { 5 - 6 } Kindergarten & 24.2 & $\mathbf{2 1 . 0}$ & $\mathbf{1 9 . 9}$ & $\mathbf{1 9 . 6}$ & $\mathbf{1 9 . 5}$ \\
Grade 1 & $\mathbf{1 9 . 2}$ & $\mathbf{1 9 . 2}$ & $\mathbf{1 9 . 2}$ & $\mathbf{1 9 . 2}$ & $\mathbf{1 9 . 2}$ \\
Grade 2 & $\mathbf{1 9 . 4}$ & $\mathbf{1 9 . 2}$ & $\mathbf{1 9 . 1}$ & $\mathbf{1 9 . 0}$ & $\mathbf{1 9 . 0}$ \\
Grade 3 & 22.4 & $\mathbf{2 0 . 1}$ & $\mathbf{1 9 . 6}$ & $\mathbf{1 9 . 4}$ & $\mathbf{1 9 . 3}$ \\
Grade 4 & 29.1 & 28.9 & 28.9 & 28.7 & 28.5 \\
Grade 5 & 29.4 & 29.3 & 29.2 & 29.3 & 29.0 \\
\hline
\end{tabular}

Notes: The numbers in the table represent average class sizes by grade and year. Grade-year combinations that were affected by CSR are in bold font. Since grade-level class sizes are not observed before 1997-98, grades 1 and 2 have no pre-CSR comparison because those grades implemented CSR during the 1996-97 and 1997-98 school years, respectively. Some pre-kindergarten classes are included in the kindergarten average class size calculation. 
Table A.8: Triple-Differences Estimates of Compositional Changes by Grade

Outcome Variable: Public School Student Demographic Compositions (\%)

Percent White Percent Hispanic Percent Black Percent Asian

\begin{tabular}{|c|c|c|c|c|}
\hline & $(1)$ & $(2)$ & $(3)$ & $(4)$ \\
\hline \multirow{2}{*}{ Kindergarten ${ }^{*}$ Post $^{*} \mathbb{1}\{$ Buffer $<3 \mathrm{~km}\}$} & $3.18^{* * *}$ & $-1.57^{* * *}$ & $-0.79 * * *$ & 0.02 \\
\hline & $(0.60)$ & $(0.41)$ & $(0.21)$ & $(0.27)$ \\
\hline \multirow{2}{*}{ Grade $1^{*}$ Post $* \mathbb{1}\{$ Buffer $<3 \mathrm{~km}\}$} & $2.77^{* * *}$ & $-1.32^{* * *}$ & $-0.78 * * *$ & 0.04 \\
\hline & $(0.67)$ & $(0.41)$ & $(0.20)$ & $(0.23)$ \\
\hline \multirow{2}{*}{ Grade $2^{*}$ Post $* \mathbb{1}\{$ Buffer $<3 \mathrm{~km}\}$} & $2.69 * * *$ & $-1.32^{* * *}$ & $-0.67^{* * *}$ & -0.01 \\
\hline & $(0.65)$ & $(0.40)$ & $(0.18)$ & $(0.22)$ \\
\hline \multirow{2}{*}{ Grade $3 *$ Post $* \mathbb{1}\{$ Buffer $<3 \mathrm{~km}\}$} & $2.82^{* * *}$ & $-1.35^{* * *}$ & $-0.64 * * *$ & -0.12 \\
\hline & $(0.63)$ & $(0.41)$ & $(0.18)$ & $(0.21)$ \\
\hline School/Grade/Year FE & Yes & Yes & Yes & Yes \\
\hline
\end{tabular}

Notes: This table shows results from a variant of the triple-differences regression described in equation (C.1). Specifically, a dummy for each CSR grade is used, individually, to see if the composition effect is driven by certain grades. Other CSR grades are not included in the regression. Therefore, the triple-differences regression in the first row (represented by coefficient on Kindergarten*Post*1 $\{$ Buffer $<3 \mathrm{~km}\}$ ) uses time (pre- vs. post-CSR), grades (Kindergarten vs. non-CSR) and closeness to a private school ('near' vs. 'far') as the three layers of differencing with data for grades 1-3 omitted. Observations are at the school-grade-year level, and cover 1990-91 through 2008-09 school years. Enrollment and enrollment squared are included as controls. All regressions are weighted by school-grade-year level enrollment and standard errors are clustered at the district level. $* * *, * *$ and $*$ denote significance at the $1 \%, 5 \%$ and $10 \%$ levels, respectively. 
Table A.9: Parallel Trends in Untreated Cohorts

Outcome Variable: Mathematics Test Scores (Percentile Rank)

School-Year: $\quad$ 1997-98 1998-99 1999-00

Panel A. Trends in Grade 5 Relative to Grade 4

$\begin{array}{lcc}\text { Grade } 5 & 43.60 & 43.53 \\ \text { Grade } 4 & 41.62 & 41.60 \\ \text { Difference } & 1.99 & 1.93 \\ \text { (Grade 5 - Grade 4) } & (0.41) & (0.41)\end{array}$

Panel B. Trends in Grade 6 Relative to Grade 5

\begin{tabular}{lccc} 
Grade 6 & 51.61 & 52.02 & 60.21 \\
Grade 5 & 43.60 & 43.53 & 52.36 \\
Difference & 8.01 & 8.49 & 7.86 \\
(Grade 6 - Grade 5) & $(0.48)$ & $(0.40)$ & $(0.49)$ \\
\hline
\end{tabular}

Notes: This table compares untreated adjacent grades for 'never treated' cohorts to bolster the argument that there are no differential achievement trends across grades (Assumption 4). For instance, the fact that the difference between fifth and fourth grade test scores in Panel A (and sixth and fifth grade in Panel B) for the final two cohorts who were never treated by the reform are nearly identical supports our assumption that the fourth versus third grade comparison among the first cohorts affected by the reform would have been the same in the absence of CSR. Given test scores become available in 1997-98, we have two pre-treatment years for the grade 5 relative to grade 4 comparison (grade 4 was first treated in 1999-00) and three pre-treatment years for the grade 6 relative to grade 5 comparison (grade 5 was first treated in 2000-01). Standard errors of the differences are reported in parentheses. The cells report mathematics test scores in percentile rank relative to a national norming sample, where one percentile rank roughly equates to $0.05 \sigma$ in the distribution of school-grade level test scores. 
Table A.10: School Statistics by Grade Span Configuration

Grade Span Number of Schools \% of Schools \% Implementing CSR in First Year

$(1)$

\begin{tabular}{lccc}
\hline K-5 & 2183 & 44.3 & 95.9 \\
K-6 & 1954 & 39.6 & 92.5 \\
K-8 & 455 & 9.2 & 90.1 \\
K-12 & 49 & 1.0 & 48.3 \\
Other & 289 & 5.9 & 90.3 \\
Total & 4,930 & 100 & 93.2 \\
\hline
\end{tabular}

Notes: This table shows the number and percentage of schools by grade span serving at least two K-3 grades in the 1998-99 school year. The most common 'Other' configuration schools are K-3 or K-4 schools. Given the data limitation that CSR implementation is first observed in 1998-99, the percentage implementing CSR in the first year is calculated as the proportion of schools that had implemented CSR in either Kindergarten or third grade in the 1998-99 school year.

Table A.11: Percentage of Inexperienced Teachers

\begin{tabular}{ccccccc}
\hline \hline \multicolumn{7}{c}{ Year } \\
Grade & $1997-98$ & $1998-99$ & $1999-00$ & $2000-01$ & $2001-02$ & $2002-03$ \\
2 & 27.3 & 26.7 & 21.6 & 18.8 & 17.0 & 15.2 \\
3 & 26.8 & 26.3 & 22.0 & 17.9 & 16.4 & 14.0 \\
4 & 26.9 & 33.1 & 32.9 & 30.1 & 27.6 & 24.5 \\
5 & 24.0 & 27.8 & 28.8 & 28.4 & 25.7 & 22.5 \\
6 & 23.5 & 26.7 & 27.4 & 26.5 & 27.0 & 23.2 \\
\hline
\end{tabular}

Notes: Percent inexperienced is defined as the fraction of full time equivalent teachers with less than three years of experience teaching in the state of California. 
Table A.12: Estimates of Teacher Quality

Outcome Variable: Mathematics Test Scores

\begin{tabular}{|c|c|c|}
\hline & $\begin{array}{c}\text { CSR } \\
(1)\end{array}$ & $\begin{array}{c}\text { non-CSR } \\
(2)\end{array}$ \\
\hline$Q_{C S R / n o n, 01-02}$ & $\begin{array}{c}1.123^{* * *} \\
(0.057)\end{array}$ & $\begin{array}{c}-0.089^{* * *} \\
(0.004)\end{array}$ \\
\hline$Q_{C S R / n o n, 00-01}$ & $\begin{array}{c}0.929 * * * \\
(0.047)\end{array}$ & $\begin{array}{c}-0.361^{* * *} \\
(0.018)\end{array}$ \\
\hline$Q_{C S R / n o n, 99-00}$ & $\begin{array}{c}0.520^{* * *} \\
(0.026)\end{array}$ & $\begin{array}{c}-0.643^{* * *} \\
(0.032)\end{array}$ \\
\hline$Q_{C S R / n o n, 98-99}$ & $\begin{array}{c}0.041^{* * *} \\
(0.002)\end{array}$ & $\begin{array}{c}-0.678^{* * *} \\
(0.034)\end{array}$ \\
\hline$Q_{C S R / n o n, 99-00, K 5}$ & $\begin{array}{c}0.997^{* * *} \\
(0.078)\end{array}$ & $\begin{array}{c}-1.132^{* * *} \\
(0.089)\end{array}$ \\
\hline$Q_{C S R / n o n, 99-00, K 6}$ & $\begin{array}{c}0.632^{* * *} \\
(0.050)\end{array}$ & $\begin{array}{c}-0.673^{* * *} \\
(0.053)\end{array}$ \\
\hline
\end{tabular}

Notes: This table shows estimates of teacher quality. Observations are at the school-grade-year level, and cover the 1997-98 through 2001-02 school years. Mathematics test scores are shown in percentile ranks relative to a national norming sample, where one percentile rank roughly equates to $0.05 \sigma$ in the distribution of schoolgrade level test scores. Standard errors are computed using the delta method and are clustered at the school level. ${ }^{* * *}, * *$ and $*$ denote significance at the $1 \%, 5 \%$ and $10 \%$ levels, respectively. 